Der Medizinischen Fakultät der Universität Göttingen eingereicht von Prof. Dr. med. W. Wuttke

\title{
Der Effekt der pränatalen Dexamethasontherapie auf die Fett- parameter der Nachkommen beim Callithrix jacchus
}

\author{
INAUGURAL - DISSERTATION \\ zur Erlangung des Doktorgrades \\ der Medizinischen Fakultät der \\ Georg-August-Universität zu Göttingen
}

vorgelegt von

Nina Koch

aus
Bad Harzburg

Göttingen 2016 
Die Arbeit entstand im Zeitraum 2009 bis 2016 in der Abteilung Klinische und Experimentelle Endokrinologie der Medizinischen Fakultät der Universität Göttingen.

Dekan:

Referent:

Ko-Referentin:
Prof. Dr. rer. nat. H. K. Kroemer

Prof. Dr. med. W. Wuttke

Prof. Dr. med. H. Siggelkow

Datum der mündlichen Prüfung: 29. März 2017 


\section{Inhaltsverzeichnis}

Abkürzungsverzeichnis.......................................................................................................................................... IV

1. Einleitung und Zielsetzung .................................................................................................................... 1

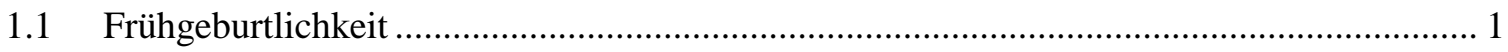

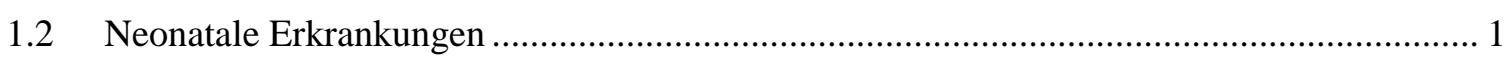

1.3 Einführung der pränatalen Glukokortikoidtherapie - Geschichte und aktueller

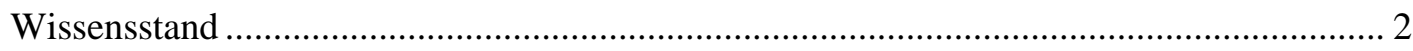

1.4 Art und Dosierung der pränatalen Glukokortikoidtherapie .................................................. 3

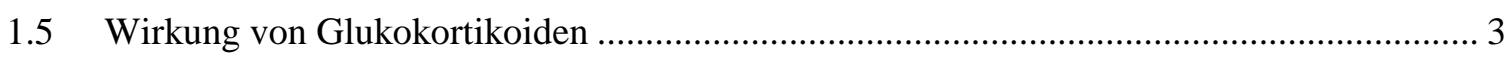

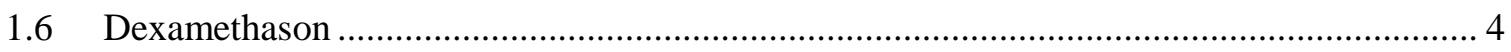

1.7 Pränatale Glukokortikoidtherapie - verändertes Geburtsgewicht, verändertes postnatales Wachstum und veränderte Gewichtszunahme................................................. 5

1.8 Programmierung durch pränatale Glukokortikoidtherapie, insbesondere bei der Entwicklung des Fettgewebes: Epigenetische Effekte ...................................................... 6

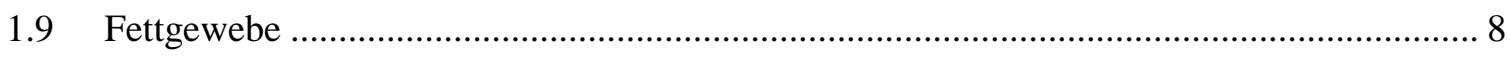

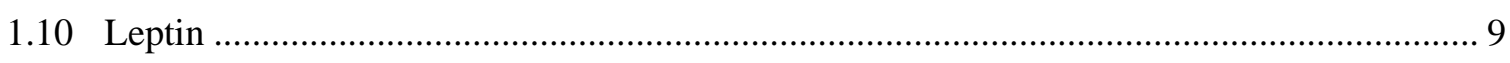

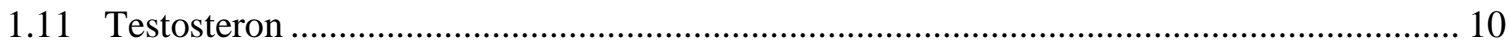

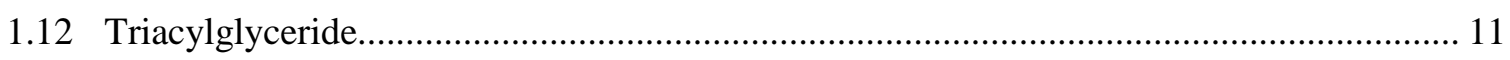

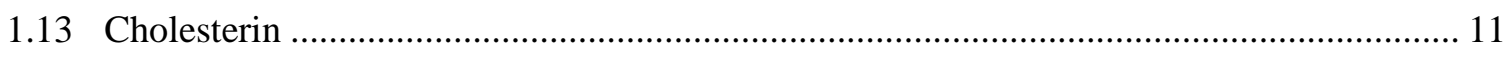

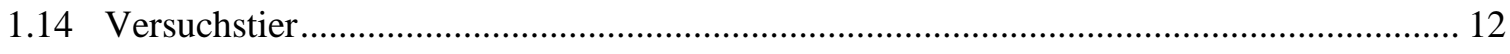

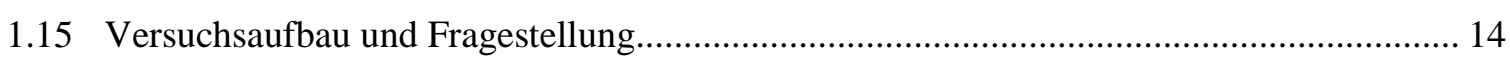

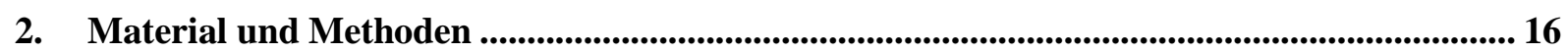

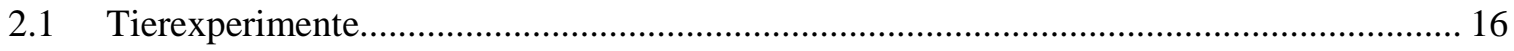

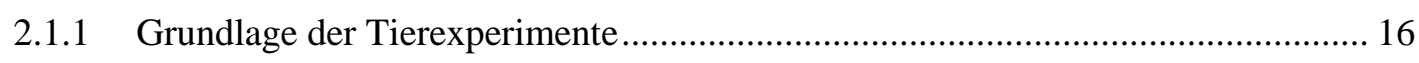

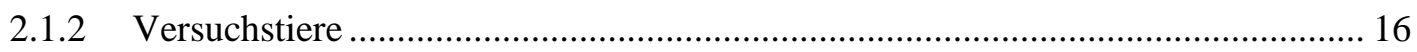

2.1.3 Rahmenbedingungen und die an den Tierexperimenten beteiligten

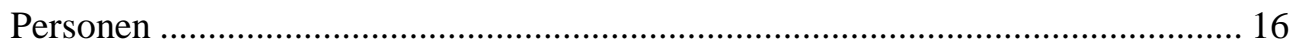

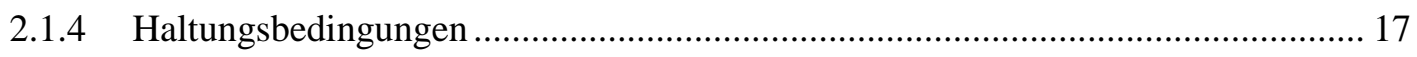




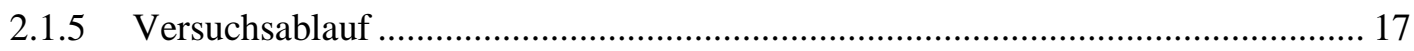

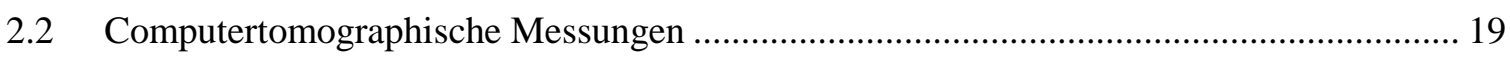

2.2.1 Prinzip der computertomographischen Messungen .............................................. 19

2.2.2 Computertomographische Messungen im Versuch .............................................. 20

2.2.2.1 Untersuchung mit dem quantitativen Computertomographen

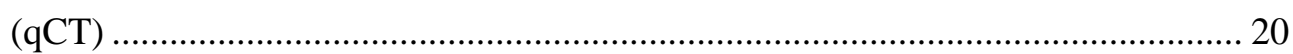

2.2.2.2 Untersuchung mit dem flat panel Volumencomputertomographen

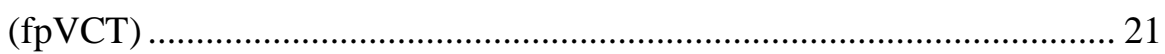

2.2.2.3 Narkose bei den computertomographischen Messungen............................ 21

2.2.2.4 Auswertungsprinzip der fpVCT-Daten und die Messbereiche am Körper der Versuchstiere ...................................................................... 22

2.2.2.5 Durchführung der Auswertung ................................................................ 25

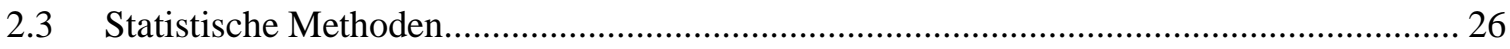

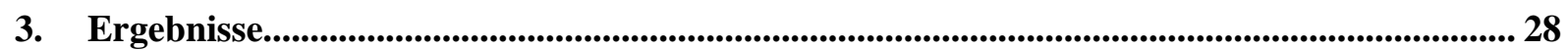

3.1 Entwicklung von Gewicht, BMI und Körperlänge der CJ bis zum Alter von

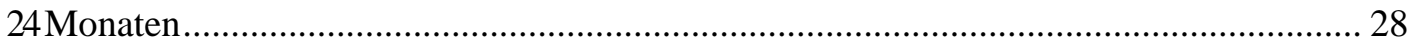

3.2 Fettanteil im Bereich L4-L5 mittels qCT über 24 Monate gemessen. ............................... 33

3.3 Fettanteile der verschiedenen Körperbereiche, gemessen mittels fpVCT im Alter von 24 Monaten

3.3.1 Fettanteil im Bereich L4-L5, gemessen mittels fpVCT im Alter von 24 Monaten

3.3.2 Fettanteil im gesamten Lendenwirbelbereich, gemessen mittels fpVCT im Alter von 24 Monaten. 36

3.3.3 Fettanteil im Brustwirbelbereich, gemessen mittels fpVCT im Alter von 24 Monaten

3.3.4 Fettanteil im Oberschenkelbereich beider Beine, gemessen mittels fpVCT im Alter von 24 Monaten.

3.3.5 Fettanteil im Unterschenkelbereich beider Beine, gemessen mittels fpVCT im Alter von 24 Monaten

3.3.6 Prozentrelativiertes Gesamtfett im Alter von 24 Monaten, gemessen mittels fpVCT 


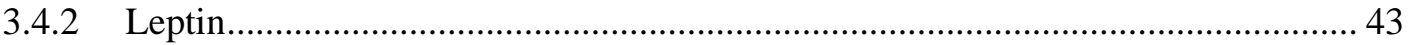

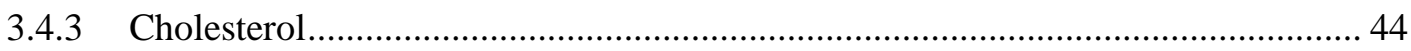

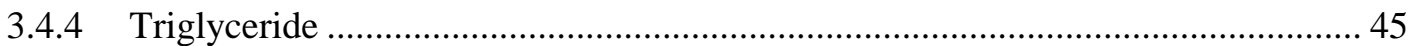

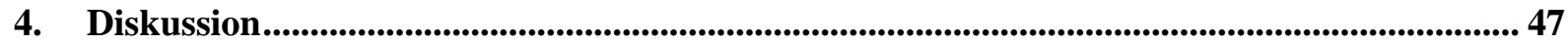

4.1 Ziel der vorliegenden Studie und Versuchsaufbau............................................................ 47

4.2 Fettanteil im Bereich L4-L5, gemessen mittels qCT über 24 Monate ............................... 48

4.3 Fettverteilung am gesamten Körper und in den einzelnen Körperbereichen, gemessen mittels fpVCT im Alter von 24 Monaten....................................................... 50

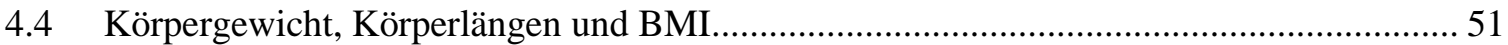

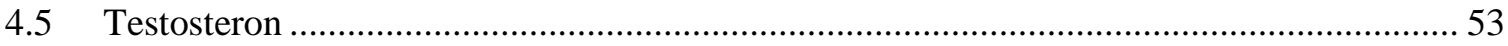

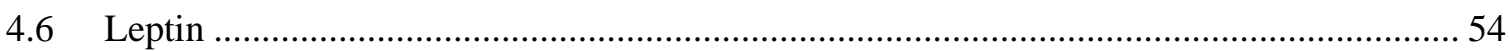

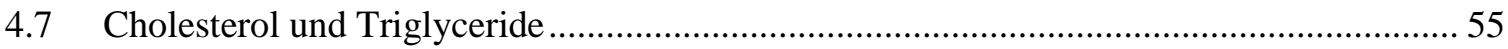

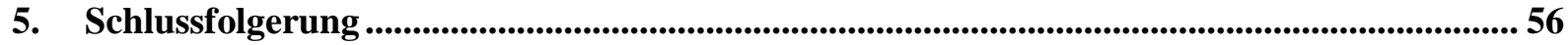

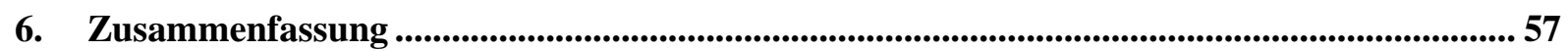

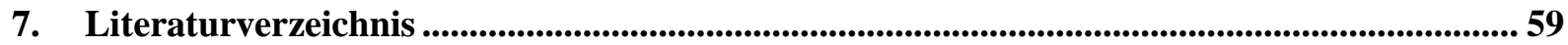

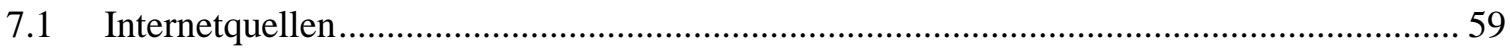

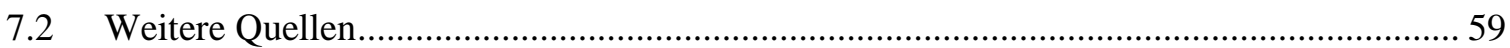

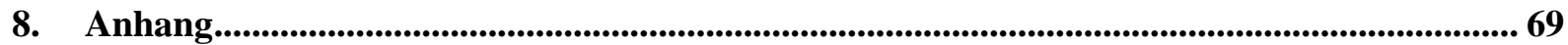

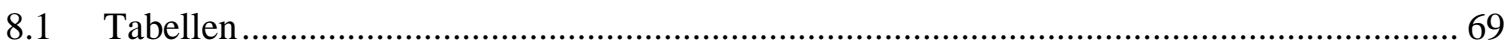

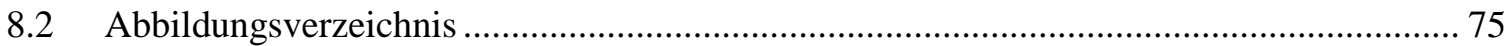




\section{Abkürzungsverzeichnis}

ACTH adrenocorticotropes Hormon

ANS

Atemnotsyndrom

BMI

Body Mass Index

BPD

bronchopulmonale Dysplasie

CJ

Callithrix jacchus

CT

Computertomograph

DNA

deoxyribonucleic acid

DPZ

Deutsches Primatenzentrum

EFCNI

European Foundation for the Care of Newborn Infants

EU

Europäische Union

FBP

filtered backprojections

fpVCT

flat panel-Volumen-Computertomograph/ Flächendetektor-Volumen-

Computertomograph

FSH

Follikel-stimulierendes Hormon

GC

Glukokortikoid

GEH

General Electric Healthcare

GnRH

Gonadotropin-Releasing-Hormon

HE

Hounsfield-Einheit

HSP 90

Hitzeschockprotein mit einem Molekulargewicht von 90 Kilodalton

IE

Internationale Einheiten

i.m.

intramuskulär

KG

Körpergewicht

$\mathrm{kV}$

Kilovolt

LH

Luteotropin

LWK

Lendenwirbelkörper

L4-L5

Messbereich Lendenwirbelkörper 4 bis Lendenwirbelkörper 5 als Maß für das viszerale Fettgewebe

MJ

Megajoule

mRNA

messenger ribonucleic acid

NEK

nekrotisierende Enterokolitis

$\mathrm{NIH}$

National Institute of Health

$\mathrm{qCT}$

quantitativer Computertomograph 
SEM

SF

SGA

SS

TAG

VCT

VLDL

WIP

11-ß-HD II

5- $\alpha$-DHT
Standardfehler des Mittelwerts

Scheitel-Fersenlänge

small for gestational age

Scheitel-Steißlänge

Triacylglyceride

Volumen Computertomograph

very low density lipoprotein

work in progress

11-ß-Hydroxysteroid-Dehydrogenase Typ II

5- $\alpha$-Dihydrotestosteron 


\section{Einleitung und Zielsetzung}

\subsection{Frühgeburtlichkeit}

In unserer modernen Gesellschaft hat die Anzahl von Frühgeburten in den letzten Jahren zugenommen. Eine Frühgeburt tritt ein, wenn der Zeitpunkt der Geburt vor dem Erreichen von 37 + 0 Schwangerschaftswochen oder 259 Gestationstagen eintritt. Ein reifes Neugeborenes wird folglich zwischen 37 und 42 Schwangerschaftswochen oder anders ausgedrückt mit einem Gestationsalter von 259 bis 294 Tagen geboren (Bartmann und Roos 2007). Im Jahr 1997 betrug laut der Stiftung „European Foundation for the Care of Newborn Infants“ (EFCNI) die Frühgeborenenrate in Deutschland $7 \%$ und hat bis zum Jahr 2009 um $2 \%$ auf insgesamt $9 \%$ zugenommen. Begründet ist die Zunahme der Frühgeborenenzahlen unter anderem durch eine Erhöhung des maternalen Durchschnittsalters bei der ersten Schwangerschaft sowie durch die steigende Zahl von künstlichen Befruchtungen, was zu einem Prävalenzanstieg von Mehrlingsschwangerschaften führt (Joseph et al. 1998; Pharmazeutische Zeitung online 2010).

\subsection{Neonatale Erkrankungen}

Zu Erkrankungen, die häufig mit der Frühgeburtlichkeit einhergehen und wegen der Unreife der kindlichen Organe und des unreifen Zustands des Neonaten entstehen, gehört unter anderem das Atemnotsyndrom des Neugeborenen (ANS). Dieses tritt aufgrund der Unreife der kindlichen Lunge mit einem Surfactantmangel häufig kurz nach der Geburt auf. Außerdem kann es u.a. zur Ausbildung einer chronischen Lungenerkrankung, der sogenannten bronchopulmonalen Dysplasie (BPD) kommen (Bartmann und Roos 2007). Auch die nekrotisierende Enterokolitis (NEK) und die Hirnblutung sind gefürchtete Komplikationen der Frühgeburtlichkeit (Speer 2012). 


\subsection{Einführung der pränatalen Glukokortikoidtherapie- Geschichte und aktueller Wissensstand}

Einen Meilenstein in der Forschung zur Verbesserung des postnatalen Outcomes legte in den sechziger Jahren der Brite Liggins. Er zeigte in Tierexperimenten am Schaf, dass eine pränatale Verabreichung von Kortikosteroiden an das Muttertier zu einer Förderung und Reifung des pulmonalen Surfactant-Systems und damit zu einer Senkung des Auftretens von ANS beim frühgeborenen Lamm führt (Liggins 1968; Liggins 1969). Im Jahre 1972 zeigte Liggins dann gemeinsam mit Howie, dass die zuvor im Tierversuch gezeigten Ergebnisse auch am Menschen reproduzierbar sind. Sie präsentierten, dass es bei den frühgeborenen Kindern ihrer Studie, deren Mütter wegen drohender Frühgeburt pränatal Kortikosteroide erhalten hatten, zu einer signifikanten Reduzierung des ANS kam (Liggins und Howie 1972). Auf diesen Forschungserfolg lässt sich folglich die Anwendung von pränatalen Kortikosteroiden zur Förderung der Lungenreife und somit zur Verbesserung der postnatalen Mortalität und Morbidität zurückführen. In den folgenden Jahren gab es zahlreiche Studien, die sich eingehend mit diesem Thema beschäftigten. So bestätigten Fiascone et al. 1987 an Hasen, dass die pränatale Verabreichung von Kortikosteroiden zu einer Erhöhung der fetalen Lungencompliance führt (Fiascone et al. 1987). Und im Jahr 1990 zeigten Crowly et al. in einer Metaanalyse von 12 randomisierten Studien mit über 3000 teilnehmenden Schwangeren, die eine Entbindung vor der 31. Schwangerschaftswoche hatten, dass die pränatale Glukokortikoidgabe zu einer deutlichen Reduzierung des ANS bei den Frühgeborenen führte (Crowly et al. 1990). Auch weitere Studien bestätigten das reduzierte Risiko, durch pränatale Glukokortikoide an ANS, BPD, Hirnblutungen und NEK zu erkranken und den neonatalen Tod zu erleiden (Crowly et al. 1990;Figueras-Aloy et al. 2005; Foix-L'helias et al. 2005; Garland et al 1995; Goldenberg und Wright 2001). Der positive Effekt auf die erwähnten unerwünschten neonatalen Krankheitsbilder und die Mortalität hängt unter anderem auch von der Dosis und dem Zeitpunkt der Kortikosteroidanwendung ab. Als wichtig stellte sich heraus, dass ein kompletter Behandlungszyklus abgeschlossen sein sollte und der größte positive Effekt zwischen 24 Stunden und 7 Tagen nach Beendigung des Behandlungszyklus mit dem jeweiligen Glukokortikoid eintritt (Figueras-Aloy et al. 2005; Hayes et al. 2008; NIH Consens Statement 1994; Roberts 2010). 


\subsection{Art und Dosierung der pränatalen Glukokortikoid- therapie}

Die empfohlenen Glukokortikoide und deren übliche Dosen lauten: 2 x 12 mg Bethamethason i. m. im Abstand von 24 Stunden oder alternativ 4 x 6 mg Dexamethason i. m. im Abstand von 12 Stunden. Im Vergleich der beiden Glukokortikoide zeigte Bethamethason eine leichte Überlegenheit in Bezug auf Wirkung und Nebenwirkungen und sollte daher abhängig von der Verfügbarkeit bevorzugt werden (Baud et al. 1999; Groneck 2001; Lee et al. 2006, Roberts 2010). Diese pränatale Behandlung sollten alle schwangeren Frauen zwischen der 24. und 34. Schwangerschaftswoche, denen eine Frühgeburt innerhalb der folgenden 7 Tage droht, erhalten (Committee on Obstretic Practice 2002; NIH Consensus Statement 2000).Wiederholte pränatale Zyklen sind wegen möglicher negativer Effekte für die Nachkommen kritisch zu betrachten und geplante mehrfache Zyklen werden nicht empfohlen (ACOG Committee on Obstetric Practice 2011). Mit diesem Thema haben sich bereits zahlreiche Studien befasst und gezeigt, dass wiederholte Zyklen von Glukokortikoiden u.a. zwar zu einer signifikanten Reduzierung von mechanischer Beatmung und dem Auftreten von Pneumothoraces führen, es aber auch zu einem reduzierten Geburtsgewicht und einer höheren Anzahl von für das Gestationsalter zu kleinen (SGA) Frühgeborenen, einem reduzierten Gehirnwachstum, reduziertem Kopfumfang und Veränderungen von Hormonen kommt (Banks et al. 1999; Bonanno et al. 2007; Ikegami et al. 1997; Mazumder et al. 2008; Walfisch et al. 2001; Wapner et al. 2006).

\subsection{Wirkung von Glukokortikoiden}

Glukokortikoide sind Steroidhormone, die in der Nebennierenrinde gebildet werden. Die Synthese entsteht aus Cholesterin in der Zona fasciculata. Nach der Entstehung werden sie ans Blut abgegeben. Kortisol, auch Hydrokortison genannt, ist das am häufigsten gebildete Glukokortikoid. Die Synthese und Sekretion wird durch die hypothalamisch-hypophysäre Steuerung geregelt. Eine besonders starke Ausschüttung erfolgt in Stresssituationen (u.a. bei Hunger, Angst oder einem Trauma). Glukokortikoide wirken auf verschiedenen Wegen. Die meisten Effekte werden durch die genomvermittelte Wirkung erreicht (Horn et al. 2003). Das Wirkspektrum der Glukokortikoide ist breit. Unter anderem greifen die Glukokortikoide in den Stoffwechsel ein, indem sie die Energiebereitstellung fördern. Des Weiteren wirken sie antiinflammatorisch, antiphlogistisch, antiallergisch, antiemetisch und 
immunsuppressiv (Karow und Lang-Roth 2012). Abgebaut werden die Glukokortikoide schließlich in der Leber und ausgeschieden zum größten Teil über die Nieren und zu einem kleinen Teil über die Galle (Horn et al. 2003).

Der Fetus ist durch die in der Plazenta enthaltene 11-ß-Hydroxysteroid-Dehydrogenase Typ II (11-ß HD II), die das aktive Kortisol in inaktive Produkte abbaut, vor überschüssigen mütterlichen Glukokortikoidspiegeln geschützt. Etwa 10 bis $20 \%$ dieser mütterlichen Hormone gelangen in den fetalen Blutkreislauf. Allerdings können synthetische Glukokortikoide wie z.B. Dexamethason die Plazenta ungehindert passieren, da sie von der 11-ß HD II nicht katalysiert werden und so in den kindlichen Organismus eingreifen (Mustoe et al 2012; Seckl 1997; Woods und Weeks 2005).

Die wohl entscheidendste und v.a. erwünschte Wirkung durch den Übertritt der Glukokortikoide vom mütterlichen zum kindlichen Organismus ist die Reifung der fetalen Lunge. Durch die Glukokortikoide kommt es zur vermehrten Synthese von Surfactant und dadurch zur Reduktion der Oberflächenspannung und zur Verbesserung der Lungencompliance. Des Weiteren wird die Entwicklung von parenchymalen Strukturen der Lunge beschleunigt und die Gefäßpermeabilität reduziert. Diese Faktoren sorgen gemeinsam für eine verbesserte respiratorische Funktion und somit eine höhere Überlebenschance (Ballard und Ballard 1995; Bolt et al. 2001).

\subsection{Dexamethason}

Das bereits erwähnte Dexamethason ist ein synthetisches Glukokortikoid, welches, gemessen am natürlichen Glukokortikoid Kortisol, eine etwa 30 bis 40 -fache relative glukokortikoide Potenz besitzt. Die Wirkdauer von Dexamethason beträgt mehr als 24 Stunden. Verabreicht werden kann Dexamethason oral, intravenös oder lokal. Eine mineralokortikoide Potenz besitzt Dexamethason im Gegensatz zu Kortisol nicht. Dexamethason wird in der Leber durch Glukuronidierung metabolisiert und renal eliminiert (Karow und LangRoth 2012).

Der Einsatz von Dexamethason ist vielfältig. Interessant für die vorliegende Arbeit ist der pränatale Einsatz von Dexamethason zur Lungenreife bei drohender Frühgeburt mit der in Kapitel 1.4 beschriebenen Dosierung (Lüllmann et al. 2003). Die Nebenwirkungen dieser Anwendungen sind Gegenstand derzeitiger Forschung und ein Teil davon Bestandteil der vorliegenden Arbeit. Es besteht Grund zu der Annahme, dass es zu Störungen beim 
Geburtsgewicht und in der Gewichtsentwicklung sowie im Wachstum von Körper und Gehirn kommen kann. Außerdem wurden Auffälligkeiten in der Entwicklung von Bewegung und kognitivem Verhalten beobachtet. Allerdings sind für diese Nebenwirkungen Dosis und Anwendungsdauer sehr entscheidend (Hauser et al. 2008; Groneck 2001; Bloom et al. 2001; Dahlgren et al. 2001; De Vries et al. 2007). Überdies ist eine teratogene Wirkung nicht sicher auszuschließen, daher sollte im ersten Trimenon der Schwangerschaft möglichst keine Substitution mit Dexamethason erfolgen (Lüllmann et al. 2003; Karow und Lang-Roth 2012).

\subsection{Pränatale Glukokortikoidtherapie - verändertes Ge- burtsgewicht, verändertes postnatales Wachstum und veränderte Gewichtszunahme}

In einigen Studien zeigte sich, dass es durch eine pränatale Glukokortikoidtherapie zu einem reduzierten Geburtsgewicht bei Mensch und Tier kommen kann. Dies ist abhängig von Dauer und Dosis der Glukokortikoide (Bloom et al. 2001; French et al. 1999; Kutzler et al. 2004). Es zeigte sich an Ratten, dass das reduzierte Geburtsgewicht nicht obligatorisch auftritt. Es kommt vorwiegend dann zu dem reduzierten Geburtsgewicht, wenn die Exposition in der späten Phase der Schwangerschaft auftritt, da hier die fetale Wachstumsphase am stärksten ist (Nyirenda et al. 1998). 2005 bestätigten Woods und Weeks dies. In diesen Versuchen hatten die Nachkommen der Ratten ein signifikant geringeres Geburtsgewicht, die der pränatalen Glukokortikoidtherapie in der späten Schwangerschaft ausgesetzt waren (Woods und Weeks 2005). Viele Kinder und Jungtiere in Versuchen mit einem niedrigen Geburtsgewicht zeigten im Verlauf ein Aufholwachstum im Sinne einer schnelleren Gewichtszunahme während der frühen postnatalen Periode und innerhalb der ersten Lebensmonate (Koppe et al. 1977; O`Regan et al. 2004). Allerdings gab es auch Ergebnisse, wonach das Aufholwachstum der Ratten nicht ausreichte, um das Körpergewicht der Kontrollgruppe im Alter von 6 Monaten einzuholen und eine Reduktion insbesondere von epididymalem Fettgewebe auftrat (Cleasby et al. 2003). 2007 konnte de Vries in seinem Versuch an nichtmenschlichen Primaten nach pränatalem Dexamethasonkein verändertes Geburtsgewicht bestätigen. Er stellte aber eine verkürzte fetale Femurlänge fest. Außerdem zeigte sich in diesem Versuch bei höheren Dexamethasondosen das postnatale Wachstum abgeschwächt und das subkutane Fettgewebe erhöht (De Vries et al. 2007). Eine weitere Studie in Bezug auf das Wachstum nach erfolgter Glukokortikoidtherapie an Primaten ließ 
den Schluss zu, dass es zuerst zu einem reduzierten Wachstum im frühen Leben kommt, welches im späteren Leben durch ein beschleunigtes Wachstum abgelöst wird (Mustoe et al. 2012).

\subsection{Programmierung durch pränatale Glukokortikoid- therapie, insbesondere bei der Entwicklung des Fettgewebes: Epigenetische Effekte}

Epidemiologische Daten und experimentelle Studien an Tieren haben gezeigt, dass einzelne Gewebe und ganze Organsysteme in utero während kritischen Entwicklungsphasen mit ungünstigen Konsequenzen für deren Funktion im späteren Leben programmiert werden können. Verschiedene Hormone passen die fetale Entwicklung an die bestehenden Umstände an, um damit eine bestmögliche Überlebenschance zu erreichen. Von diesen Hormonen ist das Glukokortikoid eines, das die Gewebe und Organprogrammierung beeinflusst. Dadurch kommt es unter anderem zu einer veränderten Endokrinologie, die vorübergehend oder anhaltend sein kann. Wenn sie dauerhaft ist, reichen die Konsequenzen für das Gewebewachstum und die Entwicklung bis ins postnatale Leben und bedingen damit die Pathogenese von Erkrankungen und Störungen im Erwachsenenalter. Endokrine Veränderungen können daher beides sein, der Grund und die Folge von intrauteriner Programmierung (Fowden und Forhead 2004). Der genaue Mechanismus dieser Programmierung ist noch nicht abschließend erforscht, gehört aber in den Kontext der Epigenetik, welche derzeit Gegenstand vieler Forschungen ist. Epigenetik bedeutet, dass es durch Umwelteinflüsse in utero wie z.B. Stress (über erhöhte Glukokortikoidspiegel bei der Mutter) oder z.B. durch Nikotinabusus der Mutter während der Schwangerschaft zu Änderungen in der Chromosomenmodifikation kommt. Nicht die DNA-Sequenz selbst wird verändert, sondern mittels veränderter DNA-Methylierung oder Veränderungen der Histonmodifikation kommt es zu Chromosomenmodifikationen (Bouwland-Both et al. 2015; Vidal et al. 2014; Walter 2009). Im Versuch von Vidal et al. (2014) führte pränataler Stress zu einer erhöhten Methylierung eines bestimmten Gens, dessen biologische Funktion noch nicht vollständig geklärt ist, das aber u.a. im Zusammenhang mit der Vermehrung von Fettzellen zu stehen scheint. Somit kann durch epigenetische Effekte im Sinne einer erhöhten Methylierung von bestimmten Genen eine Fettzellvermehrung entstehen (Vidal et al. 2014). In diesem Zusammenhang zeigte sich, dass pränataler Stress bei Müttern zu erhöhten Werten des Body Mass Index (BMI) und einem vermehrten Vorkommen von Adipositas bei den 
Nachkommen führt. Interessant ist hierbei, dass das Risiko des Übergewichts in diesen Studien nicht vor dem präpubertären Alter beobachtet wurde (Li et al. 2010). Kurz zuvor, im Jahr 2009 wurde dieses Phänomen bereits im Tiermodell beschrieben. Im Versuch an Ratten stellte sich heraus, dass pränataler Stress und/oder eine hochkalorische Ernährung des Muttertiers zu einer erhöhten Anfälligkeit der Nachkommen für eine ernährungsbedingte Adipositas führen können. Allerdings entwickelten nur die Nachkommen eine Adipositas, die nach dem Abstillen hochkalorisch ernährt wurden. Diese Nachkommen mit erhöhtem Körpergewicht zeigten signifikant mehr subkutanes und retroperitoneales Fettgewebe sowie erhöhte Plasma Leptinspiegel und eine gestörte Glukosetoleranz (Tamashiro et al. 2009). Es wurde auch eine erhöhte Anfälligkeit für die Ausbildung einer Fettleber und Veränderungen im Fettstoffwechsel mit erhöhtem hepatischen Triglyceridgehalt nach pränataler Glukokortikoidexposition und postnataler fettreicher Ernährung festgestellt (Drake et al. 2010). Auch Nahrungsunabhängige Gewichtszunahmen mit einer 30-bis 40prozentigen Zunahme des Fettgewebegewichts wurden bei 8 Wochen alten Ratten nach pränataler Glukokortikoidexposition beobachtet. Es zeigte sich insbesondere eine signifikante Zunahme des retroperitonealen Fettgewebes. Außerdem gab es eine Tendenz für erhöhte Leptinspiegel und bei den Männchen auch für reduzierte Testosteronspiegel (Dahlgren et al. 2001). Erhöhte Leptinspiegel gab es auch bei einjährigen Ratten nach pränataler Dexamethasongabe. Diese erhöhten Konzentrationen konnten aber nicht durch eine Adipositas erklärt werden. Die für das jeweilige Geschlecht repräsentativen Fettgewebe wurden in diesem Versuch untersucht. Es zeigte sich bei den männlichen Rattennachkommen eine signifikante Abnahme des epididymalen Fettgewebes nach der Glukokortikoidgabe im letzten Trimenon der Schwangerschaft. Die weiblichen Rattennachkommen zeigten keine Unterschiede des parametrischen Fettgewebes verglichen mit der Kontrolle. Angaben zu anderen Fettregionen der Ratten wurden nicht veröffentlicht (Sugden et al. 2001). Zudem veröffentlichten Franko et al. 2010 Ergebnisse aus Experimenten mit Ratten, die die Vermutung zulassen, dass erhöhte mütterliche Glukokortikoidspiegel durch Stress oder auch synthetische Gaben zu einer Fettverteilungsveränderung der männlichen Nachkommen führen. In diesem Fall waren die peritonealen und perirenalen Fettspeicher reduziert und die subkutanen und abdominellen erhöht (Franko et al. 2010). Allerdings gab es auch Beobachtungen, dass Frühgeborene mit pränataler Glukokortikoidbehandlung und niedrigem Geburtsgewicht im präpubertären Alter weniger wogen als die verglichene Gruppe von Frühgeborenen ohne Behandlung und die Gruppe der Reifgeborenen (Wang et al. 2007). Insbesondere kommt auch dem Zeitpunkt der pränatalen Einwirkung der Glukokortikoide 
hinsichtlich bereits beschriebener und auch anderer postnataler Effekte eine Bedeutung zu. (Hauser et al. 2008). Außerdem mehren sich die Daten, dass es durch die pränatale Programmierung mittels Glukokortikoiden zur Ausbildung des metabolischen Syndroms mit abdomineller Fettleibigkeit, Hypertonie, Dyslipidämie und Insulinresistenz bzw. Diabetes mellitus Typ II oder auch nur Teilen davon kommen kann (Newnham 2001; Nyirenda et al. 2009; Seckl 1997; Sugden et al. 2001; Tamashiro und Moran 2010).

Einen interessanten Aspekt stelltauch die Pubertät da. Es wird vermutet, dass die pränatale Periode ein empfindliches Zeitfenster in Bezug auf die Langzeitprogrammierung der Pubertätsentwicklung darstellt. Dies ist darin begründet, dass sich Hinweise auf der Grundlage von Tierversuchen mehren, dass pränataler Stress über erhöhte Glukokortikoide zu einem früheren Eintreten der Pubertät und einer höheren Geschwindigkeit des Pubertätswachstums führt ( $\mathrm{Li}$ et al. 2010). Außerdem gibt es im Rahmen der epigenetischen Forschung Studien, die zeigten, dass mütterlicher pränataler Stress signifikant mit der Methylierung bestimmter Genregionen korreliert, die für das Wachstum zuständig sind (Vidal et al. 2014).

\subsection{Fettgewebe}

Aus Mesenchymzellen entwickelt sich das Fettgewebe. Es besteht überwiegend aus Adipozyten, welche von interstitiellem Bindegewebe und Blutgefäßen umgeben sind. Unterschieden werden kann es in braunes und weißes Fettgewebe. In der Embryonalperiode entwickeln sich die ersten Fettzellen, welche zu dem Zeitpunkt vor allem braunes Fettgewebe bilden. Zu einem großen Teil wird dieses im Verlauf der Zeit nach der Geburt wieder abgebaut. „In der Fetalperiode und postnatal bis in die Pubertät hinein“ (Drenckhahn und Kugler 2008, S. 125) beginnt dann die Entstehung des weißen Fettgewebes und kann ein Leben lang fortgeführt werden. Von den Aufgaben unterscheiden sich diese beiden Fettgewebsarten wie folgt: Das weiße Fettgewebe dient in Form von Baufett u.a. in der Fußsohle, der Wange oder der Orbita zur Polsterung. Im subkutanen Bereich schützt es vor Kälte. Außerdem dient es besonders im Omentum major, im Bereich des Dickdarms und auch subkutan, in Form von Speicherfett, als Energiespeicher (Drenckhahn und Kugler 2008). Außerdem ist es ein großes endokrines Organ, welches durch verschiedene Prozesse teilweise den Glukose, Lipid- und Energiestoffwechsel sowie das Immun-, Blutgefäß- und Reproduktionssystem beeinflussen kann (Guerre-Millo 2002). Das braune Fettgewebe, dessen Farbe durch die hohe Anzahl von Mitochondrien mit ihrem Zytochrom und dem in 
den Fetttropfen gelösten Lipochrom entsteht, hat v.a. beim Neugeborenen die Aufgabe, durch Oxidation von Fettsäuren Wärme zu produzieren. Im menschlichen erwachsenen Körper ist kaum noch braunes Fettgewebe zu finden. Der Gesamtanteil des Fettgewebes am Körpergewicht ist geschlechtsspezifisch. Die normalgewichtige Frau hat etwa einen Fettanteil von 20 bis $25 \%$ (Drenckhahn und Kugler 2008, Müller und Bosy-Westphal 2005) und das Fett befindet sich „,vorwiegend in der Gluteal- und Femoralregion“ (Drenckhahn 2008, S. 7), was als „gynoider Fettverteilungstyp“ (Drenckhahn 2008, S. 7) bezeichnet wird. Der Mann hingegen hat einen Fettanteil von 10 bis $15 \%$ des Körpergewichts (Drenckhahn und Kugler 2008,Müller und Bosy-Westphal 2005), welcher sich zu einem großen Teil im abdominellen Bereich befindet und als ,,androgener Fettverteilungstyp“ (Drenckhahn 2008, S. 7) bezeichnet wird. Bei einem normalen BMI befinden sich beim androgenen Typ etwa $20 \%$ der Fettmasse im viszeralen Bereich, der aus intraabdominalem und intrathorakalem Fettgewebe besteht. Das darin befindliche Fett ist im Verhältnis von 9:1 aufgeteilt, was bedeutet, dass sich bei diesem Verteilungstyp nahezu $20 \%$ des Gesamtfetts intraabdominal befinden. Mit Hilfe eines CTs kann auf Höhe von LWK 4 und 5 die Fettgewebsfläche bestimmt werden und diese stellt das Maß für das viszerale Fettgewebe dar. Erwähnt sei in diesem Zusammenhang, dass bei Übergewicht der androgene Fettverteilungstyp ein höheres Risiko für gesundheitliche Schäden darstellt als der gynoide Typ (Müller und Bosy-Westphal 2005). Bei der Literaturrecherche fällt ansonsten auf, dass bisher noch recht wenig über die verschiedenen Fettdepots bekannt ist und die Definition nicht immer einheitlich erfolgt.

\subsection{Leptin}

Leptin, welches 1994 entdeckt wurde (Rassow 2008 b), ist ein Protein, welches vor allem von den Adipozyten, aber auch in den Parietalzellen des Magens und in der Plazenta synthetisiert wird und aus 167 Aminosäuren besteht. Leptin entstammt dem obese-Gen, welches für Fettleibigkeit steht. Es wird vor allem während der Lipogenese an das Blut abgegeben. Ansonsten unterliegt die Sekretion einem ,pulsatilen“ (Ritter 2005, S. 814) Schema mit der stärksten Ausschüttung um Mitternacht. Höhere Serumkonzentrationen von Leptin haben eine wichtige Funktion in der Regelung der Nahrungsaufnahme und des Energieverbrauchs. Nach der Nahrungsaufnahme wird Leptin durch ansteigende Triacylglycerinspiegel im Fettgewebe ausgeschüttet und führt über verschiedene biochemische Prozesse zur Hemmung des Hungergefühls, der Insulinausschüttung und der peripheren Wirkung des 
Insulins und versucht der Fettanreicherung entgegenzuwirken. Die Plasmakonzentration des Leptins steht im direkten Verhältnis zur Fettgewebsmasse und zum BMI. Bei Adipositas bestehen sehr hohe Leptinspiegel, dies kann als Adipositassignal gesehen werden. Allerdings scheint in diesem Fall auch eine Leptinresistenz zu bestehen, da die katabole Wirkung des Leptins nicht mehr ausgeübt werden kann (Ritter 2005; Rassow 2008 b). Laut des Endokrinologikum Hamburg gelten die in Tabelle 1 im tabellarischen Anhang dargestellten Referenzwerte des Leptins in Bezug auf den BMI.

\subsection{Testosteron}

Das Testosteron und sein biologisch aktiverer Metabolit das 5- $\alpha$-Dihydrotestosteron (5- $\alpha$ DHT) sind die wichtigsten Androgene, auch männliche Sexualhormone genannt, und gehören zur Gruppe der Steroidhormone. Die Herstellung von Testosteron erfolgt überwiegend in den Leydig-Zwischenzellen des Hodens (Deutzmann 2008; Deutzmann 2010; Pedain 2010). Zusätzlich findet noch eine geringe Synthese in der Nebennierenrinde statt und bei der Frau außerdem auch noch in den Ovarien (Mönig und Harbeck 2011). Im Blut liegt das Testosteron fast vollständig an Albumin und das sexualhormonbindende Protein gebunden vor. In den Zielzellen erfolgt dann meist eine Reduzierung von Testosteron zu 5- $\alpha$-DHT (Deutzmann 2008; Deutzmann 2010; Pedain 2010). Die Wirkung des Testosterons und seines Metaboliten 5- $\alpha$-DHT hat in den verschiedenen Lebensphasen ihre Schwerpunkte. Während der fetalen Phase ist es bereits zwischen der 10. und 18. Woche aktiv und beeinflusst „die sexuelle Differenzierung“(Nieschlag et al. 2005, S. 701). Um den Zeitpunkt der Geburt ist der Testosteronspiegel sehr hoch, es kommt zum Deszensus des Testis und es wird bereits eine „männliche Prägung des Gehirns“ (Nieschlag et al. 2005, S.701) vermutet. Danach ist die Androgenproduktion weitgehend eingestellt. Erst im Alter der Pubertät kommt es über den Regelkreis des Hypothalamus und der Hypophyse zur Ausschüttung von LH und zum Anstieg des Testosteronspiegels (Hick und Hick 2009). Dies führt u.a. zum Wachstum von Hoden und Penis sowie zum Wachstumsschub des Körpers (Deutzmann 2010; Pedain 2010). Des Weiteren steigert Testosteron die Erythropoese, den Aufbau von Muskeln und Knochen, die Libido und Potenz und „steuert Produktion und Zusammensetzung der Sekrete von Nebenhoden, Samenblase und Prostata“ (Hick und Hick 2009, S. 240). Der Referenzbereich für Testosteron ist altersabhängig. Bei Männern im Alter zwischen 20 und 49 Jahren liegt er zwischen $290 \mathrm{ng} / \mathrm{dl}$ und $1000 \mathrm{ng} / \mathrm{dl}$ und im Alter 
über 50 Jahren bei $150 \mathrm{ng} / \mathrm{dl}$ bis $560 \mathrm{ng} / \mathrm{dl}$. Bei Frauen sollte Testosteron unter $100 \mathrm{ng} / \mathrm{dl}$ liegen (Mönig und Harbeck 2011).

\subsection{Triacylglyceride}

Triacylglyceride (TAG), auch als Triglyceride oder Triacylglycerole bezeichnet, sind Ester, die aus einem Molekül Glycerin und drei Fettsäuren bestehen. Die TAG sind die wichtigsten Speicherlipide und werden aufgrund ihrer Ungeladenheit auch als Neutralfette bezeichnet. Sie werden vorwiegend im Zytoplasma der Adipozyten gespeichert. Der Anteil der TAG an der Körpermasse ist individuell. Bei einem normalgewichtigen Menschen beträgt er etwa $12 \%$. Es werden aber auch je nach Körperkostitution Schwankungen von $4 \%$ bis über $40 \%$ beobachtet. Neben ihrer Eigenschaft als Speicherfett und Energielieferant liegen sie auch als Unterhautfett, Baufett und Organfett vor und erfüllen hier ihre jeweilige Aufgabe. Ein großer Teil der Lipide wird als Triglyceride mit der Nahrung aufgenommen und in Lipoproteintransportpartikeln, den sogenannten Chylomikronen, verpackt an die Blutbahn abgegeben. Auf diesem Weg gelangen sie dann vorwiegend zu den Fett- und Muskelzellen. Der Aufbau der TAG in den Adipozyten oder u.a. in den Hepatozyten wird als Lipogenese bezeichnet und der Abbau, welcher v.a. im Fettgewebe stattfindet, als Lipolyse. Deren Regulation geschieht sowohl über Hormone als auch über Glukose. Ein hoher Blutglukosespiegel regt die Lipogenese an, ein Glukosemangel hingegen hemmt die Lipogenese und es kommt verstärkt zur Lipolyse. Auf hormoneller Ebene beeinflussen Adrenalin, Glukagon und Insulin die Regulation des TAG-Stoffwechsels. Insulin steigert die Lipogenese und Adrenalin und Glukagon als Übermittler des Zeichens für Hunger steigern die Lipolyse (Horn 2009 a; Horn 2009 b; Rassow 2008 a; Rassow 2008b). Der Referenzbereich der TRG liegt bei $<150 \mathrm{mg} / \mathrm{dl}$ oder $<1,7 \mathrm{mmol} / \mathrm{l}$. Eine Hypertriglyceridämie kommt u.a. beim Diabetes und dem Metabolischen Syndrom vor (Aufenanger 2011).

\subsection{Cholesterin}

Cholesterin ist das wichtigste Steroid (Horn 2009 a). Es kann vom Körper selbst synthetisiert werden und auch mit der Nahrung aufgenommen werden. Der Tagesbedarf beträgt etwa $1 \mathrm{~g}$ und je nach Nahrungsmenge und Zusammensetzung werden in unseren Breitengraden zirka $50 \%$ davon mit der Nahrung zugeführt (Rassow 2008 a). Der wichtigste Ort der Synthese für den Stoffwechsel befindet sich im Zytosol und im endoplasmatischen 
Retikulum der Leber. Allerdings wird Cholesterin auch in nahezu allen anderen Zellen des Organismus produziert. Cholesterin wird zur Produktion von Steroidhormonen benötigt und ist ein wichtiger Bestandteil von Zellmembranen. Im Blut transportiert wird Cholesterin an Lipoproteine gebunden. Nicht benötigtes Cholesterin kann in Form von Cholesterinester auch im Zytosol gespeichert werden. Cholesterin wird zu Gallensäuren umgebaut und auf diesem Weg sowohl zu einem Teil ausgeschieden als auch im enterohepatischen Kreislauf wieder resorbiert. Die Cholesterin-Biosynthese wird hormonell durch Insulin und Glukagon reguliert, wobei Insulin die Produktion fördert und Glukagon sie hemmt. Außerdem führt das Cholesterin selbst, im Sinne einer negativen Rückkopplung, zu einer Hemmung seiner Produktion (Horn 2009 a; Horn 2009 b; Rassow 2008 a; Rassow 2008 b; Hauser 2008). Der Referenzbereich für das Gesamtcholesterin liegt bei $<200 \mathrm{mg} / \mathrm{dl}$ oder $<5,2 \mathrm{mmol} / \mathrm{l}$. Es besteht ein Zusammenhang zwischen erhöhten TRG-Werten und Cholesterin, da die Lipoproteine, die viel TRG enthalten, auch Cholesterin transportieren. So führen sehr hohe TRG-Werte auch zu erhöhten Cholesterinwerten (Aufenanger 2011).

\subsection{Versuchstier}

Als Versuchstiere dienen in dieser Arbeit 30 männliche Affen der Primatenart Callithrix jacchus (CJ). Diese kleinen Neuweltaffen, auch Weißbüschelaffen genannt, stammen ursprünglich aus dem Nordosten Brasiliens. Durch weitverbreitete Lebensraumzerstörung in diesem Gebiet leben sie mittlerweile auch in küstennahen Regenwäldern im Südosten Brasiliens und sogar schon innerhalb von großen Städten wie Rio de Janeiro (Cawthon Lang 2005; Cover 2000). Die CJ erreichen eine Körperlänge zwischen $12 \mathrm{~cm}$ und $15 \mathrm{~cm}$, besitzen zusätzlich einen zwischen 29,5 cm und $35 \mathrm{~cm}$ langen Schwanz und haben ein Gewicht, welches beim ausgewachsenen Tier, je nach Quelle, etwa zwischen $250 \mathrm{~g}$ und $350 \mathrm{~g}$ liegt (Cawthon Lang 2005; Cover 2000). In ihren natürlichen Lebensräumen ernähren sie sich u.a. von Insekten, Blumen, Früchten, Nektar, Vogeleiern und Fröschen (Cover 2000). CJ sind tagaktiv, leben in Bereichen zwischen 5 und $65 \mathrm{~m}^{2}$ und legen täglich zwischen 500 und $1000 \mathrm{~m}$ Wegstrecke zurück. Sie sind sehr flink, können sich gut an Bäumen festhalten und bewegen sich, indem sie von Baum zu Baum springen oder auf allen Vieren über Äste und Zweige laufen (Cawthon Lang 2005). In freier Wildbahn leben sie in Gruppen von 2 bis 13 Tieren zusammen. Sie pflanzen sich durch Polyandrie fort, was bedeutet, dass sich ein Weibchen mit mehreren Männchen paart. In Freiheit lebt das Weibchen in der Regel in einer Gruppe mit zwei Männchen zusammen und paart sich in der fruchtbaren Phase mit 
beiden Männchen. Fruchtbar sind die Weibchen durchschnittlich im Alter von 477 Tagen, entsprechend knapp 16 Monaten und die Männchen mit 382 Tagen, entsprechend mit knapp 13 Monaten. Die Tragzeit entspricht im Durchschnitt 144 bis 148 Tage und in der Regel werden Zwillinge geboren (Cover 2000). In der freien Wildbahn überleben die Affen je nach Quelle im Durchschnitt 10 bis 12 Jahre (Cawthon Lang 2005; Cover 2000). In Gefangenschaft können sie bis zu 16 Jahre alt werden (Cover 2000). In der biomedizinischen Forschung werden die CJ häufig als Alternative zu traditionellen nichtmenschlichen Primaten eingesetzt, da sie relativ leicht erhältlich und gut in Gefangenschaft zu züchten sind. Außerdem sind sie wegen Ihrer geringen Größe gut artgerecht zu halten, besitzen eine schnelle Reife, eine hohe Fertilität sowie eine relativ kurze Lebensspanne und die entstehenden Kosten sind kalkulierbar (Mansfield 2003).In Versuchen zur Untersuchung des mütterlichen Einflusses auf die Nachkommen besteht der Vorteil dieser Tiere darin, dass die Muttertiere typischerweise zweieiige Zwillinge gebären. Auch für Langzeitstudien in Bezug auf das Altern und seine Prozesse v.a. auch in Bezug auf die Kognition eignen sie sich gut, da sie innerhalb von 5 Jahren vom jungen Erwachsenen zum Greis reifen und in der Lage sind, ihre Handlungen zu planen und u.a. Tests am Computer mittels Touchscreen durchzuführen (Austad 2009). Die CJ sind für diese Arbeit besonders geeignet, da sich gezeigt hat, dass sie dem Menschen in der Gewebeentwicklung sehr ähneln. CJ zeigen ähnliche durch Übergewicht hervorgerufene Veränderungen wie der Mensch. In Studien, in denen sie unter Adipositas litten, zeigten sie u.a. eine Dyslipidämie und einen veränderten Glukosemetabolismus (Tardif et al. 2009). Die Abbildung 1.1 zeigt einen CJ auf dem Arm eines Mitarbeiters der Abteilung. 


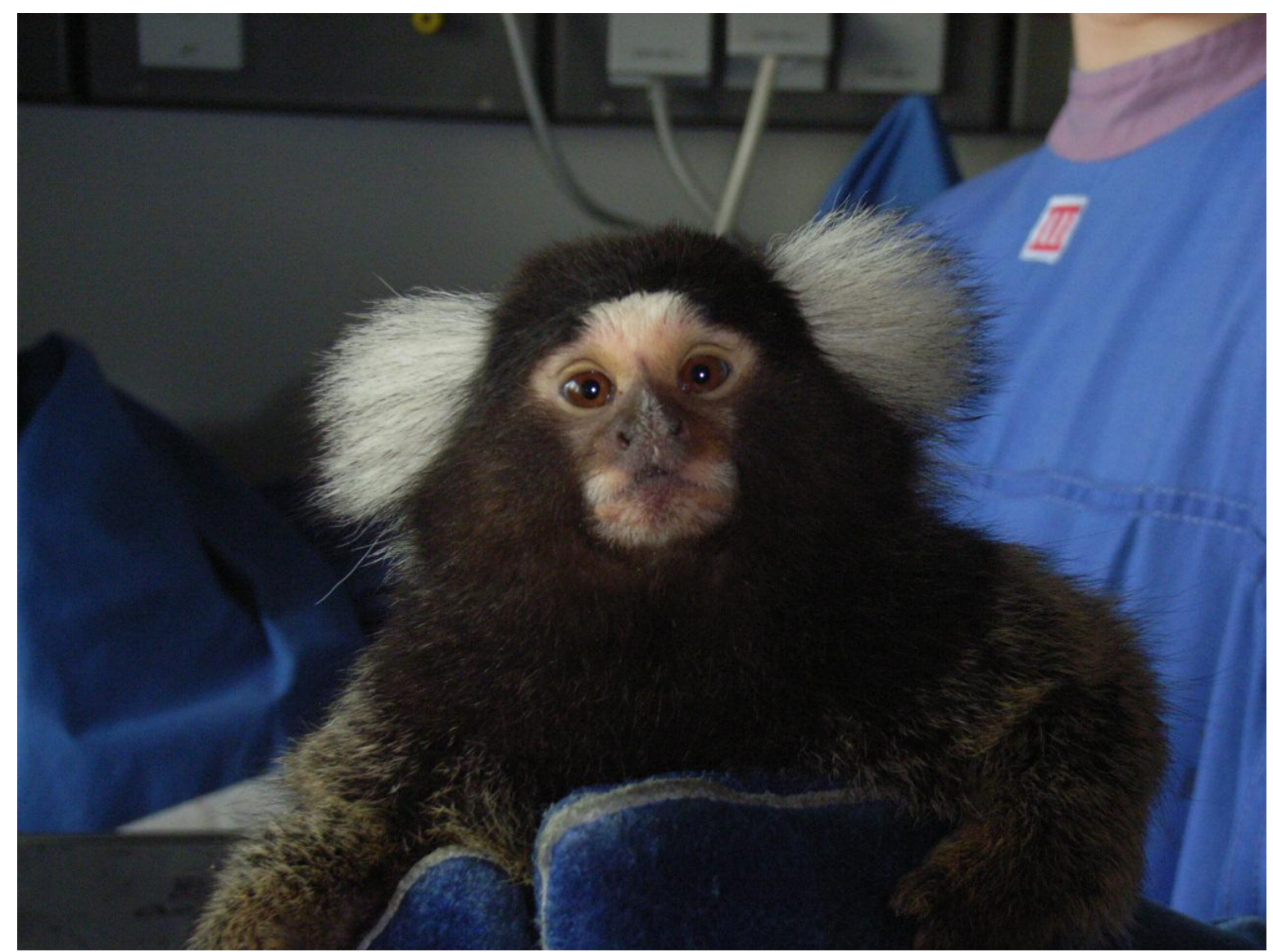

Abbildung 1.1:Callithrix jacchus auf dem Arm eines Mitarbeiters der Abteilung. Das Bild wurde von Kollegen der Abteilung während der Versuchszeit aufgenommen.

\subsection{Versuchsaufbau und Fragestellung}

Wie aus dem vorangegangenen Teil der Einleitung hervorgeht, wurde die pränatale Glukokortikoidtherapie im Laufe der Jahre eingeführt, um bei drohender Frühgeburt das postnatale Outcome zu verbessern. Allerdings scheint diese Therapie auch mit darüberhinausgehenden Effekten für die Nachkommen verbunden zu sein. Aus diesem Grund gibt es zahlreiche Studien, die sich mit der Frage beschäftigen, ob pränatale Glukokortikoidtherapien Veränderungen des Organismus mit Auswirkungen für das spätere Leben bewirken können. Es häufen sich die Aussagen, dass besonders das Fettgewebe in seiner Verteilung verändert ist. Außerdem wurde beobachtet, dass es im Laufe des Lebens zur Ausbildung von Adipositas mit Veränderungen des Hormonhaushalts kommen kann. In den der vorliegenden Arbeit zugrundeliegenden Versuchen wird das Prinzip der pränatalen Glukokortikoidtherapie auf das Tiermodell übertragen und das in der Geburtshilfe eingesetzte und im Kapitel 1.6 beschriebene, synthetische Glukokortikoid Dexamethason zu verschiedenen Zeitpunkten der Schwangerschaft den Muttertieren oral verabreicht. Hierzu dient der CJ als 
Versuchstier. Die Muttertiere wurden in drei Gruppen aufgeteilt. Die erste Versuchsgruppe, in dieser Arbeit 5-early-Gruppe genannt, sind die männlichen Nachkommen der Muttertiere, die Dexamethason im ersten Trimenon der Schwangerschaft erhalten haben. Die zweite Versuchsgruppe ist die sogenannte 5-late-Gruppe. Diese Gruppe enthält die männlichen Nachkommen, die von Muttertieren geboren wurden, die das Dexamethason im zweiten Trimenon erhielten. Diese beiden Versuchsgruppen wurden mit einer Kontrollgruppe von männlichen Nachkommen von Muttertieren ohne Behandlung verglichen. Alle Versuchstiere wurden nicht vorzeitig geboren, sondern um den errechneten Termin herum ausgetragen. Sie lebten zwei Jahre lang im Deutschen Primatenzentrum (DPZ) in Göttingen und wurden regelmäßigen Untersuchungen unterzogen. Teil dieser Untersuchungen waren computertomographische Aufnahmen mittels des quantitativen Computertomographen im Alter von 4, 6, 12, 18 und 24 Monaten. Ergänzt wurden diese Aufnahmen im Alter von 24 Monaten durch eine Messung mit dem volumetrischen Computertomographen. Mit Hilfe dieser beiden Geräte wurden die Daten zur Berechnung des Fettgewebes erstellt. (Nähere Details zu diesen beiden Computertomographen werden in „Material und Methoden“ der vorliegenden Arbeit beschrieben.) Des Weiteren wurden zahlreiche Daten zu Gewicht, Körperlänge und Hormonspiegel zu den einzelnen Untersuchungszeitpunkten erhoben.

In der vorliegenden Arbeit soll die Frage beantwortet werden, ob die pränatale Therapie mit Dexamethasondurch epigenetische Effekte Veränderungen bei der Fettverteilung und der Menge des Gesamtkörperfetts im Alter von 24 Monaten bewirkt und ob Unterschiede zwischen einer frühen und späten Verabreichung bestehen.

Außerdem wird die Gewichtsentwicklung betrachtet und der Frage nachgegangen, ob es Anzeichen einer Gewichtsveränderung in Abhängigkeit von der pränatalen Behandlung gibt.

Ferner soll festgestellt werden, ob es zu einer Veränderung der Plasmaspiegel von Leptin, Testosteron, Triglyceriden und Cholesterin kommt. 


\section{Material und Methoden}

\subsection{Tierexperimente}

\subsubsection{Grundlage der Tierexperimente}

Bei dem Projekt, in dessen Rahmendie Tierexperimente für die vorliegende Arbeit durchgeführt wurden, handelt es sich um ein internationales, aus EU-Mitteln gefördertes Projekt (EUPEAH QLRI-2002-02758), welches von Herrn Prof. Dr. E. Fuchs, DPZ, und Herrn Prof. Dr. Wuttke, Universitätsmedizin Göttingen, koordiniert wurde. Die Tierexperimente wurden von der Ethikkommission der Abteilung für Tierschutz des Landes Niedersachsen (LAVES Niedersachsen, Referenznummer 509.42502/08-8.03) gemäß dem Deutschen Gesetz zum Schutz und Wohl von Tieren genehmigt.

\subsubsection{Versuchstiere}

Für die Versuche wurden 30 männliche Affen der Primatenart CJ aus der Familie der Krallenaffen verwendet.

\subsubsection{Rahmenbedingungen und die an den Tierexperimenten beteiligten Personen}

Die Informationen zu Aufzucht, Haltung und Ernährung der Versuchstiere sowie zur Durchführung der Untersuchungen, die dieser Arbeit zu Grunde liegen, entstammen den Protokollen und Aufzeichnungen der Mitarbeiter, die die Tiere betreut und die Untersuchungen durchgeführt haben und wurden zur Erstellung dieses Kapitels freundlicherweise zur Verfügung gestellt. Das Projekt wurde von der Abteilung Klinische und Experimentelle Endokrinologie der Universitätsmedizin Göttingen (Leiter Herr Prof. Wolfgang Wuttke) unter der Leitung von Frau PD Dana Seidlová-Wuttke und Frau Dr. Christine Schlumbohm, Tierärztin am DPZ in Göttingen, die die medizinische Kontrolle der Versuchstiere hatte, durchgeführt. Herr Christian Dullin, Diplom-Physiker aus der Abteilung Diagnostische und Interventionelle Radiologie der Universitätsmedizin Göttingen, führte die computertomographischen Messungen am fpVCT und die Bildrekonstruktionen durch, die später 
von Frau Nina Koch an der Advantage Workstation 4.2 von GEH aus Buc, Frankreich bearbeitet und manuell ausgewertet wurden.

Die Durchführung der Versuchsreihe erfolgte mit insgesamt 30 männlichen Tieren. Die Affen wurden zwischen dem 20.04.2003 und dem 8.12.2004 im DPZ in Göttingen geboren und wuchsen unter der Obhut und medizinischen Kontrolle von Frau Dr. Christine Schlumbohm auf.

\subsubsection{Haltungsbedingungen}

Die männlichen Jungtiere wurden in einem fensterlosen, vollklimatisierten Stall jeweils in einem Maschendrahtkäfig von 50 x 76 x $125 \mathrm{~cm}$ innerem Maß mit ihren Familien zusammen gehalten. Die Tiere wurden von 6.00 Uhr bis 18.00 Uhr unter künstlichem Licht gehalten und danach 12 Stunden in der Dunkelheit belassen, um den Tagesrhythmus nachzuahmen.

Die Affen bekamen eine spezielle Nahrung der Firma ssniff ® Spezialdiäten GmbH, Soest, Deutschland, in Form von Sniff ® V3843 Mar Pellets. Dieses Futter setzt sich aus Getreide und Getreidenebenerzeugnissen, Ölsaatprodukten, Zucker, Milchprodukten, pflanzlichen Fetten und Ölen, Mineralstoffen, Trockenobst, Vitaminen und Spurenelementen zusammen. Diese Pellets und Leitungswasser standen den Tieren ad libitum zur Verfügung. Die genaue Nährstoffzusammensetzung der Pellets kann der Tabelle 2 des Tabellarischen Anhangs entnommen werden. Zusätzlich gab es für die Tiere jeden Morgen einen Brei, der in der Trockenmasse $21 \%$ Rohprotein, $14 \%$ Fett, $10 \%$ Ballaststoffe, $41 \%$ Stärke und Zucker, 0,95 \% Kalzium und 0,67 \% Phosphor beinhaltet und pro kg 5500 IE Vitamin D3 und 17,9 MJ umsetzbare Energie enthielt. Pro Tier wurden $30 \mathrm{~g}$ des Breis mit einem Trockensubstanzgehalt von $38 \%$ gefüttert. Am Nachmittag bekam jedes Tier zusätzlich $30 \mathrm{~g}$ sauberes, geschnittenes Obst oder Gemüse.

\subsubsection{Versuchsablauf}

An dem Versuch nahmen 30 männliche CJ teil, die in 3 Gruppen unterteilt wurden. Die Unterteilung der Affen in die 3 Versuchsgruppen verlief auf der Basis der Behandlung in der Schwangerschaft, wie folgt:

Die Kontrollgruppe (Kontrollgruppe oder Kontrolle) enthält die Kontrolltiere, deren Mütter ohne jegliche Behandlung unter Standardbedingungen des DPZs im Mutterleib heranwuchsen und dann spontan geboren wurden. 
Die 5-mg-Dexamethason-early-Gruppe (5-early-Gruppe) enthält die männlichen Affen, deren Mütter 7 Tage lang vom 42. bis zum 48. Tag der Schwangerschaft täglich $5 \mathrm{mg}$ Dexamethason erhielten. Dieses Medikament wurde in Tablettenform mit $200 \mu 1$ Wasser aufgeschwemmt und mit Nutri-Cal von Albrecht GmbH in Aulendorf (eine hochkalorische Vitamin und Mineralstoffpaste) vermischt und dann oral verabreicht. Diese Tiere kamen nach der mütterlichen Behandlung ohne Intervention spontan zum Geburtstermin auf die Welt.

Die 5-mg-Dexamethason-late-Gruppe (5-late-Gruppe) enthält die männlichen Affen, deren Mütter 7 Tage lang vom 90. bis zum 96. Tag der Schwangerschaft täglich $5 \mathrm{mg}$ Dexamethason erhielten. Die Verabreichung erfolgte auf dieselbe Art und Weise wie bei den Müttern der 5-early-Gruppe. Außerdem wurden auch diese Versuchstiere ohne äußere Beeinflussung spontan nach vollendeter Schwangerschaft geboren.

Die Gruppenzugehörigkeit der einzelnen Versuchstiere mit Namen und laufender Nummer werden in den Tabellen 3 und 4 im Anhang dargestellt.

Mit Hilfe dieser drei Versuchsgruppen sollte u.a. untersucht werden, wie sich das Fettgewebe bei den Tieren in den einzelnen Gruppen entwickelt und ob es signifikante Unterschiede zwischen den Tieren in Bezug auf Fettverteilung und Fettmasse in verschiedenen Körperregionen gibt. Bei allen Tieren der einzelnen Versuchsgruppen wurden im Alter von 4, 6, 12, 18 und 24 Monaten computertomographische Messungen mit dem quantitativen Computertomographen (qCT) durchgeführt und Blutproben entnommen. Jeweils am Tag vor den qCT Messungen wurden die Tiere nach ihrem Frühstück zwischen 9.00 Uhr und 12.00 Uhr gewogen und ihr jeweiliges Gewicht notiert. Außerdem erfolgte zu dem Zeitpunkt eine Blutentnahme. Die Blutproben von jeweils $1 \mathrm{ml}$ wurden von einer Oberschenkelvene mit einer $1 \mathrm{ml}$ Spritze $(1 \mathrm{ml}$ TBC, Dispomed®, Gelnhausen, Deutschland) und einer $0,45 \times 12 \mathrm{~mm}$ Kanüle entnommen und unverzüglich in eine Monovette (SMonovette® Serum Gel, Sarstedt, Nuembrecht, Deutschland) umgefüllt und dann zur Bestimmung bestimmter Parameter verwendet. Blutparameter, die für diese Arbeit im Labor der Abteilung Klinische und Experimentelle Endokrinologie der Universitätsmedizin Göttingen routinemäßig bestimmt wurden, sind Testosteron, Leptin, Cholesterin und Triglyceride. Testosteron und Leptin wurden mit KITs von Roche Eleasys und Cholesterin und Triglyceride wurden mit KITs von Hitachi bestimmt. Nach der Blutentnahme wurde die Vene für mindestens 5 Minuten komprimiert, um eine Hämatomentwicklung zu verhindern. 
Im Alter von 24 Monaten wurde die letzte qCT Untersuchung durchgeführt, und es wurden zusätzlich Messungen mit dem flat panel Volumencomputertomographen gemacht. Nach diesen Untersuchungen wurden den Affen per Herzpunktion Blutproben entnommen und anschließend wurden sie mit einer Ketaminspritze getötet. Bei der anschließenden Obduktion wurden diverse Organe entnommen und entsprechend ihrem jeweiligen Untersuchungszweck aufbewahrt.

\subsection{Computertomographische Messungen}

\subsubsection{Prinzip der computertomographischen Messungen}

Nachdem viele Jahre der Forschung auf dem Gebiet der Röntgendiagnostik vorausgegangen waren, fand die erste klinische Computertomographie im Jahre 1972 durch G.N. Hounsfield Anwendung (Lackner 1998). Ein wesentlicher Bestandteil des Computertomographen (CT) ist die Abtasteinheit, auch Gantry genannt, welche aus Hochspannungsgenerator, Röntgenröhre, Blendensystem, Kühlung und Detektorsystem besteht. Des Weiteren gehören zu einem CT ein Patientenlagerungstisch, ein Bedienpult und ein Computer. „Die Computertomographie zählt zu den Schnittbildverfahren“ (Hünerbein 2011, S.73). Mit Hilfe von transversalen Schichten lassen sich Gewebe und Organe überlagerungsfrei auf zweidimensionalen Querschnittsbildern darstellen und durch ihre Summe erhält man dreidimensionale Darstellungen. Diese Aufnahmen werden, je nach Gerätegeneration gibt es diesbezüglich kleine Unterschiede, wie folgt produziert: Die Röntgenröhre rotiert um das zu untersuchende Objekt und gibt einen schmalen und fächerförmigen Röntgenstrahl ab. Dessen Maße werden so eingestellt, dass er sowohl der Dicke der zu untersuchenden Körperschicht entspricht, als auch den gesamten Patientenquerschnitt erfasst. Diese Röntgenstrahlen treffen nach dem Durchtritt durch das Untersuchungsobjekt auf der gegenüberliegenden Seite auf einen Detektor, welcher die verschiedenen Schwächungen der Röntgenstrahlen beim Durchtritt durch den Patienten in jeder Winkelstellung der Röntgenröhre misst. Diese Informationen werden in elektrische Signale umgewandelt, digitalisiert und zur Bildrekonstruktion benutzt. Wie stark die Absorption und somit die Schwächung der einzelnen Röntgenstrahlen ist, wird von der Strahlungsenergie der Röntgenstrahlen und von dem Gewebe, das sie durchstrahlen, bestimmt (Hühnerbein 2011). Beschrieben wird diese Abschwächung der Röntgenstrahlung im Gewebe mit Hilfe der Hounsfield-Skala. Als Referenzwert dient Wasser mit einem Wert von 0 Hounsfield-Einheiten (HE). 
Strukturen, die eine höhere Dichte und damit auch eine höhere Röntgenabsorption und somit eine stärkere Schwächung der Strahlung als Wasser haben, stellen positive Skalenwerte dar. Gewebe, die eine niedrigere Dichte und damit auch eine kleinere Röntgenabsorption und dadurch eine geringere Schwächung der Röntgenstrahlung als Wasser haben, besitzen negative HE (Lackner 1998). Luft beispielsweise hat einen Wert von -1000 HE und Kompakta von > 1000 HE (Hünerbein 2011). „Für die bildliche Wiedergabe der Dichteverteilung der Objektstrukturen werden die in jedem Pixel der Bildmatrix gemessenen Hounsfield-Werte grauwertskaliert" (Lackner 1998, S.20). Dabei ist der Grauton umso dunkler, je niedriger die Dichte ist und andersherum.

\subsubsection{Computertomographische Messungen im Versuch}

\subsubsection{Untersuchung mit dem quantitativen Computertomographen (qCT)}

Für die Untersuchungen wurde der quantitative Computertomograph XCT 2000, Typ 803100 (Stratec Inc. Pforzheim, Deutschland) benutzt. Die folgenden Angaben folgen im Wesentlichen den Angaben des Herstellers und sind teilweise auch als Zitat aus der Bedienungsanleitung, dem Handbuch XCT 2000 von Stratec Medizintechnik GmbH [1998], entnommen. Dieser CT ist ein vollautomatisches Gerät, mit dem überwiegend die Knochendichte und die Knochengeometrie gemessen werden. Er besitzt eine Röntgenröhre mit sehr kleinem Fokus. Die Röntgenröhre rotiert um das zu untersuchende Objekt, welches in Längsrichtung auf dem Untersuchungstisch im CT-Gerät liegt. Die Röntgenstrahlung trifft nach Durchtritt durch das Gewebe auf die gegenüberliegenden Detektoreinheiten, welche Miniatur-Halbleiterkristalle besitzen. Insgesamt gibt es 12 Detektoreinheiten im Detektorgehäuse (Stratec Medizintechnik [1998]). „Die interne Steuerung der drei Bewegungsachsen sowie die parallele Verarbeitung der Zählwerte regelt ein Mikrokontroller. Dieser leitet die Messergebnisse bzw. die Achsenpositionen über eine Standard V24 Schnittstelle zu einem schnellen PC. Dieser übernimmt die Berechnung der Bildmatrix sowie die Auswertung der Messdaten“ (Stratec Medizintechnik [1998], S.8). Für diese Arbeit wurde zur Vorbereitung für die genaue Positionierung des Scanners ein Übersichtsscan in Form eines Längsschnittes des zu untersuchenden Tieres angefertigt. Dadurch entstand ein „farblich codiertes digitalisiertes Rasterbild, ähnlich einem Röntgenbild, mit hellen, knochendichten Anteilen und dunklen Weichteilanteilen“ (Stratec Medizintechnik [1998], S. 15). Anschließend wurde die Referenzlinie des Scanners je nach Länge des Tieres in der Mitte des 
Lendenwirbelkörpers 4 oder 5 positioniert und es wurden jeweils drei computertomographische Schnittebenen aufgenommen. Die erste in der Referenzlinie und die anderen beiden jeweils einen Millimeter proximal und kaudal hiervon. Zur Berechnung eines jeden CT-Bildes stehen 180 Winkelschnitte zur Verfügung. Mit Hilfe des Computerprogramms XCT 5.40 (Stratec Inc., Pforzheim) wurden die Bilder erfasst, verarbeitet und die Daten dieser Arbeit ausgewertet. Diese Untersuchungen wurden zwischen 2003 und 2006 von Frau PD Dr. med. Dana Seidlová-Wuttke durchgeführt.

\subsubsection{Untersuchung mit dem flat panel Volumencomputertomo- graphen (fpVCT)}

Der „flat panel Volumencomputertomograph“ (fpVCT) wurde von General Electric Global Research in Niskayuna, New York entwickelt (Greschus et al. 2005). Dieser Prototyp besteht aus einer Gantry mit amorphen Silizium Flachdetektoren. Diese Detektoren haben jeweils eine Größe von 20,5 x 20,5 cm, bestehend aus einer Matrix von 1024 x 1024 quadratischen Detektorelementen mit einer Kantenlänge von $200 \mu \mathrm{m}$ (Missbach-Guenter et al. 2007). Das zu untersuchende Objekt wird auf den Patiententisch gelegt und während der Untersuchung von Röntgenröhre und Detektoren umrundet. Für die Z-Abdeckung von 4,2 $\mathrm{cm}$ pro Untersuchungsschritt wird eine Rotationszeit von 8 Sekunden benötigt. Die Röntgenröhre kann von $70 \mathrm{kV}$ bis $140 \mathrm{kV}$ betrieben werden (Greschus et al. 2005). Das System des fpVCT ermöglicht die Erfassung von dreidimensionalen Volumendatensätzen mit hoher Auflösung, entsprechend etwa $150 \mu \mathrm{m}$ für Strukturen mit hohem Kontrast bei kurzen Aufnahmezeiten. Alle Datensätze in diesem Versuch wurden mit dem gleichen Protokoll erworben: 1000 Bilder pro Rotation, 8 Sekunden Rotationszeit, 360 gebrauchte Detektorreihen, $120 \mathrm{kVp}$ und $40 \mathrm{~mA}$. Mittels filtered backprojections (FBP) algorithm wurden die erhaltenen Aufnahmen dann auf einem Computer zu hochauflösenden Volumendatensätzen rekonstruiert und schließlich auf der Advantage Workstation 4.2 von General Electric Healthcare (GEH) aus Buc Frankreich ausgewertet (Missbach-Guenter et al. 2007).

\subsubsection{Narkose bei den computertomographischen Messungen}

Bei den computertomographischen Messungen mussten die Versuchstiere im jeweiligen Computertomographen bewegungslos in Längsrichtung auf dem Untersuchungstisch positioniert werden. Hierzu haben die Affen nach einer nahrungskarenten Nacht eine Narkose durch eine intramuskuläre Injektion von $6,75 \mathrm{mg} / \mathrm{kg}$ Körpergewicht Alphaxalon und 
2,25 mg/kg Körpergewicht Alphadolon (Saffan®; Schering- Plough Animal Health, Welwyn Garden City, England), 0,02 mg/kg Körpergewicht Glycopyrroniumbromid (Robinul®; Riemser, Greifswald, Deutschland) und 0,25 mg/kg Körpergewicht Diazepam (Ratiopharm, Ulm, Deutschland) bekommen.

\subsubsection{Auswertungsprinzip der fpVCT-Daten und die Messbereiche am Körper der Versuchstiere}

Die fpVCT-Bilder wurden von Herrn Christian Dullin, Diplomphysiker aus der Abteilung Diagnostische und Interventionelle Radiologie der Universitätsmedizin Göttingen, so rekonstruiert, dass sie auf der Advantage Workstation 4.2 von GEH aus Buc, Frankreich manuell ausgewertet werden konnten.

Anhand der fpVCT-Bilder wurden Körperbereiche der Affen definiert, in denen der Fettgehalt berechnet und dann zwischen den Tieren verglichen werden sollte. Im folgenden Text werden die einzelnen Messabschnitte am Körper der Affen beschrieben und bildlich dargestellt. Zur Veranschaulichung der verschiedenen Einstellungsmöglichkeiten der fpVCT-Bilder auf der Advantage Workstation 4.2 von GEH ist in Abbildung 2.1 und 2.2 der Oberkörper eines zweijährigen Callithrix jacchus in der fpVCT-Aufnahme in Weichgewebseinstellung und in einer Einstellung, die die Einzelheiten des Knochenaufbaus zeigt, dargestellt. 


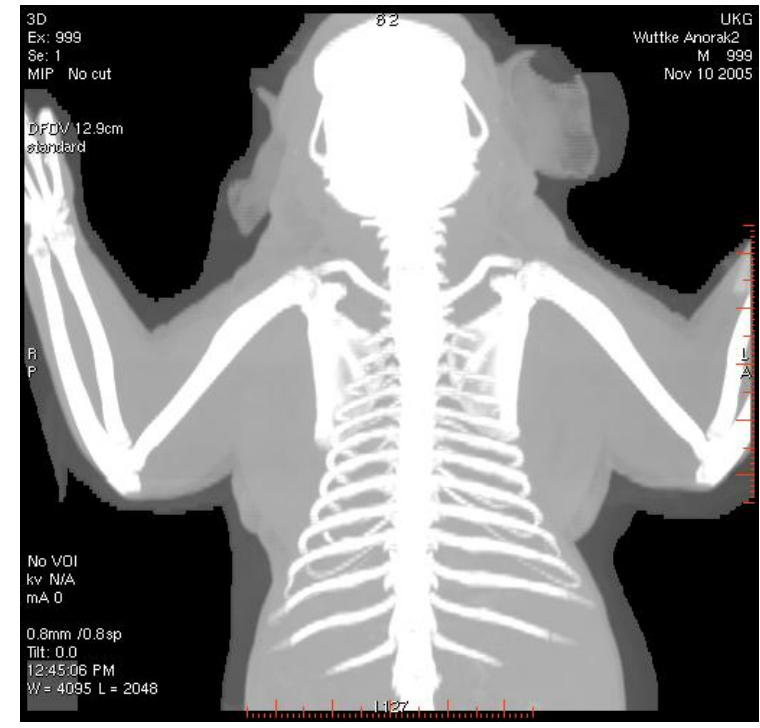

Abbildung 2.1: Oberkörperdarstellung eines $\mathrm{CJ}$ in der Weichgewebseinstellung auf dem Bildschirm der Advantage Workstation 4.2 von GEH

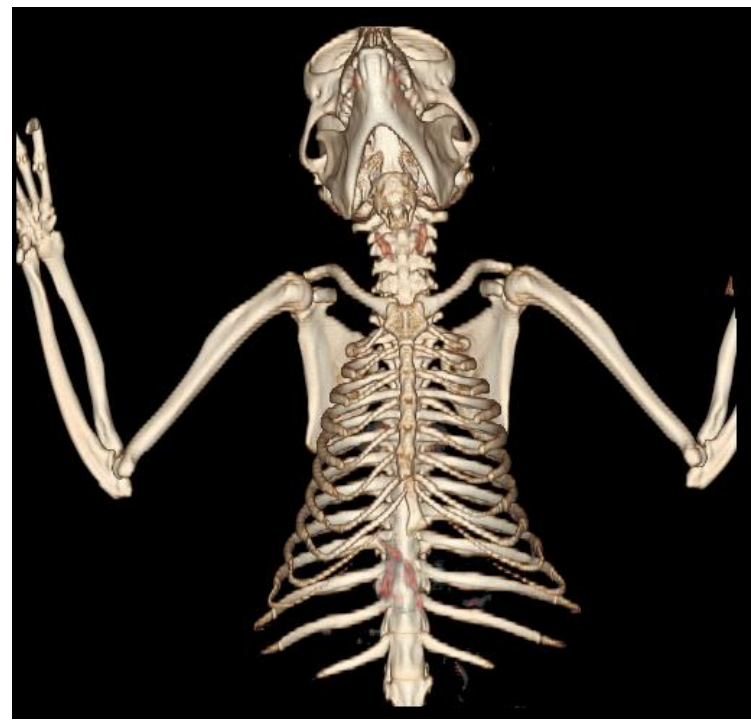

Abbildung 2.2: Darstellung des gleichen Oberkörpers wie in Abbildung 2.1 abzüglich des Weichgewebes auf dem Bildschirm der Advantage Workstation 4.2 von GEH

Es folgt die Definition der Messabschnitte am Körper der Tiere von kranial nach kaudal. Begonnen beim Thorax, über den Lendenbereich, das Gesäß und die Oberschenkel, bis hin zu den Unterschenkeln.

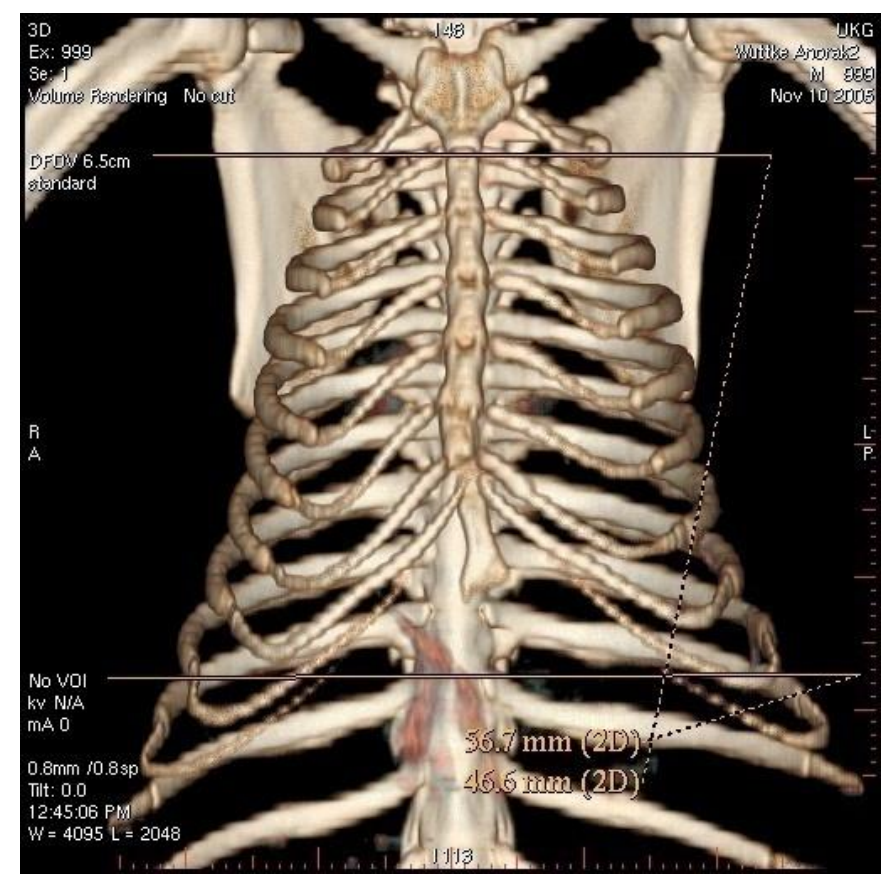

Abbildung 2.3: Darstellung der Messung des Brustwirbelbereichs eines CJ auf dem Bildschirm der Advantage Workstation 4.2 von GEH ohne Weichgewebe
Der Brustwirbelbereich wurde definiert als Oberkante der 2. Rippe bis an den Unterrand des 10. Brustwirbelkörpers. Arme, die in diesem Bereich mit angeschnitten waren, wurden mitgemessen. Die Abbildung 2.3 zeigt die Messung des Brustwirbelbereichs in einer Darstellung ohne Weichgewebe. 


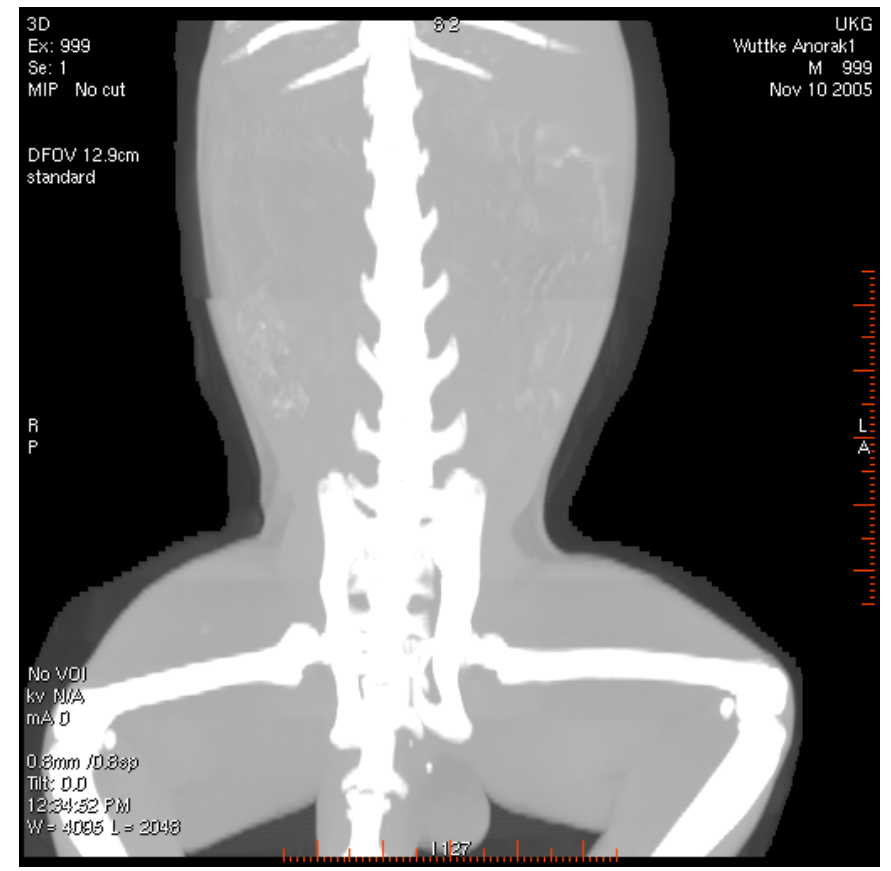

Abbildung 2.4: Darstellung eines CJ in der Weichgewebseinstellung vom unteren Rippenrand bis zur Tibia auf dem Bildschirm der Advantage Workstation 4.2 von GEH
Der gesamte Lendenwirbelbereich wurde definiert als Oberkante des 1. Lendenwirbelkörpers bis zur Unterkante des 6. Lendenwirbelkörpers. Die Oberschenkel sind im Verlauf des Rumpfes abgeschnitten worden. Die Abbildung 2.4 ist ein Beispiel für ein Bild eines CJ vom unteren Rippenrand bis zur Tibia in der Weichgewebseinstellung. Dargestellt ist in dieser Abbildung das Tier vom unteren Rippenrand bis zur Tibia. Um den Lendenwirbelbereich $\mathrm{zu}$ messen, wurden nach der zuvor beschriebenen Definition die Messlinien, ähnlich wie in Abbildung 2.3, in das entsprechende Bild gelegt und so der Messbereich bestimmt und das restliche Gewebe entfernt.

Zusätzlich zur Messung des gesamten Lendenwirbelbereichs wurde eine zweite Messung in diesem Bereich durchgeführt. Dieser Messbereich wurde von der Oberkante des 4. Lendenwirbelkörpers bis zur Unterkante des 5. Lendenwirbelkörpers definiert und L4-L5 genannt.

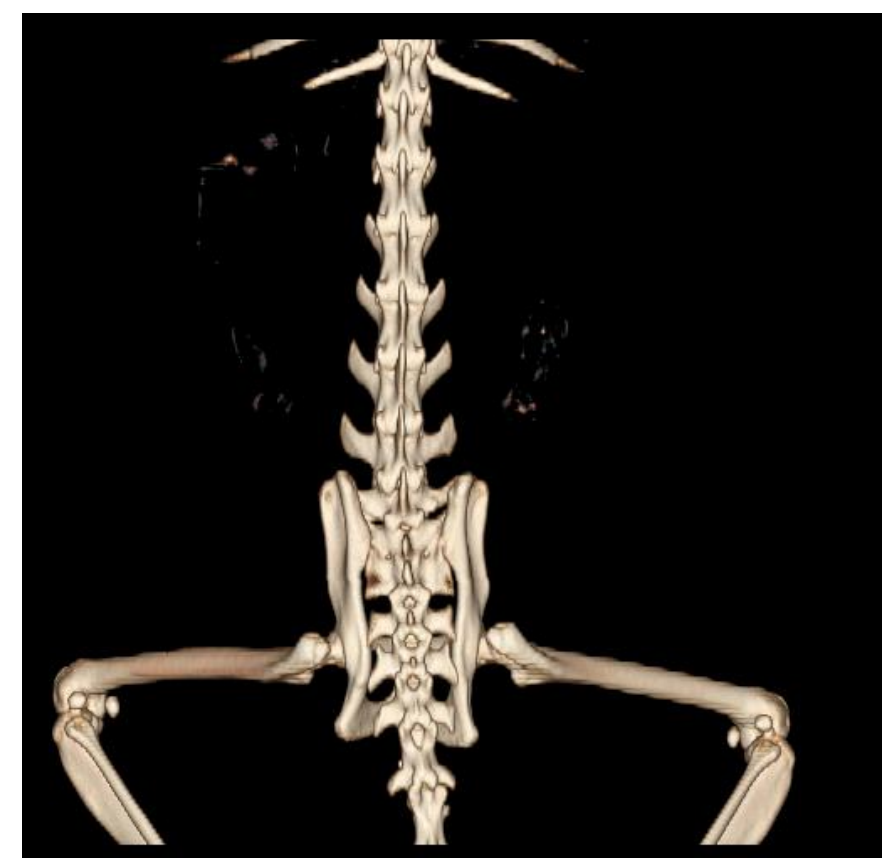

Der Oberschenkelbereich beider

Beine wurde definiert als Oberkante der Darmbeinschaufeln bis $20 \mathrm{~mm}$ unterhalb beider Knie und dann senkrecht zur Tibia. Die Oberschenkel wurden zusammen gemessen. Die Abbildung 2.5 stellt die knöcherne Anatomie eines CJ vom unteren Rippenrand bis zur Tibia dar. Zur Messung des Oberschenkelbereichs werden die entsprechenden Messlinien angelegt und der Bereich gemessen.

Abbildung 2.5: Darstellung eines CJ ohne Weichgewebe vom unteren Rippenrand bis zur Tibia auf dem Bildschirm der Advantage Workstation 4.2 von GEH 


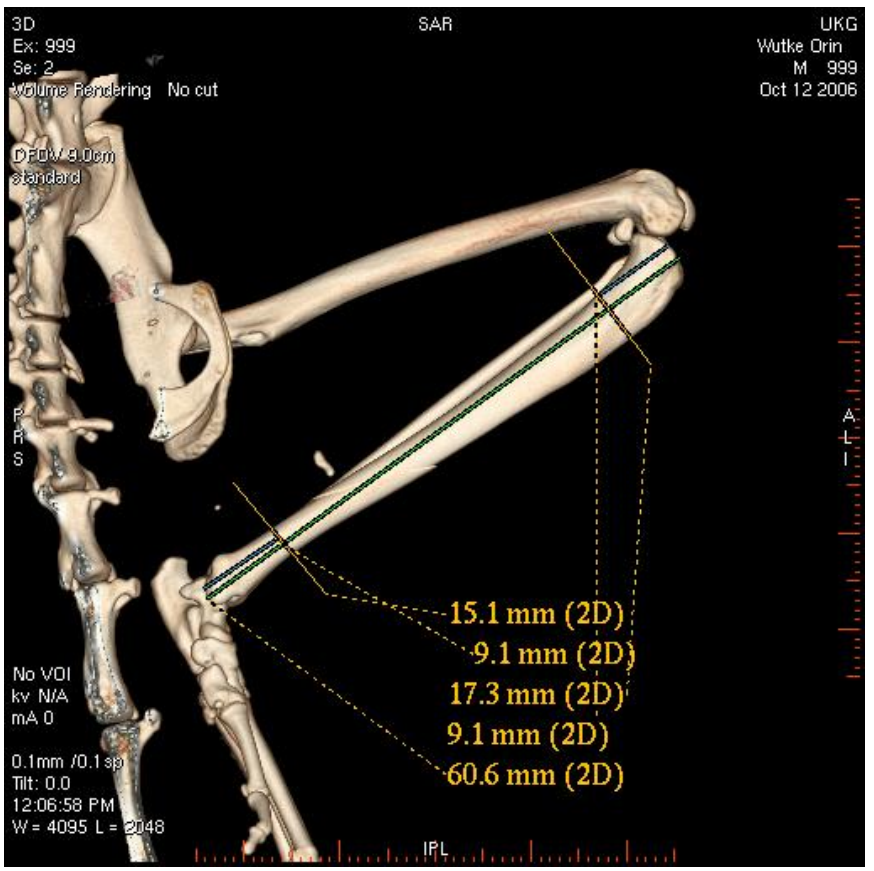

Abbildung 2.6: Darstellung der Messung des linken Beines eines CJ ohne Weichgewebe auf dem Bildschirm der Advantage Workstation 4.2 von GEH

\section{Der Unterschenkelbereich beider}

Beine wurde initial in ein rechtes und linkes Bein unterteilt. Es wurde die Länge der jeweiligen Tibia gemessen und dann von dieser Länge an den Enden je $15 \%$ abgezogen und senkrecht zur Tibia entfernt. Diese definierten Bereiche wurden dann getrennt für jedes Bein ausgewertet und anschließend für den gesamten Unterschenkelbereich zusammengerechnet. Die Abbildung 2.6 stellt die Messung an einem linken Bein eines $\mathrm{CJ}$ dar. Zusätzlich zur Definition der Messbereiche wurden die Dichtewerte für das Fettgewebe (siehe Kapitel 2.2.2.5) festgelegt.

\subsubsection{Durchführung der Auswertung}

Die Auswertung wurde in den folgenden 7 Schritten durchgeführt:

1. Zuerst wurde das jeweilige Tier mit dem WIP (Work in progress) Volume Viewer 1- Screen auf der Advantage Workstation 4.2 von GEH aus Buc, Frankreich aufgerufen.

2. Dann wurden die definierten Körperabschnitte, die im vorangegangenen Teil beschrieben wurden, ausgeschnitten und danach der untere Schwellenwert auf -600 HE festgelegt, um durch diesen Schritt die Luft um das Element auszublenden. Hierdurch entstand ein segmentierter Datensatz ohne Luft.

3. Anschließend wurden am Rand des Objekts noch 2 Voxels per Erosion abgezogen, weil diese Voxels, die sich aus Luft und Haut zusammensetzen, Mischwerte bilden, die ähnliche Dichtewerte wie Fett haben. Durch diesen Schritt wurden somit Mischwerte entfernt, die die Analyse verfälschen würden. 
4. Dann wurde der obere Schwellenwert auf 233 HE festgelegt, um den Knochen zu eliminieren. Hierdurch entstand ein segmentierter Datensatz von Weichgewebe und Fett ohne Knochen.

5. Im Anschluss errechnete das Programm das Volumen, angegeben in $\mathrm{mm}^{3}$, des gesamten Weichgewebes inklusive Fettgewebe ohne Knochen.

6. Schließlich wurde der obere Schwellenwert auf -112 HE festgelegt und damit das restliche Weichgewebe eliminiert. Durch diesen Schritt ergab sich das absolute Volumen des Fettgewebes in $\mathrm{mm}^{3}$.

7. Zum Schluss wurde der prozentuelle Fettanteil am gesamten Weichgewebe in dem entsprechenden Körperbereich errechnet, indem das Volumen des Fettgewebes durch das Volumen des Weichgewebes dividiert und mit 100 multipliziert wurde. Der Dichtebereich für Fett ist bei unseren Berechnungen folglich von $-600 \mathrm{HE}$ bis $-112 \mathrm{HE}$ und der gesamte Weichgewebsbereich von -600 HE bis 233 HE definiert.

Beim Vergleich der in diesem Versuch gewählten Schwellenwerte für Knochen, Weichgewebe und Fettgewebe mit den Dichtebereichen der Hounsfieldskala in Lehrbüchern fällt auf, dass diese Werte etwas voneinander abweichen. Diese Tatsache lässt sich dadurch erklären, dass sich die Dichtewerte von Fett und Weichgewebe mischen und wenn der Schwellenwert zu hoch gewählt wird, zu viel Weichgewebe eliminiert wird. Wenn hingegen die Schwelle zu niedrig liegt, wird zu viel Fettgewebe weggenommen. Aus diesem Grund wurden nach zahlreichen praktischen Versuchen an der Workstation die oben beschriebenen Dichtebereiche benutzt. Die so erhaltenen Daten wurden in Exceltabellen dokumentiert. Entscheidend für die Auswertung ist, dass diese Parameter bei jedem Tier gleich gewählt wurden, damit die Tiere untereinander verglichen werden konnten. Die Auswertung und graphische Darstellung dieser Daten folgt in den folgenden Kapiteln.

\subsection{Statistische Methoden}

Zur Berechnung und Auswertung der Statistik wurde das Computerprogramm Graph Pad Prism 5 @ benutzt. Mit diesem Programm wurden auch die Abbildungen der Säulendiagramme erstellt. Jede Säule repräsentiert den Mittelwert der dargestellten Untersuchungswerte. Des Weiteren sind in diesen Säulendiagrammen die Standardfehler des Mittelwerts (SEM) als Antennen am oberen Ende der Säulen gekennzeichnet. Mit Hilfe des unpaarigen 
t-Tests wurde die statistische Analyse durchgeführt und das Signifikanzniveau auf $\mathrm{p}<0,05$ festgelegt. Wenn signifikante Unterschiede festgestellt werden konnten, wurde dies mit einem Sternchen $(*)$ gekennzeichnet.

Um einen repräsentativen Mittelwert des Gesamtfettanteils zu ermitteln, wurde in der vorliegenden Arbeit jeder Mittelwert der Kontrolle der jeweiligen fpVCT-Schnittebene gleich $100 \%$ gesetzt. Somit war eine Prozentrelativierung jedes Einzelwertes sowohl der Kontrolle als auch der behandelten Tiere möglich und damit vergleichbar. Die daraus entstandenen Werte der einzelnen Messabschnitte des Körpers wurden anschließend in den einzelnen Versuchsgruppen zusammengefasst und daraus der Mittelwert des Gesamtfettanteils in den Gruppen ermittelt und mit Hilfe der oben beschriebenen statistischen Methode ausgewertet. 


\section{Ergebnisse}

\subsection{Entwicklung von Gewicht, BMI und Körperlänge der CJ bis zum Alter von 24 Monaten}

Die im folgenden Abschnitt dargestellten Ergebnisse über Körpergewicht und Körperlänge entstammen dem Datenpool der Abteilung Klinische und Experimentelle Endokrinologie der Universitätsmedizin Göttingen (Leiter Herr Prof. Dr. med. Wolfgang Wuttke) unter der Leitung von Frau PD Dr. med. Dana Deidlová-Wuttke und Frau Dr. Christine Schlumbohm und wurden im Rahmen der EUPEAH-Versuchsreihe im DPZ an den CJ erhoben. Diese Daten wurden für die Erstellung der vorliegenden Promotion zur Verfügung gestellt.

Es folgt die Darstellung der Gewichtsentwicklung der Versuchstiere der Kontrollgruppe, der 5-early-Gruppe und der 5-late-Gruppe. Im Alter von 4, 6, 12, 18 und 24 Monaten wurden die Tiere gewogen und mit 18 und 24 Monaten zusätzlich gemessen, sodass die Gewichtsentwicklung im Verlauf der ersten 24 Monate verfolgt und unter den Gruppen verglichen werden kann. Diese Gewichtsentwicklung verdeutlicht die Abbildung 3.1. Zusätzlich wurde der BMI für das Alter von 18 und 24 Monaten aus den vorhandenen Daten zu Körpergewicht und Körperlänge ermittelt und dargestellt (siehe Abbildung 3.2).

Der BMI lässt sich mit folgender Formel errechnen: Körpergewicht in Kilogramm dividiert durch die Größe, gemessen in Metern zum Quadrat $\left(\mathrm{kgKG} / \mathrm{m}^{2}\right)$.

In der Abbildung 3.1 ist zu sehen, dass es in der Kontrollgruppe bis zum Alter von 18 Monaten zu einer annähernd linearen Zunahme des Gewichts kommt, danach nimmt diese Gruppe bis zum Alter von 24 Monaten nur noch gering zu. Ähnlich linear verhält sich die Gewichtszunahme in der 5-early-Gruppe, nur dass hier sowohl das Ausgangsgewicht, die Gewichtszunahme über die Zeit und das Gewicht mit 24 Monaten geringer sind. Auch die 5-late-Gruppe zeigt eine weitgehend lineare Gewichtszunahme innerhalb der ersten 18 Lebensmonate und startet mit dem höchsten Ausgangsgewicht im Alter von 4 Monaten. Zwischen dem 18. und 24. Monat kommt es schließlich zu einer Gewichtsabnahme dieser Versuchstiere. Daraus ergibt sich, dass im Alter von 24 Monaten die Kontrollgruppe mit einem Mittelwert von $430 \mathrm{~g}$ das höchste Gewicht hat. Die 5-early-Gruppe und die 5-lateGruppe folgen mit $404 \mathrm{~g}$ und $408 \mathrm{~g}$ und haben zu diesem Zeitpunkt ein annähernd gleiches 
Gewicht. Signifikante Unterschiede bestehen zwischen der Kontrollgruppe und den anderen beiden Versuchsgruppen, in Bezug auf das Körpergewicht innerhalb des Untersuchungszeitraums von 24 Monaten, zu keinem Zeitpunkt.

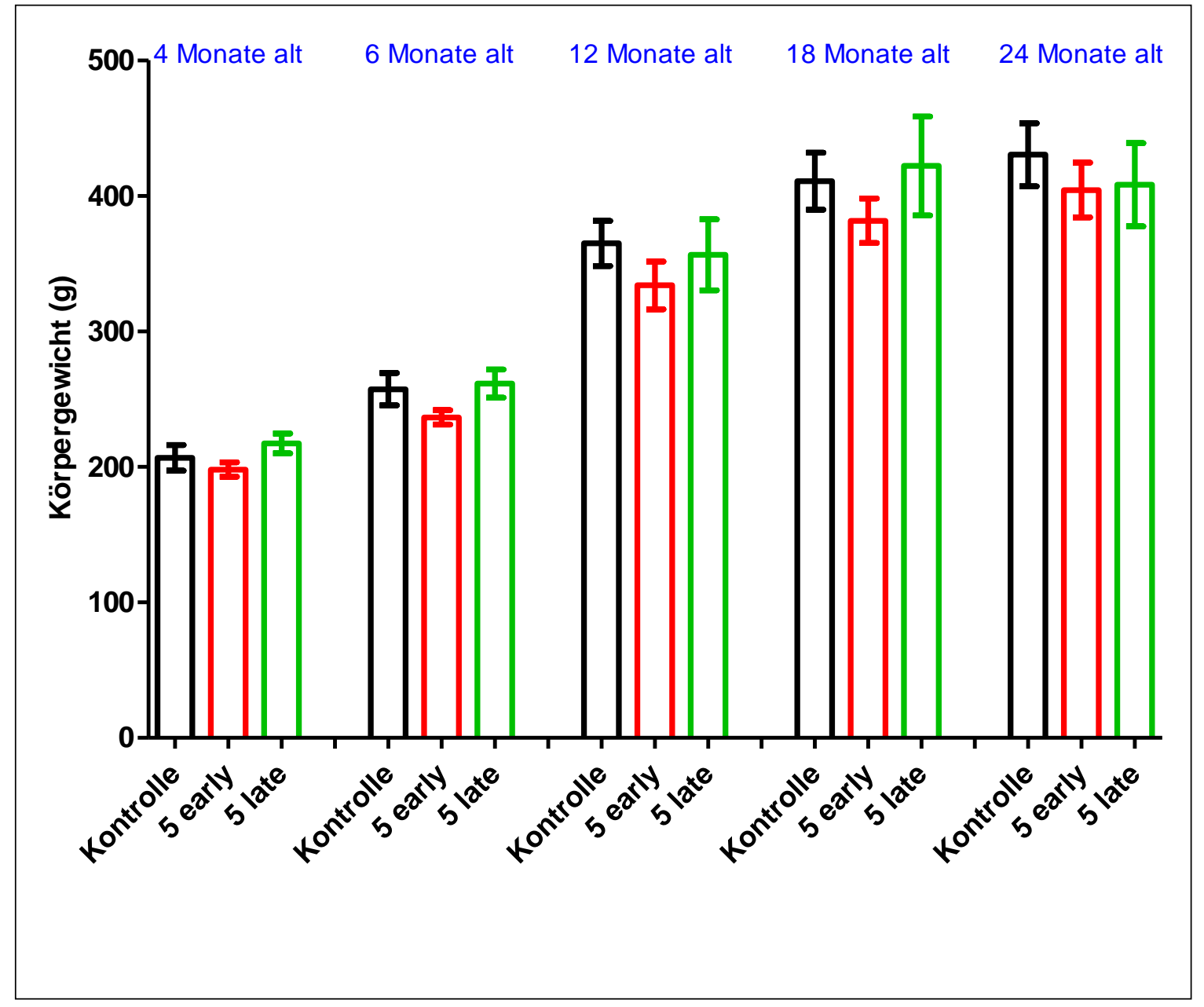

Abbildung 3.1: Die Abbildung zeigt die Gewichtsentwicklung der männlichen CJ der 5-early-Gruppe (roter Balken) und der 5-late-Gruppe (grüner Balken) verglichen mit der Kontrollgruppe (schwarzer Balken) innerhalb von 24 Monaten. 
In der Abbildung 3.2 ist der BMI im Alter von 18 und 24 Monaten dargestellt. Die 5-lateGruppe hat mit 18 Monaten mit einem Mittelwert von $4,38 \mathrm{~kg} / \mathrm{m}^{2}$ den höchsten BMI, dicht darauf folgt die Kontrollgruppe mit einem BMI von $4,27 \mathrm{~kg} / \mathrm{m}^{2}$ und den geringsten BMI im Vergleich hat die 5-early-Gruppe mit einem Mittelwert von 3,93 kg/m². In den kommenden 6 Monaten kommt es zu einer Zunahme der BMI-Werte in der Kontrollgruppe und der 5-early-Gruppe. Der BMI der 5-late-Gruppe hat sich in diesem Zeitraum leicht reduziert. Darum besitzt die Kontrollgruppe im Alter von 24 Monaten mit einem Mittelwert von $4,40 \mathrm{~kg} / \mathrm{m}^{2}$ den höchsten BMI. Dicht darauf folgen die 5-early-Gruppe und die 5-lateGruppe mit annähernd gleichen Werten von $4,18 \mathrm{~kg} / \mathrm{m}^{2}$ und $4,16 \mathrm{~kg} / \mathrm{m}^{2}$. Insgesamt weisen diese Werte keine signifikanten Unterschiede auf.

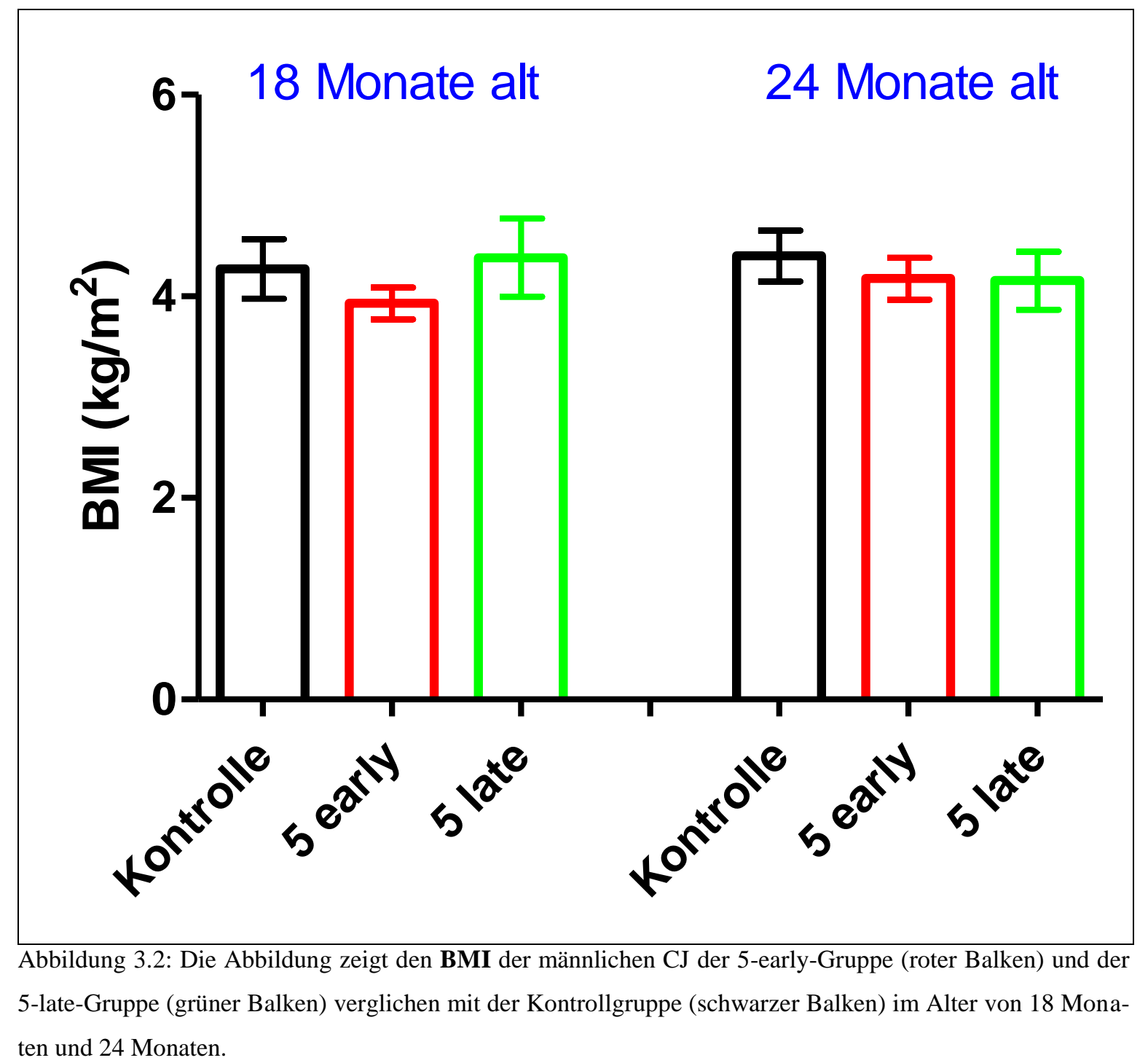


Die Abbildung 3.3 zeigt die als Scheitel-Fersenlänge (SF) definierte Körperlänge der drei Versuchsgruppen im Alter von 18 und 24 Monaten. Im Alter von 18 Monaten hat die Kontrollgruppe im Mittel eine Größe von 31,25 cm und die 5-early-Gruppe sowie die 5-lateGruppe sind mit einem Mittelwert von $31 \mathrm{~cm}$ gleich groß. In den kommenden 6 Monaten kommt es zu keinem Wachstum mehr. Im Alter von 24 Monaten hat die Kontrollgruppe einen Mittelwert von 31,3 cm, die 5-late-Gruppe folgt mit 31,25 cm und die 5-earlyGruppe mit 31,12 cm. Somit bestehen kaum Größenunterschiede zwischen den Gruppen und die Tiere scheinen mit 18 Monaten ausgewachsen zu sein.

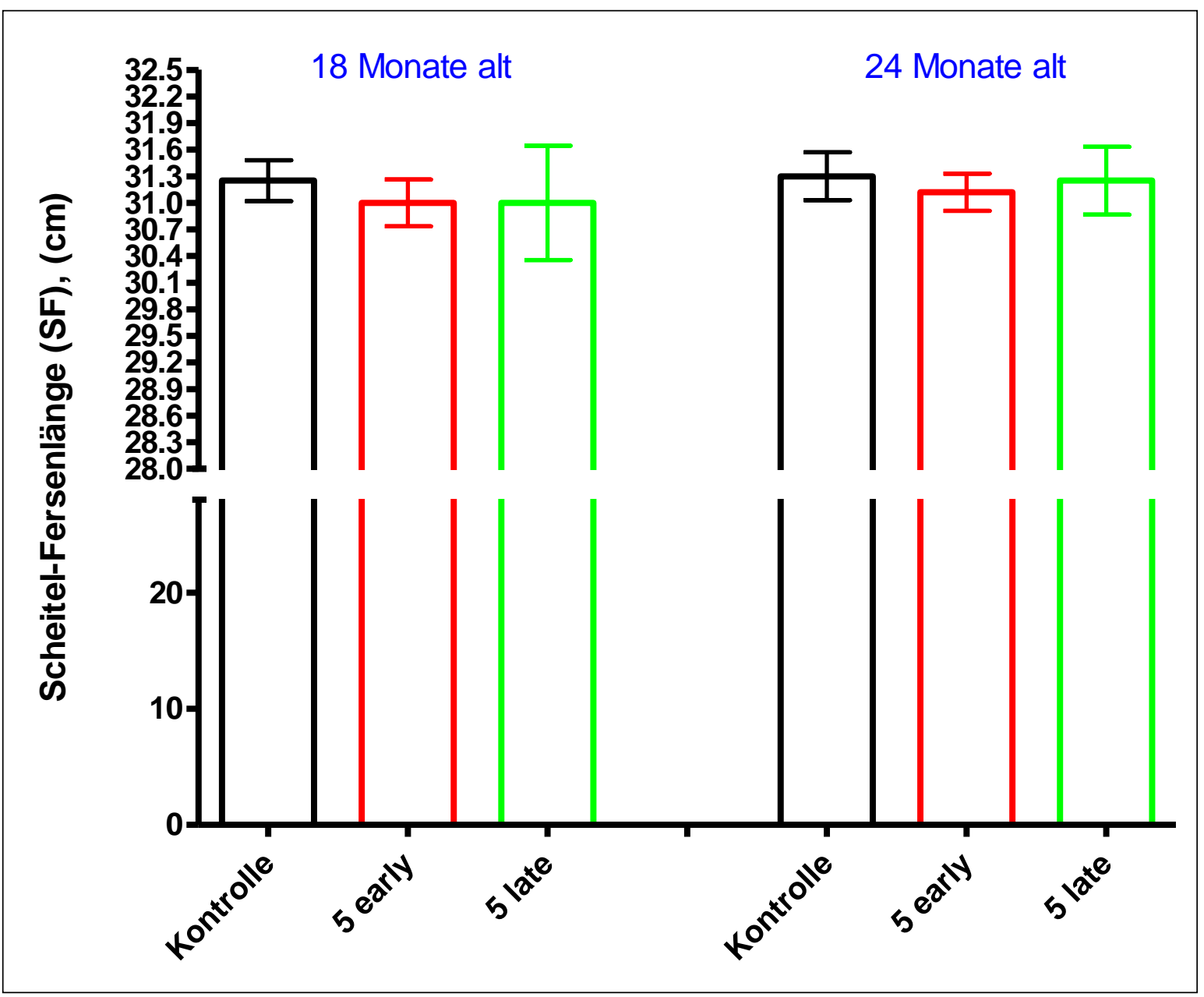

Abbildung 3.3: Die Abbildung zeigt die Scheitel-Fersenlänge der männlichen CJ der 5-early-Gruppe (roter Balken) und der 5-late-Gruppe (grüner Balken) verglichen mit der Kontrollgruppe (schwarzer Balken) im Alter von 18 und 24 Monaten. 
Die Abbildung 3.4 stellt die Scheitel-Steißlänge (SS) der drei Versuchsgruppen im Alter von 18 und 24 Monaten dar. Ähnlich wie bei der SF kommt es auch in diesem Bereich des Körpers zwischen dem 18. und 24. Lebensmonat zu keinem Wachstum mehr. Allerdings besteht sowohl mit 18 Monaten, als auch mit 24 Monaten ein signifikanter Unterschied der SS zwischen der Kontrollgruppe und der 5-late-Gruppe. Zu beiden Zeitpunkten ist die Länge vom Scheitel zum Steiß in der 5-late-Gruppe mit $20 \mathrm{~cm}$ sowie 20,15 cm signifikant kürzer als in der Kontrollgruppe mit 21,07 cm bzw. $21 \mathrm{~cm}$. Die 5-early-Gruppe befindet sich zu beiden Zeitpunkten mit ihrer SS von 20,45 cm bzw. 20,5 cm zwischen den anderen beiden Versuchsgruppen, ohne einen signifikanten Unterschied zu erreichen.

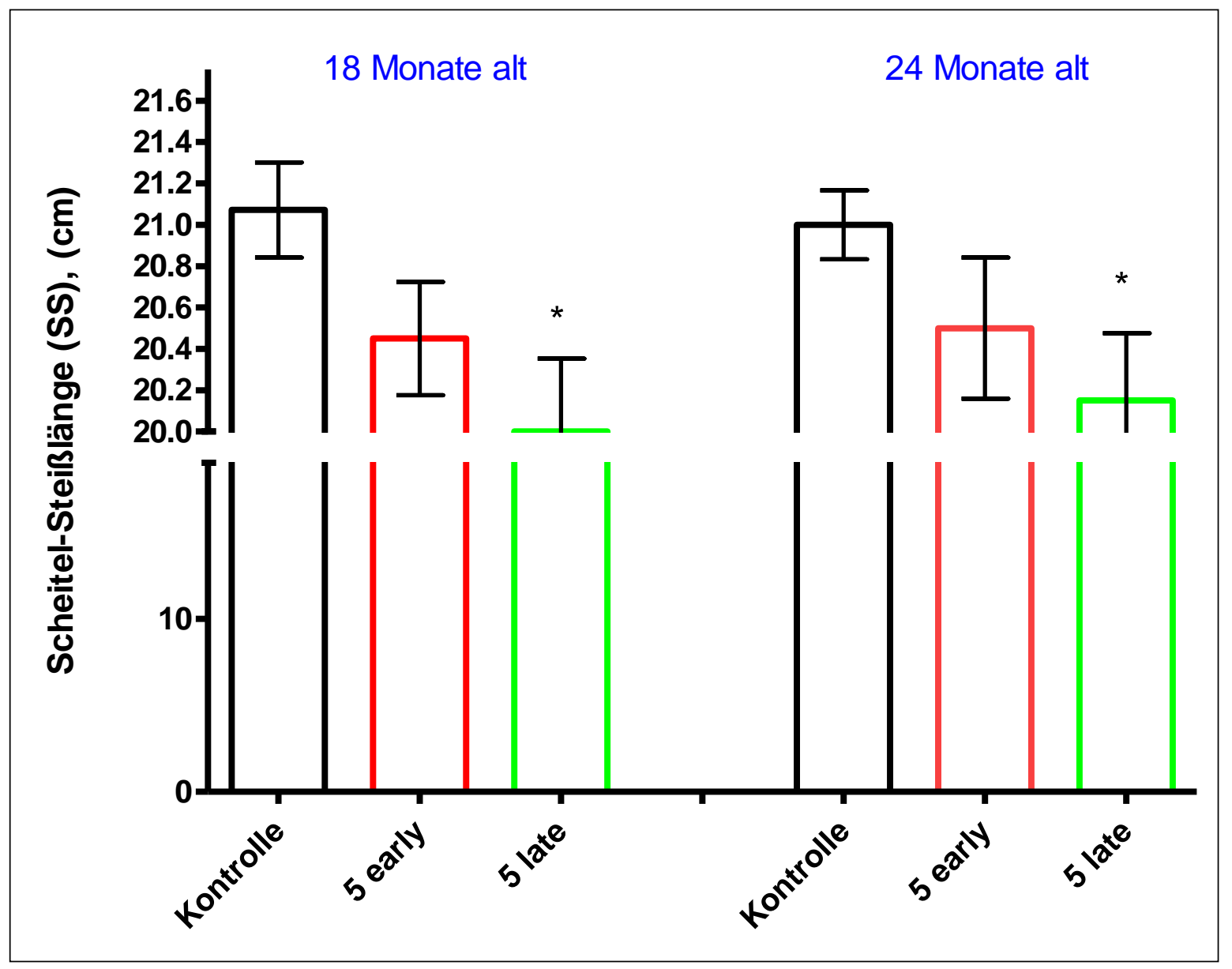

Abbildung 3.4: Die Abbildung zeigt die Scheitel-Steißlänge der männlichen CJ der 5-early-Gruppe (roter Balken) und der 5-late-Gruppe (grüner Balken) verglichen mit der Kontrollgruppe (schwarzer Balken) im Alter von 18 und 24 Monaten. Es besteht ein signifikanter Scheitel-Steißlänge Unterschied (p < 0,05) zwischen der 5-late-Gruppe und der Kontrollgruppe sowohl im Alter von 18 Monaten als auch im Alter von 24 Monaten. 


\subsection{Fettanteil im Bereich L4-L5 mittels qCT über 24 Monate gemessen.}

Grundlage von weiteren Untersuchungen der vorliegenden Arbeit mittels fpVCT sind die mit dem qCT erstellten Daten über die Wirkung von pränatalen Dexamethasongaben auf die Entwicklung des viszeralen Fettgewebes, entsprechend dem Bereich L4-L5 bei männlichen CJ-Nachkommen. Diese Daten wurden von der Projektleiterin Frau PD Dr. med. Dana Seidlová-Wuttke aus der Abteilung Klinische und Experimentelle Endokrinologie der Universitätsmedizin Göttingen (Leiter Herr Prof. Dr. med. Wolfgang Wuttke) erstellt und für die Basis der vorliegenden Promotion bereitgestellt.

Die Abbildung 3.5 zeigt die Entwicklung des Fettanteils im Bereich L4-L5 in den drei Versuchsgruppen der CJ über 24 Monate als Maß für den Anteil des viszeralen Fettgewebes am Weichgewebe dieses Bereichs. Die Kontrolltiere zeigen eine kontinuierliche Zunahme des Fettanteils von einem Ausgangswert von 11,06 \% im Alter von 4 Monaten bis zu einem Maximum von 26,04 \% im Alter von 18 Monaten. Danach nimmt der Fettanteil dieser Gruppe wieder ab und beträgt im Alter von 24 Monaten 24,18 \%. Der Fettanteil der 5-early-Gruppe entwickelt sich ähnlich wie bei der Kontrollgruppe mit einem geringeren Ausgangswert von 10,65 \% und einem langsameren Anstieg zwischen dem 6. und 12. Monat. Im Alter von 12 Monaten ist der Fettanteil dieser Gruppe im Vergleich zur Kontrollgruppe signifikant kleiner. Darauf folgt dann ein deutlicher Anstieg des Fettanteils bis auf 25,67\% im Alter von 18 Monaten und verändert sich in den kommenden Monaten nur noch marginal, um im Alter von 24 Monaten etwa einen Prozentpunkt über der Kontrollgruppe zu liegen und mit 25,58 \% zu diesem Zeitpunkt den höchsten Fettanteil zu haben. Die Entwicklung des Fettanteilsder 5-late-Gruppe stellt sich wie folgt dar: Diese Tiere haben im Alter von 4 Monaten im Vergleich zur Kontrollgruppe einen um knapp $2 \%$ höheren Fettanteil. In den folgenden zwei Monaten verändert sich dieser kaum. Dies führt dazu, dass die Tiere der 5-late-Gruppe im Alter von 6 Monaten einen signifikant kleineren Fettanteil als die Kontrolltiere haben. Innerhalb der darauffolgenden 6 Monate verdoppelt sich der Fettanteil fast und befindet sich im Alter von 12 Monaten etwa auf gleicher Stufe mit der Kontrollgruppe bei einem Mittelwert von ca. $24 \%$. Bis zum Alter von 18 Monaten ist die weitere Fettanteilzunahme nur noch sehr gering. Schließlich nimmt der Fettanteil der 5-late-Gruppe in den letzten 6 Monaten deutlich ab und ist im Alter von 24 Monaten mit einem Mittelwert von 18,02 \% signifikant kleiner als der der Kontrollgruppe. 


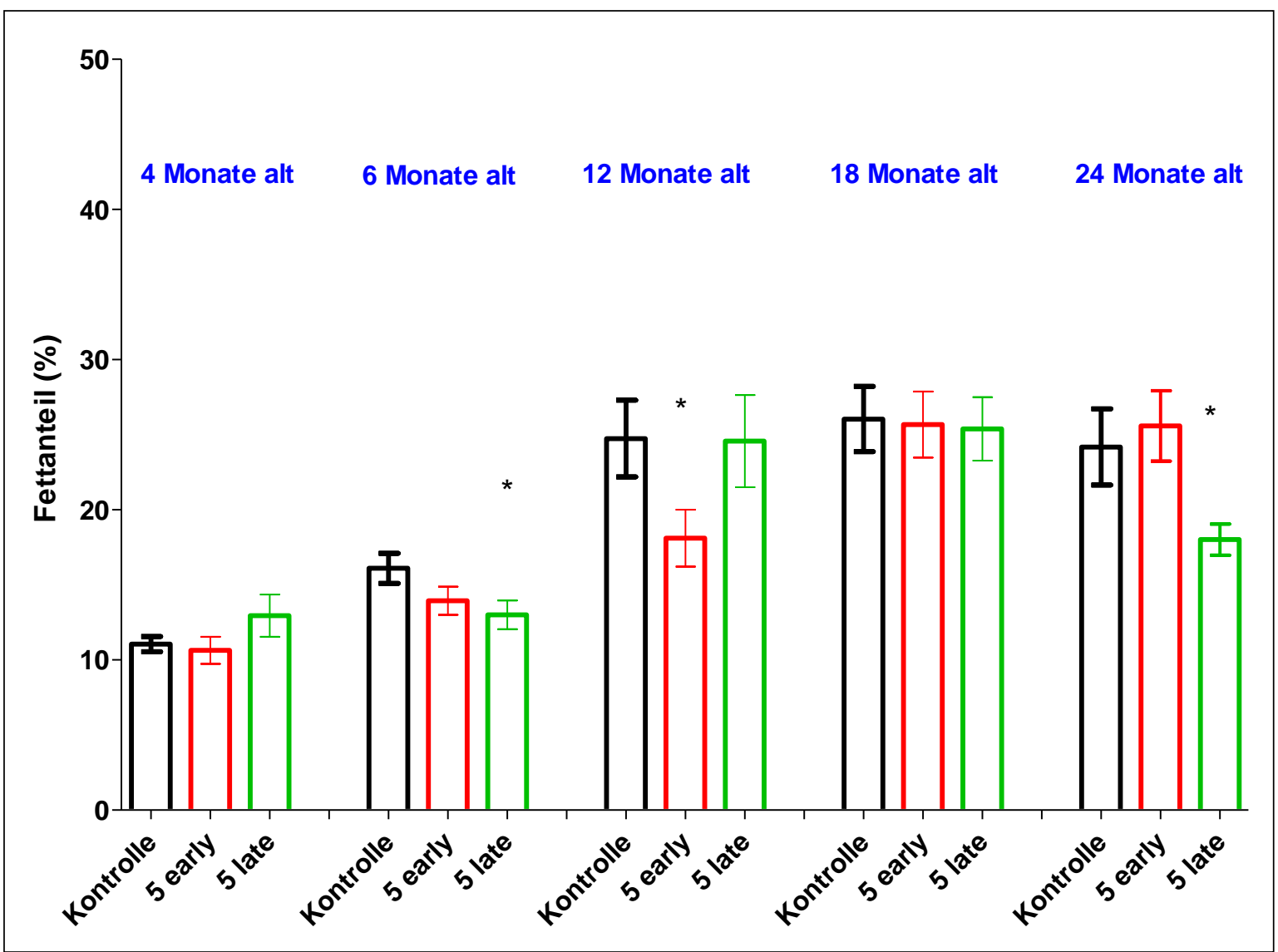

Abbildung 3.5: Die Abbildung zeigt den mittels qCT (CT STRATEC) gemessenen Fettanteil im Bereich L4-L5 der männlichen CJ der 5-early-Gruppe (roter Balken) und der 5-late-Gruppe (grüner Balken) verglichen mit der Kontrollgruppe (schwarzer Balken) im Zeitraum von 24 Monaten. Ein signifikanter Unterschied ( $\mathrm{p}<0,05$ ) zwischen der Kontrollgruppe und der 5-late-Gruppe besteht im Alter von 6 und 24 Monaten. AuBerdem besteht ein signifikanter Unterschied $(\mathrm{p}<0,05)$ zwischen der Kontrollgruppe und der 5-early-Gruppe im Alter von 12 Monaten. 


\subsection{Fettanteile der verschiedenen Körperbereiche, gemessen mittels fpVCT im Alter von 24 Monaten}

\subsubsection{Fettanteil im Bereich L4-L5, gemessen mittels fpVCT im Alter von 24 Monaten}

Im folgenden Abschnitt werden die durch das fpVCT erstellten Daten, welche zeitlich nach den qCT Daten erhoben wurden, beschrieben. Die Abbildung 3.6 zeigt den Fettanteil im Alter von 24 Monaten im Bereich L4-L5 wie zuvor auch mittels qCT gemessen. Bei dieser Messung hat die Kontrollgruppe den größten Fettanteil mit einem Mittelwert von 17,39 \%, die 5-early-Gruppe folgt mit einem Mittelwert von $17 \%$ und die 5-late-Gruppe hat den geringsten Fettanteil mit 12,14\%. Ein signifikanter Unterschied besteht nicht. Die unterschiedlichen prozentualen Fettanteile in der gleichen Körperregion (Bereich L4-L5), welche mit qCT und fpVCT gemessen wurden, sind auf die unterschiedlichen Dichteschwellen zurückzuführen. Für das qCT liegen jahrelange Erfahrungen für die Bestimmung der Dichte unterschiedlicher Organe vor, für das fpVCT war die Bestimmung von Fettgewebe ein Novum und, wie bereits in Kapitel 2.2.2.5 beschrieben, mit gewissen Schwierigkeiten und Voraussetzungen verbunden.

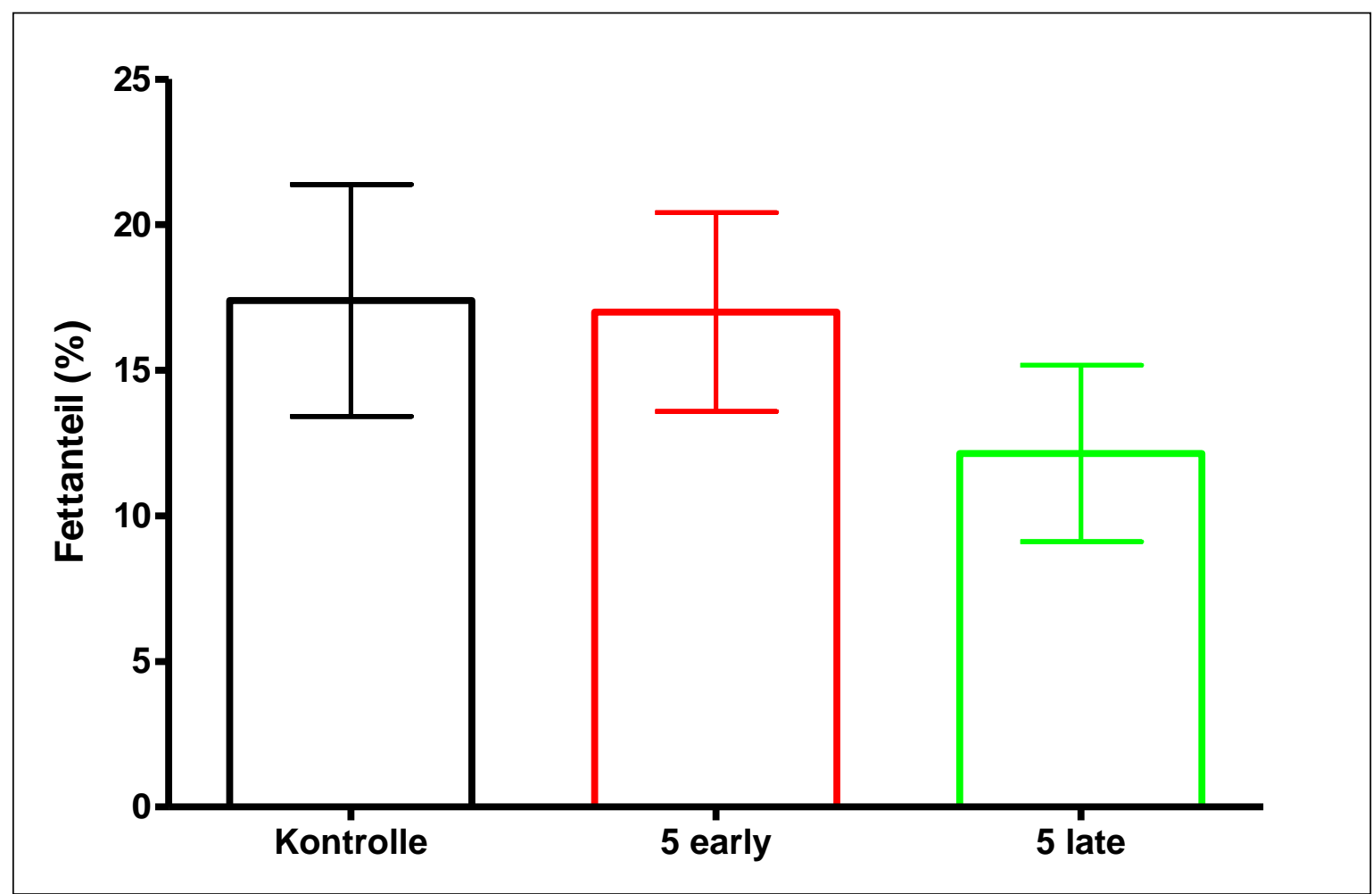

Abbildung 3.6: Die Abbildung zeigt den mittels fpVCT gemessenen Fettanteil im Bereich L4-L5 der männlichen CJ der 5-early-Gruppe (roter Balken) und der 5-late-Gruppe (grüner Balken) verglichen mit der Kontrollgruppe (schwarzer Balken) im Alter von 24 Monaten. 


\subsubsection{Fettanteil im gesamten Lendenwirbelbereich, gemessen mittels fpVCT im Alter von 24 Monaten}

In der Abbildung 3.7 ist der Fettanteil im gesamten Lendenwirbelbereich im Alter von 24 Monaten dargestellt. In der Kontrollgruppe beträgt der Mittelwert 20,30 \%, in der 5-earlyGruppe $18,34 \%$ und in der 5-late-Gruppe $14,65 \%$. Das bedeutet, dass im gesamten Lendenwirbelbereich, die Kontrollgruppe den höchsten Fettgehalt und die 5-late-Gruppe den geringsten Fettanteil hat. Die 5-early-Gruppe befindet sich mit ihrem Fettanteil zwischen den beiden anderen Gruppen. Es besteht kein signifikanter Unterschied zwischen den Gruppen.

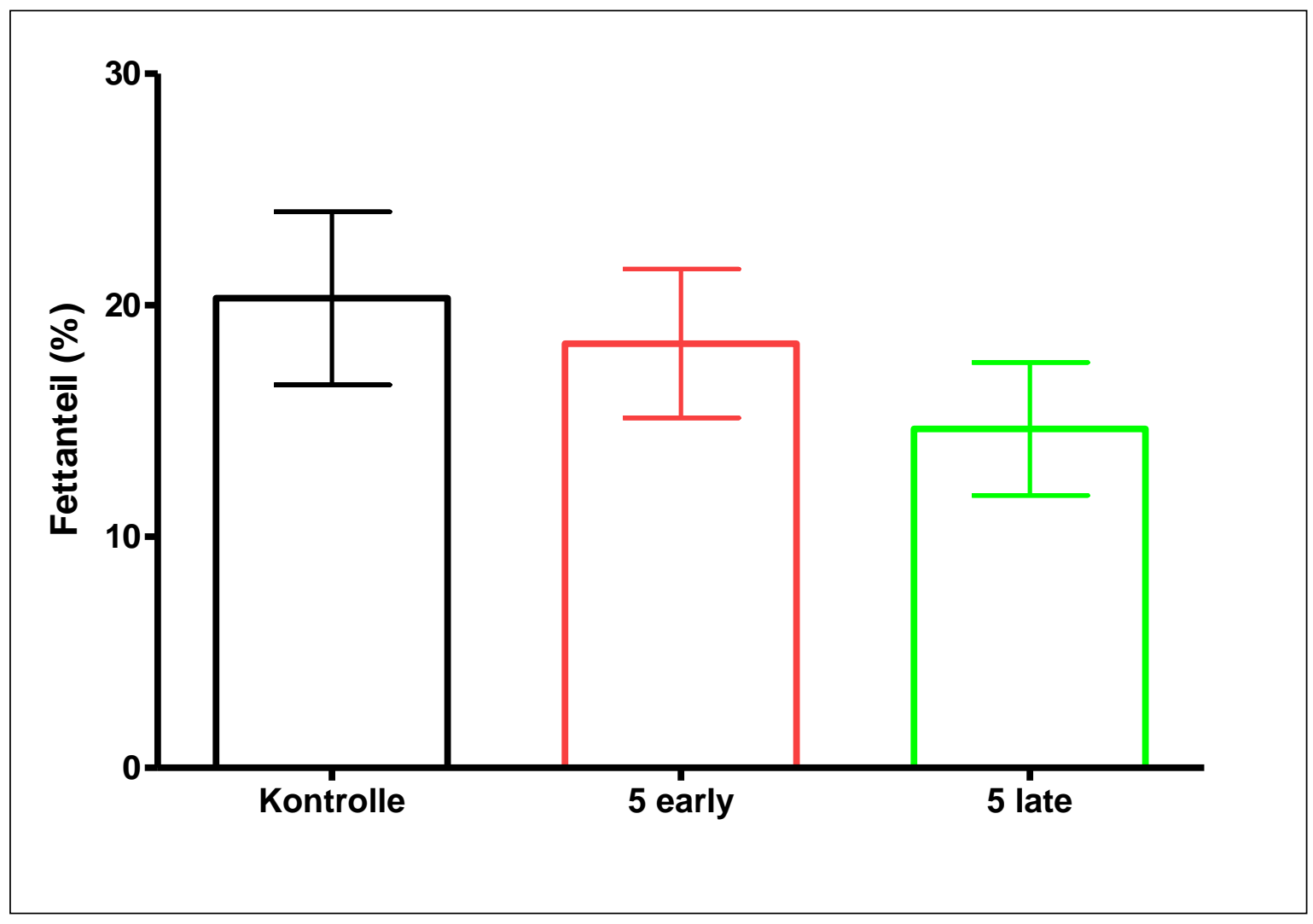

Abbildung 3.7: Die Abbildung zeigt den mittels fpVCT gemessenen Fettanteil im gesamten Lendenwirbelbereich der männlichen CJ der 5-early-Gruppe (roter Balken) und der 5-late-Gruppe (grüner Balken) verglichen mit der Kontrollgruppe (schwarzer Balken) im Alter von 24 Monaten. 


\subsubsection{Fettanteil im Brustwirbelbereich, gemessen mittels fpVCT im Alter von 24 Monaten}

In der Abbildung 3.8 ist der Fettanteil im Brustwirbelbereich im Alter von 24 Monaten dargestellt. In der Kontrollgruppe beträgt der Fettanteil 25,19 \%, in der 5-early-Gruppe 23,37\% und in der 5-late-Gruppe 25,67\%. Somit existiert im Brustwirbelbereich das meiste Fett in der 5-late-Gruppe, gefolgt von der Kontrollgruppe und schließlich der 5early-Gruppe. Ein signifikanter Unterschied besteht im thorakalen Bereich nicht.

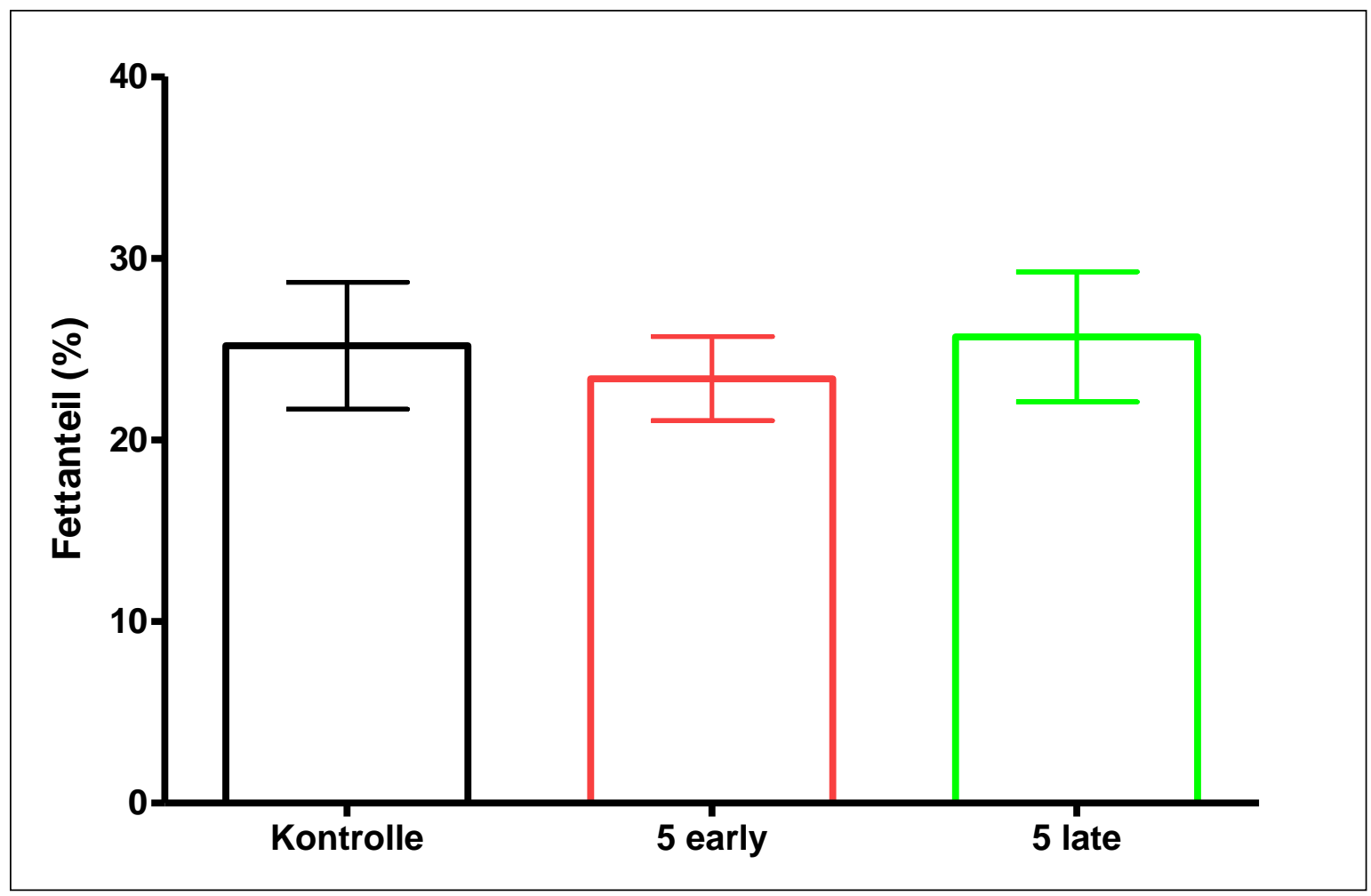

Abbildung 3.8: Die Abbildung zeigt den mittels fpVCT gemessenen Fettanteil im Brustwirbelbereich der männlichen CJ der 5-early-Gruppe (roter Balken) und der 5-late-Gruppe (grüner Balken) verglichen mit der Kontrollgruppe (schwarzer Balken) im Alter von 24 Monaten. 


\subsubsection{Fettanteil im Oberschenkelbereich beider Beine, gemessen mittels fpVCT im Alter von 24 Monaten}

In der Abbildung 3.9 wird der Fettanteil im Oberschenkelbereich beider Oberschenkel im Alter von 24 Monaten dargestellt. Die Kontrollgruppe besitzt mit einem Mittelwert von $11,73 \%$ den höchsten Fettanteil. Darauf folgen die 5-early-Gruppe mit 10,99\% und schließlich die 5-late-Gruppe mit dem kleinsten Mittelwert von 7,56\%. Es besteht kein signifikanter Unterschied.

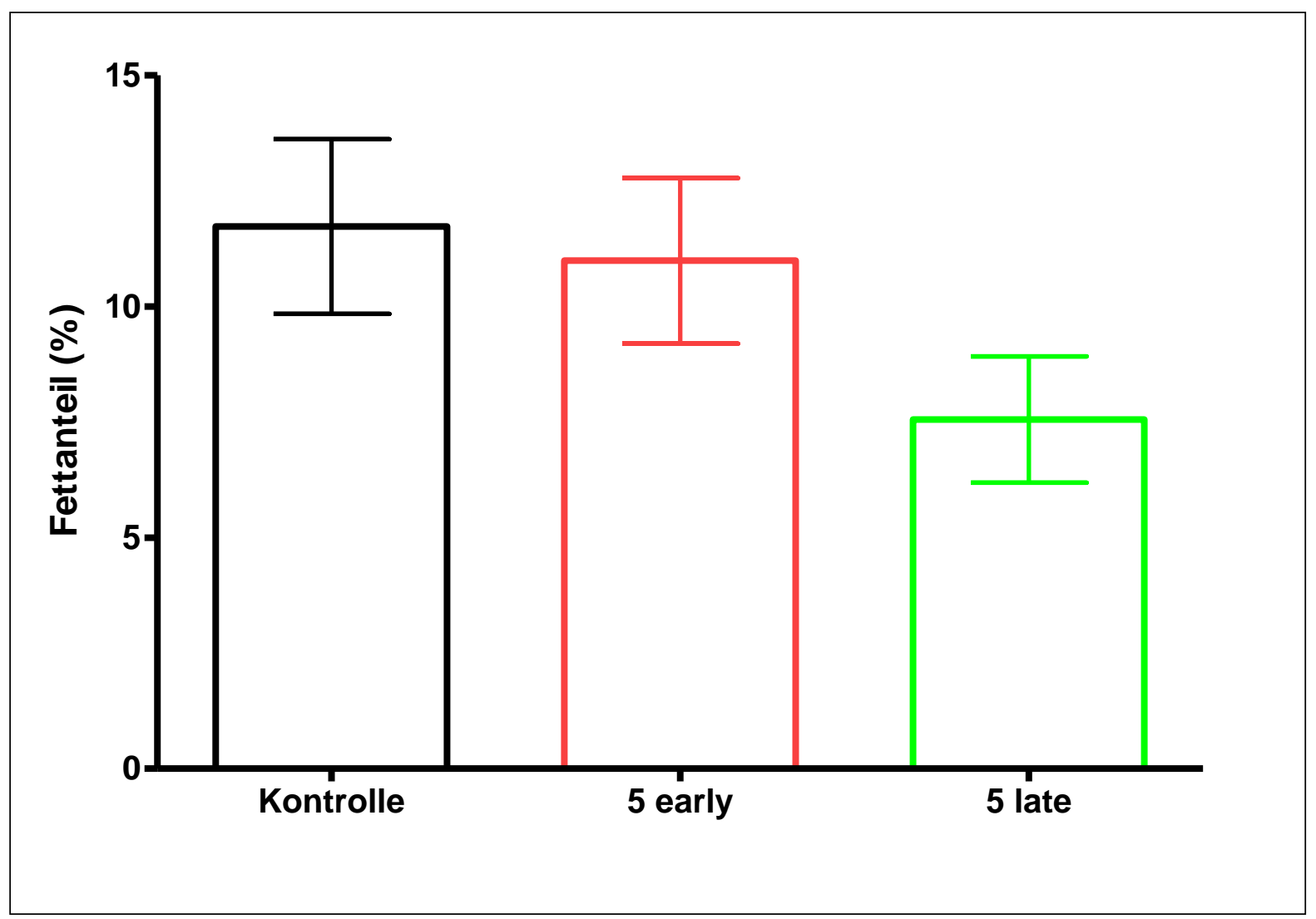

Abbildung 3.9: Die Abbildung zeigt den mittels fpVCT gemessenen Fettanteil im Oberschenkelbereich beider Beine der männlichen CJ der 5-early-Gruppe (roter Balken) und der 5-late-Gruppe (grüner Balken) verglichen mit der Kontrollgruppe (schwarzer Balken) im Alter von 24 Monaten. 


\subsubsection{Fettanteil im Unterschenkelbereich beider Beine, gemessen mittels fpVCT im Alter von 24 Monaten}

Die Abbildung 3.10 zeigt den Fettanteil im Unterschenkelbereich beider Beine im Alter von 24 Monaten. Er beträgt in der Kontrollgruppe 7,14 \%. Die 5-early-Gruppe hat einen geringfügig höheren Fettgehalt von 7,32 \% und die 5-late-Gruppe besitzt mit 6,28 \% den geringsten Fettanteil. Es besteht kein signifikanter Unterschied zwischen der Kontrollgruppe und den beiden anderen Versuchsgruppen.

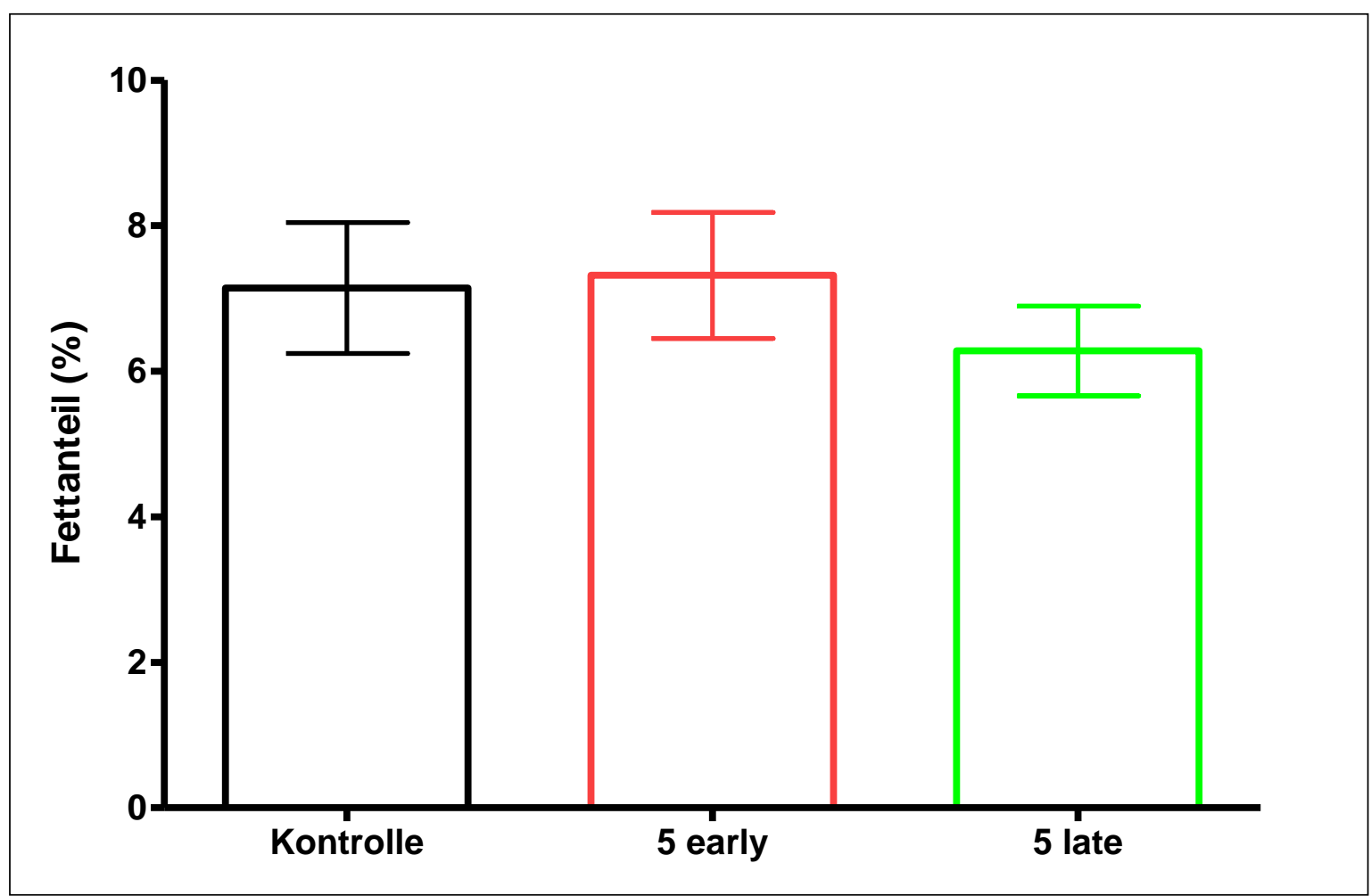

Abbildung 3.10: Die Abbildung zeigt den mittels fpVCT gemessenen Fettanteil im Unterschenkelbereich beider Beine bei den männlichen CJ der 5-early-Gruppe (roter Balken) und der 5-late-Gruppe (grüner Balken) verglichen mit der Kontrollgruppe (schwarzer Balken) im Alter von 24 Monaten. 


\subsubsection{Prozentrelativiertes Gesamtfett im Alter von 24 Monaten, gemessen mittels fpVCT}

Um einen repräsentativen Mittelwert für das Gesamtfett der Versuchstiere im Alter von 24 Monaten zu ermitteln, wurde für diese Darstellung in der Abbildung 3.11 das prozentrelativierte Gesamtfett bestimmt (Vorgehensweise siehe Kapitel 2.4). Der Mittelwert der Kontrollgruppe beträgt durch die beschriebene Vorgehensweise $100 \%$. Die 5-early-Gruppe hat einen Mittelwert für das Gesamtfett des Körpers von 95,99 \% und die 5-late-Gruppe zeigt mit Hilfe dieser Berechnung einen signifikant geringeren Gesamtfettanteil mit einem Mittelwert von $78,50 \%$.

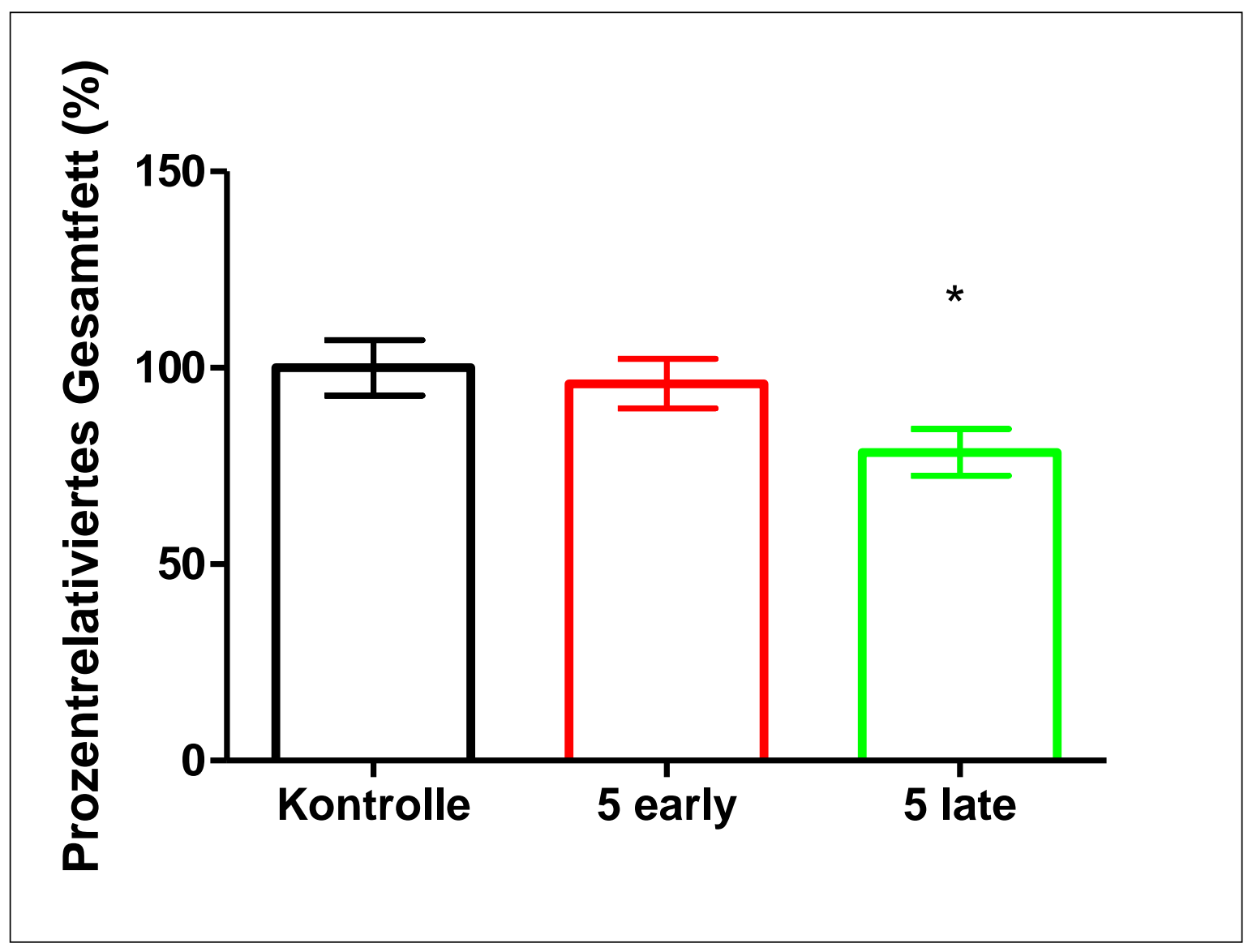

Abbildung 3.11: Die Abbildung zeigt das aus den gesamten Messbereichen des fpVCT berechnete prozentrelativierte Gesamtfett der männlichen CJ der 5-early-Gruppe (roter Balken) und der 5-late-Gruppe (grüner Balken) verglichen mit der Kontrollgruppe (schwarzer Balken) im Alter von 24 Monaten. Es besteht ein signifikanter Unterschied $(\mathrm{p}<0,05)$ zwischen der 5-late-Gruppe und der Kontrollgruppe. 


\subsection{Serumwerte}

Auch die folgenden Serumwerte von Testosteron, Leptin, Cholesterol und Triglyceriden entstammen dem Datenpool der Abteilung Klinische und Experimentelle Endokrinologie der Universitätsmedizin Göttingen unter der Leitung von Herrn Prof. Dr. med. Wolfgang Wuttke und wurden im Rahmen der EUPEAH-Versuchsreihe an den CJ erhoben. Diese Daten wurden für die Erstellung der vorliegenden Promotion zur Verfügung gestellt.

\subsubsection{Testosteron}

In der Abbildung 3.12 wird die Entwicklung des Testosterons im Serum (gemessen in $\mathrm{ng} / \mathrm{ml}$ ) innerhalb der ersten 24 Lebensmonate dargestellt. Im Alter von 4 Monaten ist das Testosteron der Kontrollgruppe kaum zu messen, in den folgenden 2 Monaten nimmt die Testosteronproduktion innerhalb dieser Gruppe dann langsam zu, um im Alter von 6 Monaten einen Mittelwert von 2,79 ng/ml zu erreichen. Bis zum 12. Lebensmonat bleibt dieser Testosteronwert nahezu gleich. Bis zum Alter von 18 Lebensmonaten kommt es dann zu einer Vervierfachung des Wertes auf $12,34 \mathrm{ng} / \mathrm{ml}$ und erreicht damit den höchsten Wert innerhalb der Kontrollgruppe, um bis zum Alter von 24 Monaten wieder um etwa die Hälfte auf 6,48 ng/dl abzunehmen. In der 5-early-Gruppe verhält sich die Testosteronentwicklung ähnlich wie in der Kontrollgruppe. Der Ausgangswert im Alter von 4 Lebensmonaten ist gering und beträgt $0,88 \mathrm{ng} / \mathrm{ml}$. Bis zum 12. Lebensmonat kommt es dann zu einem nahezu linearen Anstieg des Testosterons auf 2,66 ng/ml. Ähnlich wie bei der Kontrollgruppe kommt es auch in der 5-early-Gruppe innerhalb der nächsten 6 Monate zu einer Vervierfachung des Testosterons auf 12,73 ng/ml, sodass auch in dieser Gruppe das Testosteron im Alter von 18 Monaten den höchsten Wert hat. Bis zum Alter von 24 Monaten fällt das Testosteron dann um mehr als die Hälfte auf 5,47 ng/ml zurück. Auch die 5-late-Gruppe startet mit einem niedrigen Testosteronausgangswert von $0,62 \mathrm{ng} / \mathrm{ml}$. In dieser Gruppe kommt es allerdings zu einem früheren Anstieg. Im Alter von 6 Monaten liegt das Testosteron bei $3,45 \mathrm{ng} / \mathrm{ml}$ und im Alter von 12 Monaten bei $17,25 \mathrm{ng} / \mathrm{ml}$, was bedeutet, dass sich das Testosteron in diesem Zeitraum verfünffacht hat. Folglich erreicht das Testosteron der 5-lateGruppe sowohl früher als die anderen beiden Gruppen sein Maximum als auch mit 17,25 ng/ml ein deutlich höheres Maximum. Dies hat zur Folge, dass im Alter von 12 Monaten ein signifikanter Unterschied zwischen der Kontrollgruppe und der 5-late-Gruppe besteht. In den folgenden 6 Monaten nimmt das Testosteron der 5-late-Gruppe etwa um ein Drittel ab und verändert sich bis zum Alter von 24 Monaten kaum noch. Daraus ergibt 
sich, dass bei diesen Tieren das Testosteron mit 24 Monaten mit 10,85 ng/ml im Vergleich zu den beiden anderen Gruppen am höchsten ist.

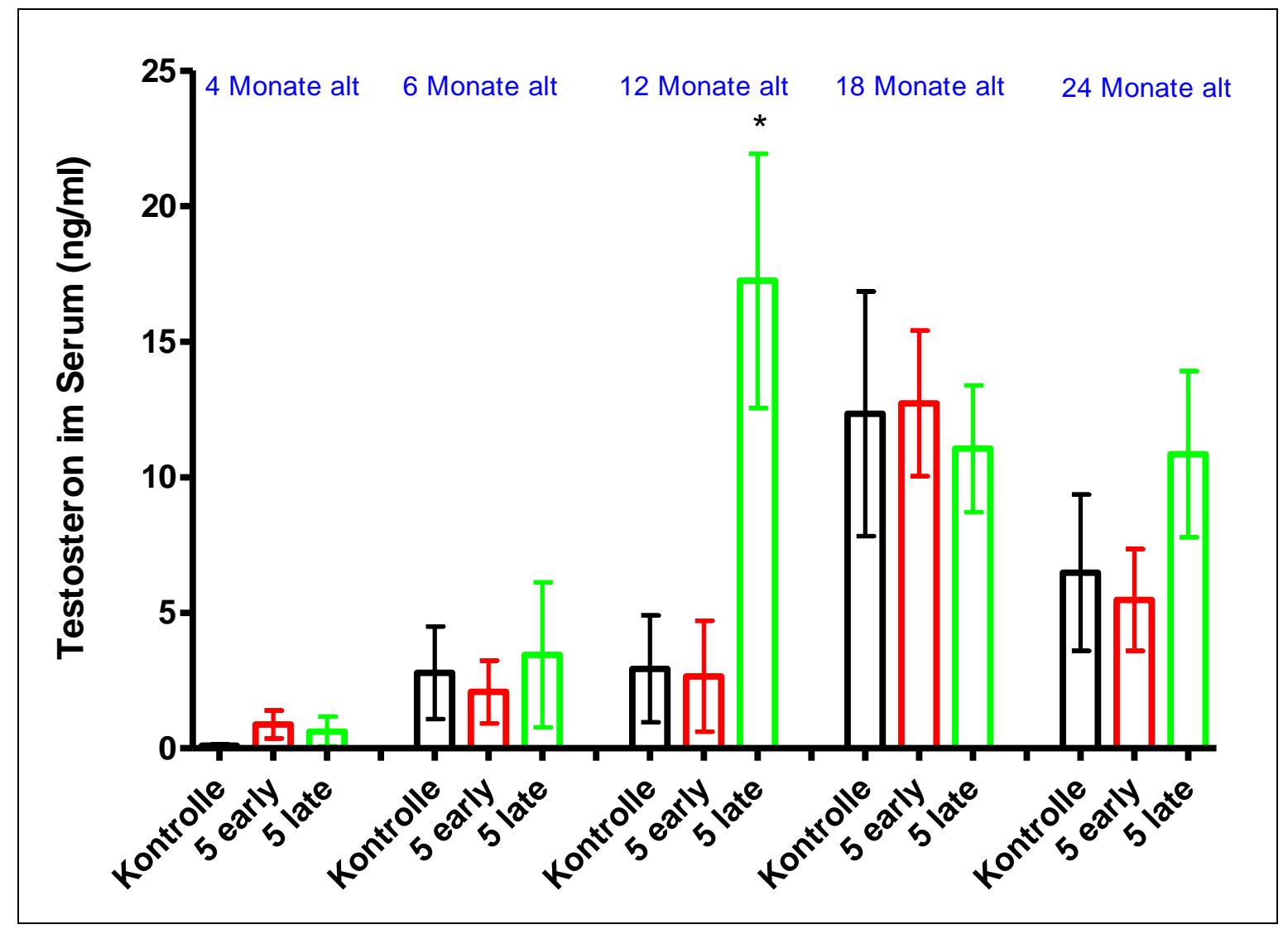

Abbildung 3.12: Die Abbildung zeigt die Entwicklung des Testosterons im Serum bei den männlichen CJ der 5-early-Gruppe (roter Balken) und der 5-late-Gruppe (grüner Balken) verglichen mit der Kontrollgruppe (schwarzer Balken) im Verlauf von 24 Monaten. Es besteht ein signifikanter Unterschied $(p<0,05)$ zwischen der 5-late-Gruppe und der Kontrollgruppe im Alter von 12 Monaten. 


\subsubsection{Leptin}

In der Abbildung 3.13 ist das Leptin im Serum (gemessen in ng/ml) im Alter von 6 und 24 Monaten dargestellt. Im Alter von 6 Monaten hat die Kontrollgruppe das höchste Leptin mit einem Mittelwert von 2,85 ng/ml, darauf folgt die 5-late-Gruppe mit einem Wert von 2,47 ng/ml und schließlich mit einem signifikanten Unterschied zur Kontrollgruppe die 5early-Gruppe mit einem Mittelwert von 2,09 ng/ml. Im Alter von 24 Monaten hat das Leptin in allen 3 Gruppen abgenommen. Die 5-early-Gruppe besitzt weiterhin das geringste Leptin mit einem Wert von 1,41 ng/ml. Die Kontrollgruppe hat einen Mittelwert von 1,64 ng/ml und die 5-late-Gruppe hat mit 1,86 ng/ml im Alter von 24 Monaten das höchste Leptin im Serum. Ein signifikanter Unterschied besteht zu diesem Zeitpunkt nicht mehr.

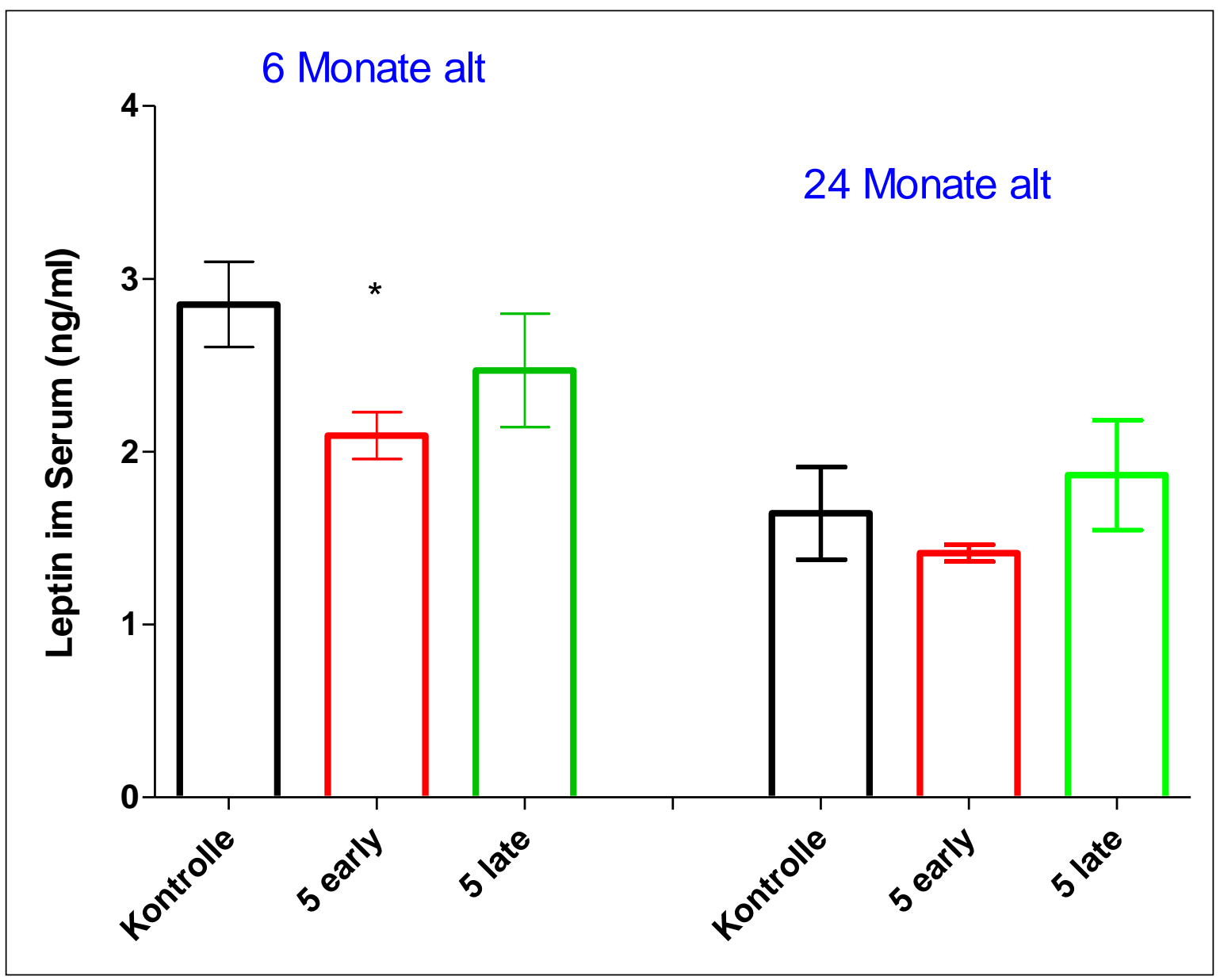

Abbildung 3.13: Die Abbildung zeigt das Leptin im Serum bei den männlichen CJ der 5-early-Gruppe (roter Balken) und der 5-late-Gruppe (grüner Balken) verglichen mit der Kontrollgruppe (schwarzer Balken) mit 6 und 24 Monaten. Im Alter von 6 Monaten besteht ein signifikanter Unterschied $(\mathrm{p}<0,05)$ zwischen der 5 early-Gruppe und der Kontrollgruppe. 


\subsubsection{Cholesterol}

In der Abbildung 3.14 auf der folgenden Seite wird das Cholesterol innerhalb der ersten 12 Lebensmonate (gemessen in $\mathrm{ng} / \mathrm{ml}$ ) dargestellt. Die Darstellung beschränkt sich auf diesen Zeitraum, da eine Messung später nicht mehr möglich war, weil das Untersuchungsmaterial danach für die Bestimmung anderer Parameter gebraucht wurde. Im Alter von 4 Monaten beträgt das Cholesterol der Kontrolle 132,6 ng/ml. In den kommenden 2 Monaten steigt dieser Wert bis auf 140,7 ng/ml an und sinkt im Alter von 12 Monaten dezent unter den Ausgangswert ab. In der 5-early-Gruppe ist der Ausgangswert im Alter von 4 Monaten mit $138,2 \mathrm{ng} / \mathrm{ml}$ etwas höher als bei der Kontrollgruppe und steigt innerhalb der nächsten 2 Lebensmonate ganz geringfügig an. Bis zum Alter von 12 Monaten kommt es dann zu einem deutlichen Anstieg des Cholesterols. Zu diesem Zeitpunkt hat die 5-early-Gruppe im Vergleich mit den anderen beiden Gruppen mit $170 \mathrm{ng} / \mathrm{ml}$ den höchsten Cholesterolwert. Ein signifikanter Unterschied besteht jedoch nicht. Die 5-late-Gruppe hat im Alter von 4 Monaten mit 129,2 ng/ml den geringsten Cholesterolausgangswert. Innerhalb der folgenden 2 Monate steigt der Wert um $10 \mathrm{ng} / \mathrm{ml}$ auf 129,5 ng/ml. Im Alter von 6 Monaten haben alle drei Gruppen somit ein sehr ähnliches Cholesterol. Bis zum 12. Lebensmonat kommt es dann nur noch zu einer leichten Zunahme des Cholesterols, sodass schließlich zu diesem Zeitpunkt die 5-late-Gruppe mit $144 \mathrm{ng} / \mathrm{ml}$ einen Wert zwischen der Kontrollgruppe und der 5-early-Gruppe erreicht. 


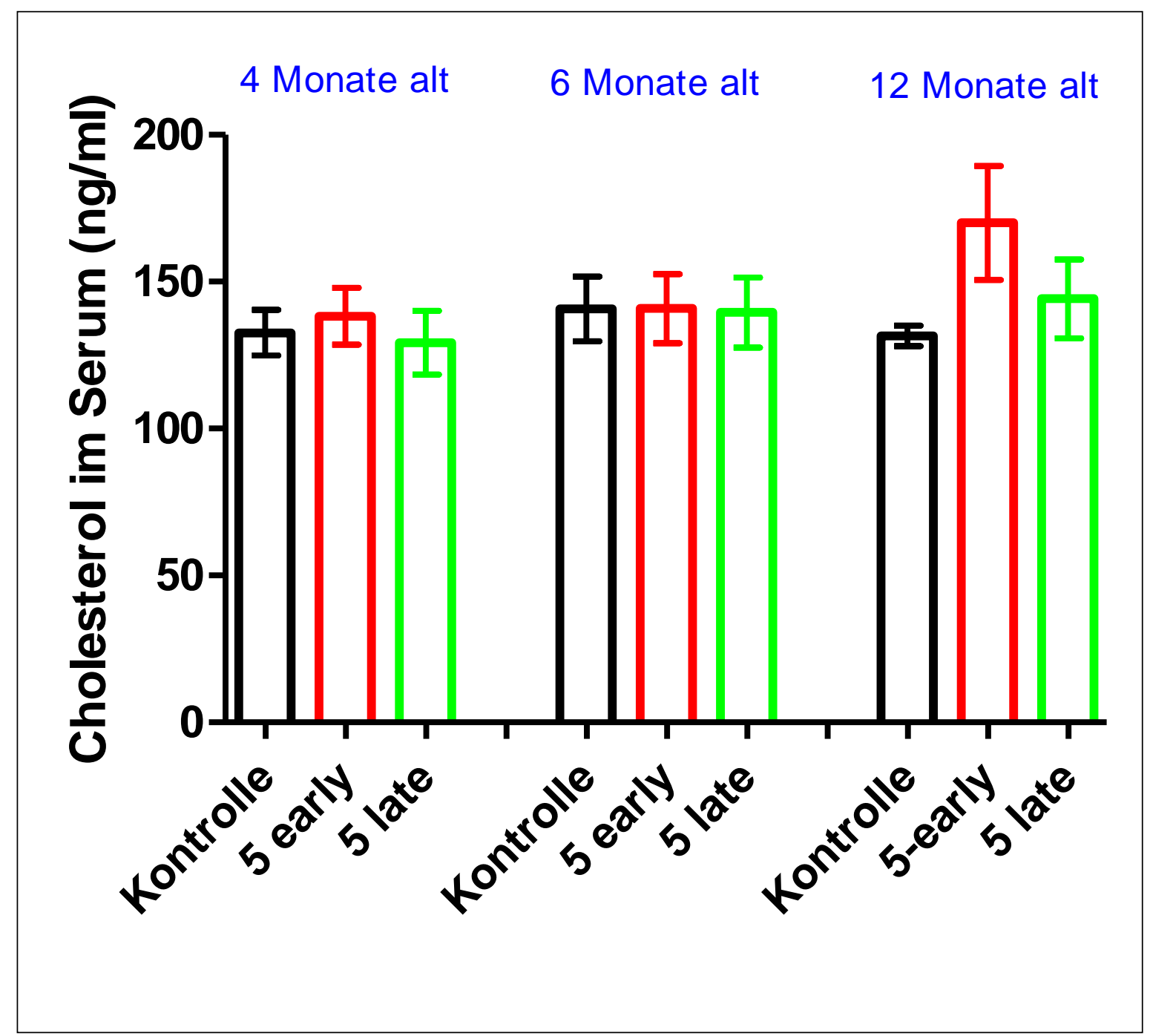

Abbildung 3.14: Die Abbildung zeigt die Entwicklung des Cholesterols bei den männlichen CJ der 5-early-Gruppe (roter Balken) und der 5-late-Gruppe (grüner Balken) verglichen mit der Kontrollgruppe (schwarzer Balken) mit 4, 6 und 12 Monaten.

\subsubsection{Triglyceride}

Die Abbildung 3.15 auf der folgenden Seite stellt den Triglyceridgehalt der Versuchstiere im Serum innerhalb der ersten 12 Lebensmonate (gemessen in $\mathrm{mg} / \mathrm{dl}$ ) dar. Messungen zu späteren Zeitpunkten wurden zugunsten anderer Parameter bei unzureichendem Untersuchungsmaterial nicht mehr durchgeführt. Die Kontrollgruppe beginnt im Alter von 4 Monaten mit einem Triglyceridgehalt von $110 \mathrm{mg} / \mathrm{dl}$. In den kommenden 8 Monaten schwankt dieser Wert leicht, nimmt ab und dann wieder leicht zu, bleibt aber bis zum 12. Lebensmonat mit $104 \mathrm{mg} / \mathrm{dl}$ unter dem Ausgangswert vom 4. Lebensmonat zurück. In der 
5-early-Gruppe ist der Ausgangswert mit 127,3 mg/dl im Alter von 4 Monaten höher als in der Kontrollgruppe. Auch hier kommt es in den kommenden 8 Monaten zu leichten Schwankungen. Erst nehmen die Triglyceride leicht ab und dann wieder zu, um sich im Alter von 12 Lebensmonaten mit 129,7 mg/dl leicht über dem Ausgangswert von 4 Lebensmonaten einzupendeln. Zu jedem Messzeitpunkt sind die Triglyceride dieser Versuchsgruppe leicht höher, als in der zu vergleichenden Kontrollgruppe. In der 5-lateGruppe ist der Ausgangswert der Triglyceride im Alter von 4 Monaten mit einem Wert von $104,8 \mathrm{mg} / \mathrm{dl}$ im Vergleich mit den anderen beiden Gruppen am geringsten. Im Verlauf der nächsten Monate kommt es dann zu einer kontinuierlichen Zunahme der Triglyceride, wobei sich die Zunahme ab dem 6. Lebensmonat beschleunigt, sodass die 5-late-Gruppe im Alter von 12 Monaten mit 178,5 mg/dl einen deutlich höheren Triglyceridwert als die anderen beiden Versuchsgruppen hat.

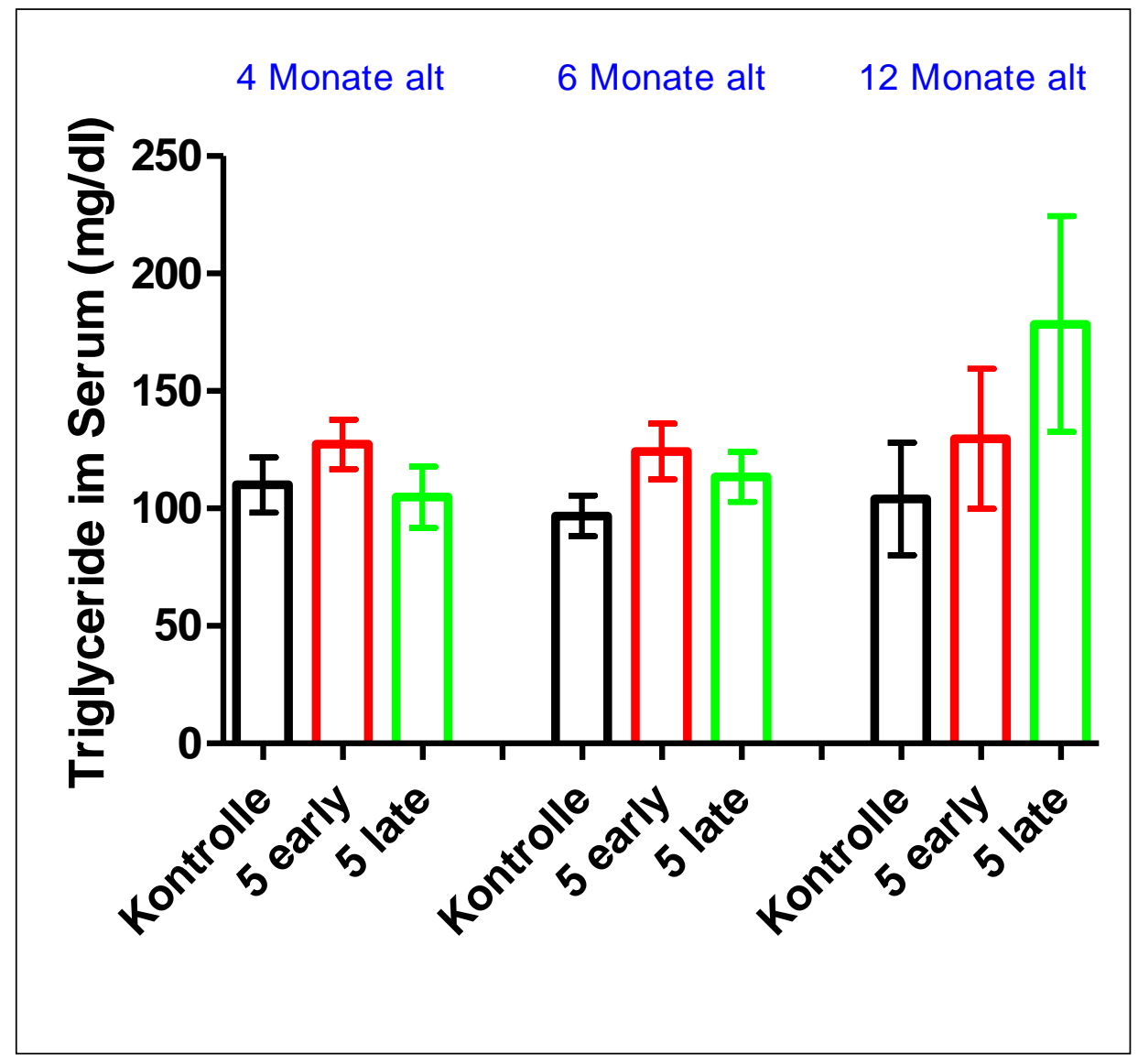

Abbildung 3.15: Die Abbildung zeigt den Serumwert der Triglyceride bei den männlichen CJ der 5-early-Gruppe (roter Balken) und der 5-late-Gruppe (grüner Balken) verglichen mit der Kontrollgruppe (schwarzer Balken) mit 4, 6 und 12 Monaten. 


\section{Diskussion}

\subsection{Ziel der vorliegenden Studie und Versuchsaufbau}

Das Ziel der vorliegenden Arbeit bestand darin, vor dem Hintergrund der zunehmenden Frühgeburtlichkeit und dem damit verbundenen vermehrten Einsatz einer pränatalen Glukokortikoidtherapie zur Lungenreifung die Auswirkungen dieser Therapie auf den Organismus zu untersuchen. Die vorliegende Studie beschränkt sich auf die Auswirkungen der pränatalen Therapie auf das Körpergewicht, die Körperlänge und das Fettgewebe und die Blutparameter Testosteron, Leptin, Cholesterol und Triglyceride. Dieser Fokus wurde gewählt, da u.a. in den Studien von Cleasby et al. (2003), Dahlgren et al (2001), De Vries et al. (2007), Franko et al. (2010) und Li et al.(2010) festgestellt wurde, dass es bei Ratten und anderen Versuchstieren mit einer pränatalen Dexamethasontherapie oder auch bei Kindern, deren Mütter während oder kurz vor der Schwangerschaft starkem emotionalem Stress ausgesetzt waren und daher erhöhte Glukokortikoidspiegel hatten, im Laufe des Lebens zur Ausbildung von Adipositas mit Veränderungen der Fettverteilung und/oder des Fettgehalts und Veränderungen des Hormonhaushalts kommen kann. Dieser Mechanismus wird durch epigenetische Effekte erreicht. Wie bereits in der Einleitung erklärt, führen bestimmte Umwelteinflüsse in utero (z.B. Stress über erhöhte Glukokortikoidspiegel) zu Chromosomenmodifikationen und somit zu Änderungen des Phänotyps, ohne Änderungen des Genotyps hervorzurufen, denn die DNA-Sequenz bleibt unverändert (Bouwland-Both et al. 2015; Vidal et al. 2014; Walter 2009).

Einen weiteren Schwerpunkt der Untersuchungen bildet außerdem der Zeitpunkt der pränatalen Glukokortikoidverabreichung, da sich gezeigt hat, dass v.a. diesem eine besondere Bedeutung in Hinblick auf verschiedene postnatale Veränderungen zukommt (Hauser et al. 2008). In dem nun folgenden Kapitel werden die Ergebnisse der vorliegenden Studie dargestellt, diskutiert und in den Kontext der aktuellen Literatur eingeordnet. Die zu Beginn der Arbeit formulierte Fragestellung, ob es bei den CJ durch die pränatale Therapie mit Dexamethason mittels epigenetischer Effekte zu einer Veränderung des Gesamtkörperfetts oder auch zu einer Veränderung der Fettverteilung im Alter von 24 Monaten kommt und ob es Unterschiede macht, dieses Medikament im ersten oder zweiten Trimenon der Schwangerschaft zu verabreichen, soll an dieser Stelle beantwortet und diskutiert werden. 
Des Weiteren wurde untersucht, ob es Anzeichen einer Gewichtsveränderung in Abhängigkeit von der pränatalen Behandlung gibt und ob es zu Veränderungen der Plasmaspiegel von Testosteron, Leptin, Cholesterol und Triglyceriden kommt. Auf Grund der soeben angeführten Literatur wurde zu Beginn der vorliegenden Studie davon ausgegangen, dass die Resultate, in Abhängigkeit vom Zeitpunkt der pränatalen Dexamethasongabe, zu einer Zunahme des Körpergewichts, Veränderungen des Fettgehalts und der Verteilung des Fettgewebes sowie Veränderungen von Testosteron, Leptin, Cholesterol und Triglyceriden führen würde.

Zur Durchführung der vorliegenden Studie wurden CJ als Tiermodell benutzt. Die Primaten wurden im DPZ Göttingen aufgezogen und betreut. Die 30 männlichen CJ-Jungtiere wurden in drei Versuchsgruppen unterteilt. Diese drei Gruppen wurden in Abhängigkeit von der Behandlung der Muttertiere in der Schwangerschaft gebildet. Die Kontrollgruppe enthielt zehn männliche Tiere, deren Mütter keiner Behandlung unterlagen, unter Standardbedingungen des DPZ im Mutterleib heranwuchsen, spontan geboren wurden und somit als gesunde Kontrollgruppe dienten. Die 5-early-Gruppe beinhaltete diejenigen zehn männlichen Versuchstiere, deren Mütter im ersten Trimenon der Schwangerschaft sieben Tage lang Dexamethason verabreicht bekamen. In der dritten und letzten Versuchsgruppe, der 5-late-Gruppe, erhielten die Mütter dieser zehn männlichen Versuchstiere im zweiten Trimenon der Schwangerschaft die Dexamethasontherapie. Alle Nachkommen wurden spontan als reife Jungtiere geboren und danach 24 Monate lang beobachtet und regelmäßigen Untersuchungen unterzogen. Im Alter von 4, 6, 12, 18 und 24 Monaten wurden computertomographische Messungen mit Hilfe des qCTs durchgeführt. Im Alter von 24 Monaten wurden auf der Grundlage der qCT-Ergebnisse die aufwendigen Messungen mit dem fpVCT ergänzt und manuell ausgewertet. Diese Daten wurden zur Berechnung des Fettgehalts benutzt. Des Weiteren wurden zahlreiche Daten zu Gewicht, Körperlänge und Hormonspiegel zu den einzelnen Untersuchungszeitpunkten erhoben.

\subsection{Fettanteil im Bereich L4-L5, gemessen mittels qCT über 24 Monate}

Einen der ersten Schritte der vorliegenden Arbeit stellte die Bestimmung des Fettanteils im Bereich L4-L5 nach pränataler Dexamethasontherapie bei den CJ dar. Dieser Bereich verkörpert das viszerale Fettgewebe und wurde im Verlauf der ersten 24 Lebensmonate per 
qCT gemessen. Das viszerale Fettgewebe gilt als das pathogenste Fettgewebe und scheint u.a. in der Entstehung des metabolischen Syndroms eine wichtige Rolle einzunehmen und kann somit auch längerfristige Auswirkungen auf den Organismus haben (Vissers et al 2013). Nicht zuletzt deshalb ist die Betrachtung dieses Bereichs von Bedeutung.

Mittels qCT zeigte sich, dass eine pränatale Dexamethasontherapie im ersten Trimenon der Schwangerschaft im Alter von 12 Monaten zu einer signifikanten Reduktion des viszeralen Fettgewebes bei den männlichen Nachkommen führte. Eine pränatale Dexamethasontherapie im zweiten Trimenon der Schwangerschaft führte zu einer signifikanten Reduktion des viszeralen Fettgewebes bei den männlichen Nachkommen im Alter von 6 und 24 Monaten.

Durch die vorliegenden Ergebnisse wurde somit die ursprüngliche Annahme, dass Dexamethason, welches pränatal zur fetalen Lungenreife eingesetzt wird, durch epigenetische Effekte zu postnatalen Veränderungen, insbesondere zu einer Veränderung von Fettanteilen führt, bestätigt. Grund zu dieser Annahme hatte die Verfasserin der vorliegenden Arbeit unter anderem durch die Studie von Franko et al. (2010), in der es nach pränataler Dexamethasontherapie bei männlichen Ratten zu einer Fettverteilungsveränderung mit einer Abnahme des peritonealen und perirenalen und einer Zunahme des subkutanen und abdominellen Fettspeichers kam. Und auch bei nichtmenschlichen Affen führte eine pränatale Dexamethasontherapie zu einer Erhöhung des subkutanen Fettanteils (De Vries et al. 2007). Da zu Beginn der vorliegenden Arbeit, u.a. wegen der Auswirkung von pränatalem Stress auf die menschlichen Nachkommen (Li et al. 2010), vermutet wurde, dass es in der vorliegenden Arbeit zu einer Ausbildung von Adipositas kommen würde, verwunderten die signifikanten Abnahmen im viszeralen Fettbereich. Umso interessanter erschien es daher, die anderen Körperbereiche und das Gesamtkörperfett zu betrachten, da die Vermutung nahe lag, dass es in den anderen Körperregionen zu erhöhtem Fettanteil gekommen sein musste. Zu diesem Zweck wurden die Messungen mittels fpVCT zur Bestimmung der Fettverteilung am gesamten Körper im Alter von 24 Monaten durchgeführt

Außerdem wurde durch die vorliegenden Ergebnisse in diesem Kapital festgestellt, dass die beschriebenen Veränderungen, je nach Zeitpunkt der pränatalen Therapie, unterschiedlich ausfallen, was hinsichtlich anderer postnataler Veränderungen oder auch möglicher Folgeerkrankungen auch bereits durch andere Versuche bestätigt worden ist (Hauser et al. 2008). Die pränatale Dexamethasontherapie im ersten Trimenon der Schwangerschaft hat auf Grundlage der vorliegenden Daten hinsichtlich der Programmierung des viszeralen Fettgewebes nur bis in die Kindheit bzw. Pubertät reichende Auswirkungen. Die 
Dexamethasonverabreichung in einer späteren Phase, in diesem Fall dem zweiten Trimenon der Schwangerschaft, hat aber Auswirkungen von der Kindheit bis ins Alter der Reproduktion. In diesem Zusammenhang ist die Studie von Nyirenda et al. (1998) zu erwähnen, in der eine Dexamethasontherapie zu einem späteren Zeitpunkt der Schwangerschaft bei Ratten zu einem geringeren Geburtsgewicht der Nachkommen führte. Außerdem wurde in einer anderen Studie gezeigt, dass eine Dexamethasontherapie in einer späten Phase der Schwangerschaft zu signifikanten Gewichtsveränderungen bei Affen innerhalb der ersten 24 Monate führt, ohne jedoch im Alter von 24 Monaten signifikant verändert zu sein (Nyirenda et al. 2009). Somit sollte die Indikation für eine Therapie mit Dexamethason insbesondere in einer späteren Phase der Schwangerschaft sorgfältig geprüft werden, denn sowohl das Geburtsgewicht (Nyirenda et al. 1998) als auch die Fettentwicklung in der Kindheit und zu späteren Zeitpunkten des Lebens können durch diese Therapie verändert werden. Die Folgen dieser epigenetisch bedingten Veränderungen sind noch nicht ausreichend bekannt, sodass deren Stellenwert noch nicht sicher eingeordnet werden kann.

\subsection{Fettverteilung am gesamten Körper und in den einzelnen Körperbereichen, gemessen mittels fpVCT im Alter von 24 Monaten}

Die fpVCT-Messungen wurden aufgrund des signifikant geringeren viszeralen Fettgewebeanteils der 5-late-Gruppe im Vergleich mit der Kontrollgruppe in den qCT-Messungen im Alter von 24 Monaten ergänzt. In dem fpVCT wurde nicht der Verlauf über die Zeit von 24 Monaten am Beispiel einer Fettregion untersucht, sondern im Alter von 24 Monaten wurden verschiedene Fettregionen am gesamten Körper der drei Versuchsgruppen untersucht, um eine Aussage über den ganzen Körper tätigen zu können. Wichtig bei diesem Punkt ist, dass die Messungen mittels fpVCT für Fettgewebe ein Novum waren und nicht auf jahrelange Erfahrung (wie bei dem qCT bezüglich der Messung von Fettgewebe) zurückgegriffen werden konnte.

Bei den Tieren der 5-early-Gruppe wurden sowohl beim prozentrelativierten Gesamtfett als auch beim Fettgehalt der verschiedenen untersuchten Körperregionen im Alter von 24 Monaten keine signifikanten Unterschiede, verglichen mit der Kontrollgruppe, festgestellt. Bei der 5-late-Gruppe konnte allerdings, verglichen mit der Kontrollgruppe, in der prozentrelativierten Berechnung des Gesamtfettanteils im Alter von 24 Monaten ein signifikant 
geringerer Fettanteil am gesamten Körper festgestellt werden. Diese Reduktion des Gesamtfettanteils setzt sich (mit Ausnahme des Brustwirbelbereichs) aus verminderten Fettanteilen der verschiedenen Messabschnitte zusammen, welche einzeln jedoch nicht signifikant geringer waren.

Somit bestätigen die Messungen mittels fpVCT die bereits durch das qCT gewonnene Erkenntnis, dass eine pränatale Dexamethasontherapie im zweiten Trimenon der Schwangerschaft zu einer Reduktion von Fettgewebe bei den männlichen Nachkommen im Alter von 24 Monaten führt. Durch diese Ergebnisse konnte die vorliegende Arbeit bestätigen, dass Dexamethason, welches pränatal zur Lungenreifung eingesetzt wird, durch epigenetische Effekte zu postnatalen Veränderungen führt. Außerdem konnte erneut die ursprüngliche Annahme bestätigt wird, dass v.a. der Zeitpunkt der pränatalen Therapie entscheidend dafür ist, ob, und in welchem Ausmaß Veränderungen bei den Nachkommen und deren Entwicklung entstehen. Das signifikant reduzierte Fettgewebe im Bereich L4-L5 (qCT) mit 6 und 24 Monaten und das signifikant reduzierte Gesamtkörperfett (fpVCT) im Alter von 24 Monaten zeigen, dass insbesondere die späte pränatale Phase empfindlich gegenüber einwirkenden Glukokortikoiden ist. Auch Sugden et al. (2001) zeigten dies bereits in seiner Arbeit, denn eine Glukokortikoidgabe im letzten Trimenon der Schwangerschaft führte in seiner Arbeit zu einer signifikanten Abnahme des geschlechtsspezifischen Fettgewebes bei den männlichen Rattennachkommen.

Nicht zu erwarten war in der vorliegenden Arbeit allerdings, dass es sich bei den vorliegenden Veränderungen um eine Reduktion des Gesamtfetts handelt, da insbesondere in den Studien von Dahlgren et al. (2001) und Li et al. (2010) eine pränatale Dexamethasontherapie oder pränataler Stress im Verlauf des Lebens bei Ratten und auch beim Menschen zu erhöhten BMI-Werten und einem Vermehrten Vorkommen von Adipositas führten. Allerdings gab es auch bereits Versuche an Ratten, die zeigten, dass nur die Tiere nach pränataler Glukokortikoidtherapie adipös wurden, die postnatal hochkalorisch ernährt wurden (Tamashiro et al. 2009). Auch in den Arbeiten von Cleasby et al. (2003) wurde eine Abnahme verschiedener Fettregionen nach pränataler Therapie bei Ratten beschrieben.

\subsection{Körpergewicht, Körperlängen und BMI}

Auch die regelmäßige Dokumentation der Körpermaße der CJ gehörte zu der vorliegenden Studie. Durch die Untersuchung des Körpergewichts konnte dokumentiert werden, dass 
sich die Versuchstiere innerhalb von 24 Lebensmonaten gut entwickelt haben. Alle Tiere zeigten über diese Zeit eine Gewichtszunahme und zwischen den drei Versuchsgruppen gab es keine signifikanten Unterschiede und auch die Berechnung des BMI mit 18 und 24 ergab keine relevanten Unterschiede zwischen den Gruppen.

Wichtig ist in diesem Zusammenhang insbesondere der Blick auf die Versuchstiere der 5-late-Gruppe. Denn, wie bereits erwähnt, zeigte die pränatale Dexamethasontherapie im zweiten Trimenon der Schwangerschaft keine signifikanten Effekte hinsichtlich des Körpergewichts, obwohl sich interessanterweise im Alter von 24 Monaten bei diesen Tieren eine signifikante Reduktion vom gesamten Körperfettgewebe ergab. Dass daraus keine signifikante Gewichtsreduktion resultierte, könnte darauf hindeuten, dass bei den Tieren andere Körperelemente (z.B. Muskulatur) vermehrt waren. Insgesamt stützten somit die Ergebnisse des Körpergewichts und des BMI der vorliegenden Arbeit weder die ursprüngliche Annahme, dass die pränatale Dexamethasontherapie zu erhöhten BMI-Werten oder Adipositas führen würde (Dahlgren et al. 2001; Li et al. 2010), noch die Ergebnisse der Arbeit von Wang et al. (2007). Denn diese haben an Frühgeborenen mit pränataler Glukokortikoidbehandlung gezeigt, dass diese Kinder mit einem reduzierten Geburtsgewicht zur Welt kamen und auch im präpubertären Alter noch weniger als die Kinder ohne Behandlung wogen.

Im Alter von 18 Monaten fiel in der vorliegenden Arbeit erstmals auf, dass verschiedene Versuchstiere gedrungener wirkten. Deshalb wurden zu diesem Zeitpunkt und noch einmal mit 24 Monaten verschiedenen Körperlängen betrachtet. Mit 18 Monaten zeigte sich zum einen, dass alle Tiere bereits ausgewachsen und annähernd gleich lang waren, zum anderen, dass die Tiere der 5-late-Gruppe eine signifikant kürzere Scheitel-Steißlänge besaßen, was sich bis zum Alter von 24 Monaten bei ausbleibendem weiteren Wachstum nicht mehr änderte. Aus dieser kürzeren Scheitel-Steißlänge und der Tatsache, dass die ScheitelFersenlänge von Kontrolle und 5-late-Gruppe gleich waren, resultierte rechnerisch die Erkenntnis, dass die untere Extremität dieser Tiere länger sein musste. Somit hat die pränatale Dexamethasontherapie im zweiten Trimenon der Schwangerschaft neben einer Veränderung von Körperfett auch Auswirkungen auf das Knochenwachstum gezeigt. Es scheint so, als bewirke diese Therapie, eventuell auch durch das erhöhte Testosteron, das im nächsten Kapitel genauer beschrieben wird, ein verstärktes Knochenwachstum der Röhrenknochen der unteren Extremität und einen gedrungenen Körperbau des Oberkörpers. Auch De Vries et al. stellten 2007 bereits Knochenveränderungen nach pränataler Dexamethasontherapie 
an Grünen Meerkatzen fest. Allerdings war bei diesen Tieren zum Zeitpunkt der Geburt eine verkürzte fetale Femurlänge festzustellen. Im weiteren Verlauf des Lebens zeigte sich bei den Grünen Meerkatzen mit höheren Medikamentendosen dann zuerst ein reduziertes und im späteren Leben ein beschleunigtes Wachstum. Somit scheint ferner nicht mehr die Frage zu bestehen, ob pränatale Dexamethasongaben das Knochenwachstum beeinflussen, sondern in welcher Art dies geschieht. Um diese Frage zu beantworten sind weitere Studien notwendig.

\subsection{Testosteron}

Die Bestimmung des Testosterons erbrachte in der vorliegenden Arbeit interessante Erkenntnisse. Alle drei Versuchsgruppen hatten innerhalb der ersten 6 Lebensmonate einen langsamen Testosteronanstieg. Im Alter von 12 Monaten verfünffachte sich dann das Testosteron der 5-late-Gruppe, während sich das Testosteron der anderen beiden Versuchsgruppen kaum veränderte. Zu diesem Zeitpunkt konnte ein signifikanter Unterschied zwischen der Kontrollgruppe und der 5-late-Gruppe festgestellt werden. Diese Tatsache lässt vermuten, dass eine Dexamethasontherapie im zweiten Trimenon der Schwangerschaft einen früheren Beginn der Pubertät bewirkt. Auch Li et al. formulierten 2010 auf der Grundlage verschiedener Studien die Vermutung, dass die pränatale Periode ein empfindliches Zeitfenster der Langzeitprogrammierung der Pubertätsentwicklung darstellt. Da die Dexamethasontherapie im ersten Trimenon der Schwangerschaft in der vorliegenden Studie keine signifikanten Unterschiede im Vergleich mit der Kontrollgruppe verursachte, wird auch durch diese Ergebnisse erneut deutlich, dass v.a. der Zeitpunkt der Dexamethasonapplikation in der Schwangerschaft entscheidend ist.

In Zusammenschau mit den Ergebnissen des Fettgewebes der vorliegenden Arbeit bewirkte eine Dexamethasontherapie im zweiten Trimenon der Schwangerschaft eine signifikante Reduktion des Gesamtfettgewebes mit 24 Monaten und sowohl einen signifikanten Testosteronanstieg im Alter von 12 Monaten, als auch leicht erhöhte Testosteronwerte (ohne einen signifikanten Unterschied zu erreichen) mit 24 Monaten. Das Vorliegen von leicht erhöhtem Testosteron und signifikant reduziertem Gesamtfettgewebe im Alter von 24 Monaten lässt die Frage aufkommen, ob die pränatale Dexamethasontherapie über einen leicht erhöhten Testosteronspiegel, im Sinne einer anabolen Wirkung (Hick und Hick 2009), zu einer erhöhten Muskelmasse und einem geringeren Gehalt an Fettgewebe führt. Diese Annahme würde auch durch die Tatsache unterstrichen, dass es zu keiner signifikanten 
Veränderung des Körpergewichts gekommen ist und somit andere Körperelemente vermehrt sein mussten. Da diese Frage hier nicht geklärt werden kann, empfiehlt es sich weitere Forschungen in dieser Richtung zu ergänzen.

Ferner liegt die Vermutung eines Zusammenhangs zwischen dem frühen signifikanten Anstieg des Testosterons der 5-late-Gruppe mit 12 Monaten und der längeren unteren Extremität ab dem Alter von 18 Monaten nahe. Möglicherweise führt der frühe und sehr hohe Testosteronanstieg nach einer pränatalen Therapie im zweiten Trimenon der Schwangerschaft zu einem verlängerten Röhrenknochenwachstum, da Testosteron bekanntlich den Wachstumsschub im Rahmen der Pubertät bewirkt (Deutzmann 2010; Pedain 2010). Das erhöhte Testosteron zeigt somit vielfältige Auswirkungen. Es scheint für den früheren Beginn der Pubertät verantwortlich zu sein, sich eiweißanabol zu verhalten und zu einem gedrungenen Körperbau und verlängertem Röhrenknochenwachstum zu führen.

\subsection{Leptin}

Bei der Untersuchung des Leptins zeigte sich im Alter von 6 Monaten im Vergleich mit der Kontrollgruppe ein signifikant geringerer Wert bei den Tieren, die eine Dexamethasontherapie im ersten Trimenon der Schwangerschaft erhalten hatten. Da physiologischerweise die Plasmakonzentration des Leptins im direkten Verhältnis zur Fettgewebsmasse und zum BMI steht, war zu erwarten, dass es bei den Tieren der 5-early-Gruppe zu diesen Zeitpunkten ein dementsprechend geringeres Fettgewebe und einen kleineren BMI gibt. Dies traf allerdings nicht zu. Auch die Ergebnisse der 5-late-Gruppe warfen Fragen auf. Die, wegen des signifikant geringeren viszeralen Fettgewebes im Alter von sechs Monaten und des signifikant geringeren Gesamtkörperfetts mit 24 Monaten, zu erwartende signifikante Reduzierung des Leptins blieb aus. Auf Grund dieser vorliegenden Ergebnisse kann vermutet werden, dass eine pränatale Dexamethasontherapie zu verschiedenen Zeitpunkten der Schwangerschaft neben den oben beschriebenen Folgen auch die Biochemie der Adipozyten beeinträchtigt. Bestätigt wird diese Vermutung auch durch die Hinweise für eine gestörte Leptinproduktion bei Ratten nach pränataler Dexamethasongabe, die Sugden et al. bereits 2001 fanden. Denn diese Ratten zeigten im Alter von einem Jahr erhöhte Leptinspiegel, die nicht durch eine Adipositas erklärt werden konnten und bei weiteren Untersuchungen an den männlichen Tieren, die das Glukokortikoid im letzten Trimenon der Schwangerschaft erhalten hatten, stellte sich sogar heraus, dass das für das männliche Geschlecht repräsentative Fettgewebe, das epididymale Fettgewebe, signifikant reduziert war. 
Den eben beschriebenen Ergebnissen stehen allerdings auch Studien an Ratten gegenüber, die neben einer Adipositas nach pränataler Glukokortikoidexposition, durch Stress oder Medikamentengabe die damit verbundenen erhöhten Leptinspiegel besaßen (Dahlgren et al. 2001; Tamashiro et al. 2009). Da es durch die vorliegende Arbeit allerdings auch nicht zur Ausbildung einer Adipositas nach pränataler Therapie kam, ist es nicht überraschend, dass auch andere Leptinergebnisse erzielt wurden.

\subsection{Cholesterol und Triglyceride}

Die Cholesterol- und Triglyceridbestimmung wurde ergänzend $\mathrm{zu}$ den bisher erhaltenen Ergebnissen bis zum 12. Lebensmonat durchgeführt. Danach wurde wegen mangelndem Untersuchungsmaterial zugunsten anderer Parameter auf die Bestimmung der Lipide verzichtet. Somit kann nur eine Aussage über deren Entwicklung in der Kindheit gemacht werden. Aufgrund großer Streuungen innerhalb der Versuchsgruppen sind keine signifikanten Unterschiede erkennbar. Initial lag die Vermutung nahe, dass eine pränatale Dexamethasontherapie auch Auswirkungen auf den Fettstoffwechsel haben könnte. Diese Vermutung beruhte u.a. darauf, dass beispielsweise Tamashiro und Moranin ihrem Review 2010 nach der Zusammenfassung der Literatur über perinatale Einflüsse auf die metabolische Programmierung der Nachkommen einen Zusammenhang zwischen erhöhten pränatalen Kortisonspiegeln und Dyslipidämien ansprachen. Des Weiteren bewirkte im Jahr 2009 in der Studie von Nyirenda et al. eine pränatale Dexamethasonexposition in einer späten Phase der Schwangerschaft leicht erhöhte Triglyceridwerte. Auch durch die vorliegenden Ergebnisse ergibt sich ein Hinweis darauf, dass die pränatale Dexamethasontherapie solche Auswirkungen haben könnte. Im Verlauf und besonders gegen Ende der 12 Monate zeigt sich insbesondere bei den Triglyceriden eine Tendenz zum Anstieg dieser Parameter und stützt somit den Verdacht, dass eine pränatale Dexamethasontherapie Veränderungen des Fettstoffwechsels bewirken könnte. Da die Ergebnisse allerdings nur eine Tendenz aufzeigen und nach 12 Lebensmonaten nicht weiter verfolgt wurden, können sie nicht abschließend bewertet werden, somit lohnen sich diesbezüglich weitere Studien. 


\section{Schlussfolgerung}

Auch in der vorliegenden Studie konnten epigenetische Effekte einer pränatalen Glukokortikoidexposition auf körperliche Merkmale wie Knochenlänge, Körperfett und Hormone der Nachkommen gefunden werden. Das bestätigt die im internationalen Schrifttum immer wieder beschriebenen Effekte von einer pränatalen Glukokortikoidexposition auf die spätere Entwicklung des Organismus. 


\section{Zusammenfassung}

Die Aufgabe der vorliegenden Arbeit bestand darin, zu untersuchen, ob eine pränatale Dexamethasontherapie im ersten und/oder zweiten Trimenon der Schwangerschaft zu bestimmten metabolischen Veränderungen bei den männlichen Nachkommen führt. Als Versuchstiere dienten dieser Studie CJ.

Die pränatale Dexamethasontherapie im zweiten Trimenon der Schwangerschaft führte zu einer signifikanten Reduktion des viszeralen Fettgewebes im 6. und 24. Lebensmonat, einem signifikant geringeren, prozentrelativierten Gesamtfett im Alter von 24 Monaten, einem signifikant höheren Testosteron mit 12 Monaten und einer signifikant geringeren Scheitel-Steißlänge im Alter von 18 und 24 Monaten.

Aufgrund dieser Ergebnisse lässt sich zusammenfassen, dass mittels der vorliegenden Arbeit bestätigt werden konnte, dass Dexamethason, welches pränatal zur fetalen Lungenreife eingesetzt wird, durch epigenetische Effekte zu postnatalen Veränderungen führt. Nach einer pränatalen Dexamethasontherapie im zweiten Trimenon der Schwangerschaft zeigten sich sowohl Auswirkungen im präpubertären Alter, als auch in der Adoleszenz. Eine Dexamethasontherapie zu diesem Zeitpunkt führt wahrscheinlich zu einem früheren Eintritt der Pubertät und, eventuell als Folge dieses frühzeitig hohen Testosteronspiegels, zu einem veränderten Längenwachstum mit gedrungenem Oberkörper und rechnerisch längerer unterer Extremität. Außerdem kommt es zu einer Reduktion des viszeralen Fettgewebes in der Kindheit und Adoleszenz, welche sich auch in dem geringeren prozentrelativierten Gesamtfett mit 24 Monaten widerspiegelt.

Die pränatale Therapie im ersten Trimenon der Schwangerschaft führte zu einer signifikanten Abnahme des Leptins im Alter von 6 Monaten und einer signifikanten Reduktion des viszeralen Fettgewebes mit 12 Monaten.

Demzufolge kann an dieser Stelle formuliert werden, dass eine pränatale Dexamethasontherapie im ersten Trimenon der Schwangerschaft zu einer Abnahme des viszeralen Fettgewebes und zu einer Abnahme der Leptinproduktion im präpubertären Alter führt. Im Gegensatz dazu scheinen die Auswirkungen durch diese Art der Dexamethasontherapie auf die spätere metabolische Entwicklung eher unbedeutend zu sein. 
Grundsätzlich sollte, durch die gewonnenen Erkenntnisse der vorliegenden Arbeit und die Tatsache, dass viele Aspekte auf diesem Gebiet noch nicht abschließend erforscht sind, die Indikation der pränatalen Dexamethasontherapie jederzeit individuell genau geprüft werden. 


\section{Literaturverzeichnis}

\subsection{Internetquellen}

Cawthon Lang KA (2005): Primate Factsheets: Common marmoset (Callithrix jacchus). Taxonomy, Morphology and Ecology. National Primate Research Center. Primate Info Net, online verfügbar: http://pin.primate.wisc.edu/factsheets/entry/common_marmoset (abgerufen am 20.10.2014, 13:40 Uhr)

Cover S (2000): Callithrix jacchus white-tufted-ear marmoset. Animal Diversity Web, online verfügbar: http://animaldiversity.org/accounts/Callithrix_jacchus/ (abgerufen am 20.10.2014, 13:36 Uhr)

Pharmazeutische Zeitung online (2010): Frühgeborenenrate steigt. Pharmazeutische Zeitung, online verfügbar: http://www.pharmazeutische-zeitung.de/index.php?id=35929 (abgerufen am 23.10.2013, 15:26 Uhr)

Roberts D (2010): Antenatal Corticosteroids to Reduce Neonatal Morbidity and Mortality. Royal College of Obstetricians and Gynaecologists.Greentop Guideline no 7, online verfügbar: https://www.rcog.org.uk/globalassets/documents/guidelines/gtg_7.pdf (abgerufen am 01.09.2015, 13:02 Uhr)

Walter J (2009): Epigenetik: Einführung. Portal epigenetischer Forschung in D, A und CH, online verfügbar: http://epigenetics.uni-saarland.de/de/home/ (abgerufen am 04.09.2015, 13:05 Uhr)

\subsection{Weitere Quellen}

ACOG Committee on Obstetric Practice (2011): ACOG Committee Opinion No 475:

Antenatal corticosteroid therapy for fetal maturation. Obstet Gynecol 117, 422-4

Aufenanger J: Diagnostik bei Stoffwechselstörungen: Lipidstoffwechselstörungen. In: Bruhn HD, Junker R, Schäfer H, Schreiber S (Hrsg.): LaborMedizin. 3. Auflage; Schattauer Verlag, Stuttgart 2011, 228-250 
Austad SN (2009): Comparative Biology of Aging. J Gerontol A Biol Sci Med Sci $\underline{64 A}$, 199201

Ballard PL, Ballard RA (1995): Scientific basis and therapeutic regimes for use of antenatal glucocorticoids. Am J Obstet Gynecol 173, 254-62

Banks BA, Cnaan A, Morgan MA, Parer JT, Merrill JD, Ballard PL, Ballard RA (1999): Multiple courses of antenatal corticosteroids and outcome of premature neonates. North American Thyrotropin-Releasing Hormone Study Group. Am J Obstet Gynecol $\underline{181}, 709-17$

Bartmann P, Roos R: Erkrankungen in der Neugeborenenperiode. In: Sitzmann FC (Hrsg.): Duale Reihe Pädiatrie. 3. überarbeitete und erweiterte Auflage; Georg Thieme Verlag, Stuttgart 2007, 71-123

Baud O, Foix-L'Helias L, Kaminski M, Audibert F, Jarreau PH, Papiernik E, Huon C, Lepercq J, Dehan M, Lacaze-Masmonteil T (1999): Antenatal glucocorticoid treatment and cystic periventricular leukomalacia in very premature infants. $\mathrm{N}$ Engl J Med $\underline{341}, 1190-6$

Bloom SL, Sheffield JS, McIntire DD, Leveno KJ (2001): Antenatal dexamethasone and decreased birth weight. Obstet Gynecol $\underline{97}$, 485-90

Bolt RJ, van Weissenbruch MM, Lafeber HN, Delemarre-van de Waal HA (2001): Glucocor ticoids and lung development in the fetus and preterm infant. Pediatr Pulmonol $\underline{32}$, 7691

Bonanno C, Fuchs K, Wapner RJ (2007): Single versus repeat courses of antenatal steroids to improve neonatal outcomes: risks and benefits. Obstet Gynecol Surv $\underline{62}$, 261-71

Bouwland-Both MI, Van Mil NH, Tolhoek CP, Stolk L, Eilers PH, Verbiest MM, Heijmans BT, Uitterlinden AG, Van Ijendorn MH, Duijts L, et al. (2015): Prenatal parental tobacco smoking, gene specific DNA methylation, and newborns size: the Generation R study. Clin Epigenetics $\underline{7}, 83$

Cleasby ME, Kelly PAT, Walker BR, Seckl JR (2003): Programming of Rat Muscle and Fat Metabolism by in Utero Overexposure to Glucocorticoids. Endocrinology 144, 9991007 
Committee on Obstetric Practice (2002): ACOG committee opinion. Antenatal corticostero id therapy for fetal maturation. American College of Obstetricians and Gynecologists. Int J Gynaecol Obstet $\underline{78}, 95-7$

Crowley P, Chalmers I, Keirse MJ (1990): The effects of corticosteroid administration before preterm delivery: an overview of the evidence from controlled trials. $\mathrm{Br} \mathrm{J}$ Obstet Gynaecol 97, 11-25

Dahlgren J, Nilsson C, Jennische E, Ho HP, Eriksson E, Niklasson A, Björntorp P, Wikland KA, Holmäng A (2001): Prenatal cytokine exposure results in obesity and genderspecific programming. Am J Physiol Endocrinol Metab 281, E326-34

Deutzmann R (2008): Hormone: Hormone der Gonaden. In: Rassow J, Hauser K, Netzker R, Deutzmann R (Hrsg.): Duale Reihe Biochemie. 2.aktualisierte Auflage; Georg Thieme Verlag, Stuttgart 2008, 602-608

Deutzmann R (2010): Hormonelle Regulation: Grundlagen. In: Behrends JC, Bischofberger J, Deutzmann R, Ehmke H, Frings S, Grissmer S, Hoth M, Kurtz A, Leipziger J, Müller F et al. (Hrsg.):Duale Reihe Physiologie.1.Auflage; Georg Thieme Verlag, Stuttgart 2010, 35-347

De Vries A, Holmes MC, Heijnis A, Seier JV, Heerden J, Louw J, Wolfe-Coote S, Meaney MJ, Levitt NS, Seckl JR (2007): Prenatal dexamethasone exposure induces changes in nonhuman primate offspring cardiometabolic and hypothalamic-pituitary-adrenal axis function. J Clin Invest $\underline{117}$, 1058-67

Drake AJ, Raubenheimer PJ, Kerrigan D, McInnes KJ, Seckl JR, Walker BR (2010): Prenatal Dexamethasone Programs Expression of Genes in Liver and Adipose Tissue and Increased Hepatic Lipid Accumulation But Not Obesity on a High-Fat Diet. Endocrinology $\underline{151}, 1581-1587$

Drenckhahn D: Einführung. In: Benninghoff A, Drenckhahn D (Hrsg.): Anatomie: Makroskopische Anatomie, Histologie, Embryologie, Zellbiologie. Band 1. 17. durchgesehene Auflage; Urban und Fischer Verlag, München 2008, 2-8 
Drenckhahn D, Kugler P: Allgemeine Gewebelehre: Fettgewebe. In: Benninghoff A, Drenckhahn D (Hrsg.): Anatomie: Makroskopische Anatomie, Histologie, Embryologie, Zellbiologie. Band 1. 17. durchgesehene Auflage; Urban und Fischer Verlag, München 2008, 125-128

Fiascone JM, Jacobs HC, Moya FR, Mercurio MR, Lima DM (1987): Betamethasone increases pulmonary compliance in part by sufactant-independent mechanisms in preterm rabbits. Pediatr Res $\underline{22}, 730-5$

Figueras-Aloy J, Serrano MM, Rodríguez JP, Pérez CF, Serradilla VR, Jiménez JQ,González RJ; SEN 1500 Spanish Neonatal Network (2005): Antenatal glucocorticoid treatment decreases mortality and chronic lung disease in survivors among 23- to 28week gestational age preterm infants. Am J Perinatol 22, 441-8

Foix-L'helias L, Baud O, Lenclen R, Kaminski M, Lacaze-Masmonteil T (2005): Benefit of antenatal glucocorticoids according to the cause of very premature birth. Arch Dis Child Fetal Neonatal Ed 90, 46-48

Fowden AL, Forhead AJ (2004): Endocrine mechanisms of intrauterine programming. Reproduction $\underline{127}, 515-26$

Franko KL, Forhead AJ, Fowden AL (2010): Differential effects of prenatal stress and glucocorticoid administration on postnatal growth and glucose metabolism in rats. $\mathbf{J}$ Endocrinol 204, 319-29

French NP, Hagan R, Evans SF, Godfrey M, Newnham JP (1999): Repeated antenatal corti costeroids: size at birth and subsequent development. Am J Obstet Gynecol 180, 11421

Garland JS, Buck R, Leviton A (1995): Effect of maternal glucocorticoid exposure on risk of severe intraventricular hemorrhage in surfactant-treated preterm infants. J Pediatr $\underline{126}$, 272-9

Goldenberg RL, Wright LL (2001): Repeated courses of antenatal corticosteroids. Obstet Gynecol 97, 316-7

Greschus S, Kiessling F, Lichy MP, Moll J, Mueller MM, Savai R, Rose F, Ruppert C, Günther A, Luecke M et al. (2005): Potential applications of flat-panel volumetric $\mathrm{CT}$ in morphologic and functional small animal imaging. Neoplasia $\underline{7}, 730-740$ 
Groneck P (2001): Perinatal glucocorticosteroid therapy: time for reconsideration. Z Geburtshilfe Neonatol $\underline{205}, 231-5$

Guerre-Millo M (2002): Adipose tissue hormones. J Endocrinol Invest 25, 855-61

Hauser J, Knapman A, Zürcher NR, Pilloud S, Maier C, Diaz-Heijtz R, Forssberg H, Dettling A, Feldon J, Pryce CR (2008): Effects of Prenatal Dexamethasone Treatment on Physical Growth, Pituitary-Adrenal Hormones, and Performance of Motor, Motivational, and Cognitive Tasks in Juvenile and Adolescent Common Marmoset Monkeys. Endocrinology $\underline{149}, 6343-6355$

Hauser K: Aufbau biologischer Membranen: Membranlipide; In: Rassow J, Hauser K, Netzker R, Deutzmann R (Hrsg.): Duale Reihe Biochemie.2. aktualisierte Auflage; Georg Thieme Verlag, Stuttgart 2008, 331-344

Hayes EJ, Paul DA, Stahl GE, Seibel-Seamon J, Dysart K, Leiby BE, Mackley AB, Berghella V (2008): Effect of antenatal corticosteroids on survival for neonates born at 23 weeks of gestation. Obstet Gynecol 111, 921-6

Hick C, Hick A: Intensivkurs Physiologie. 6. überarbeitete Auflage; Urban und Fischer Verlag, München 2009

Horn F (2009a): Lipide. In: Horn F (Hrsg.): Biochemie des Menschen. 4. aktualisierte und erweiterte Auflage; Georg Thieme Verlag, Stuttgart 2009, 28-36

Horn F (2009b): Stoffwechsel der Lipide. In: Horn F (Hrsg.): Biochemie des Menschen. 4. aktualisierte und erweiterte Auflage; Georg Thieme Verlag, Stuttgart 2009, 123-170

Horn F, Lindemeier G, Moc I, Grillhösl C, Berghold S, Schneider N, Münster B: Biochemie des Menschen. 2. korrigierte Auflage; Thieme Verlag, Stuttgart 2003

Hünerbein R: Radiologische Verfahren: Computertomografie. In: Reiser M, Kuhn F-P, Debus J (Hrsg.): Duale Reihe Radiologie. 3. vollständig überarbeitete und erweiterte Auflage; Georg Thieme Verlag, Stuttgart 2011, 73-79

Ikegami M, Jobe AH, Newnham J, Polk DH, Willet KE, Sly P (1997): Repetitive prenatal glucocorticoids improve lung function and decrease growth in preterm lambs. Am $\mathbf{J}$ Respir Crit Care Med $\underline{156}, 178-84$ 
Joseph KS, Kramer MS, Marcoux S, Ohlsson A, Wen SW, Allen A, Platt R (1998): Determinants of preterm birth rates in Canada from 1981 through 1983 and from 1992 through 1994. N Engl J Med $\underline{339}$, 1434-9

Karow T, Lang-Roth R: Allgemeine und Spezielle Pharmakologie und Toxikologie. 20. Auflage; Eigenverlag Karow, Köln 2012

Koppe JG, Smolders-de Haas H, Kloosterman GJ (1977): Effects of glucocorticoids during pregnancy on the outcome of the children directly after birth and in the long run. Eur $\mathbf{J}$ Obstet Gynecol Reprod Biol 7, 293-9

Kutzler MA, Ruane EK, Cosksaygan T, Vincent SE, Nathanielsz PW (2004): Effects of three courses of maternally administered dexamethasone at $0,7,0,75$, and 0,8 of gestation on prenatal and postnatal growth in sheep. Pediatrics $\underline{113}, 313-9$

Lackner KJ: Geschichte und technisch-physikalische Grundlagen. In: Thurn P, Bücheler E, Lackner K-J, Thelen M (Hrsg.):Einführung in die radiologische Diagnostik. 10. völlig neubearbeitete Auflage; Georg Thieme Verlag, Stuttgart-New York1998, 1-55

Lee BH, Stoll BJ, McDonald SA, Higgins RD; National Institute of Child Health and Human Development Neonatal Research Network (2006): Adverse Neonatal Outcomes Associated With Antenatal Dexamethasone Versus Antenatal Bethamethasone. Pediatrics $\underline{117}, 1503-10$

Liggins GC (1968): Premature parturition after infusion of corticotrophin or cortisol into foetal lambs. J. Endocrinol 42, 323-329

Liggins GC (1969): Premature delivery of fetal lambs infused with glucocorticoids. J. Endocinol $\underline{45}, 515-523$

Liggins GC, Howie RN (1972): A controlled trial of antepartum glucocorticoid treatment for prevention of the respiratory distress syndrome in premature infants. Pediatrics $\underline{50}$, $515-525$

Li J, Olsen J, Vestergaard M, Obel C, Baker JL, Sorensen TIA (2010): Prenatal Stress Exposure Related to Maternal Bereavement and Risk of Childhood Overweight. PLoS One $\underline{5}$, e11896

Lüllmann H, Mohr K, Wehling M: Pharmakologie und Toxikologie. 15. komplett überarbeitete Auflage; Georg Thieme Verlag, Stuttgart 2003 
Mansfield K (2003): Marmoset models commonly used in biomedical research. Comp Med $\underline{53}, 383-92$

Mazumder P, Dutta S, Kaur J, Narang A (2008): Single versus multiple courses of antenatal betamethasone and neonatal outcome: a randomized controlled trial. Indian Pediatr $\underline{45}$, $661-7$

Missbach-Guenter J, Dullin C, Zientkowska M, Domeyer-Missbach M, Kimmina S, Obenauer S, Kauer F, Stühmer W, Grabbe E, Vogel WF et al. (2007): Flat-Panel Detector-Based Volume Computed Tomography: A Novel 3D Imaging Technique to Monitor Osteolytic Bone Lesions in a Mouse Tumor Metastasis Model. Neoplasia 9,755765

Mönig H, Harbeck B: Endokrinologische Diagnostik: Hormone und ihre spezifische Diagnostik. In: Bruhn HD, Junker R, Schäfer H, Schreiber S (Hrsg.): LaborMedizin. 3. Auflage; Schattauer Verlag, Stuttgart 2011, 189-208

Müller MJ, Bosy-Westphal A: Energiehaushalt und Ernährung: Ernährungszustand. In: Deetjen P, Speckmann E-J, Hescheler J (Hrsg.): Physiologie. 4. Vollständig überarbeitete Auflage; Urban und Fischer Verlag, München 2005, 634-637

Mustoe AC, Birnie AK, Korgan AC, Santo JB, French JA (2012): Natural variation in gestational cortisol is associated with patterns of growth in marmoset monkeys (Callithrix geoffroyi). Gen Comp Endocrinol 175, 519-526

Newnham JP (2001): Is prenatal glucocorticoid administration another origin of adult disease? Clin Exp Pharmacol Physiol 28, 957-61

Nieschlag E, Weinbauer GF, Cooper TG, Wittkowski W:Reproduktion:Wirkung der Sexualsteroide. In: Deetjen P, Speckmann E-J, Hescheler J(Hrsg.): Physiologie. 4. vollständig überarbeitete Auflage; Urban und Fischer Verlag, München 2005, 700-701

NIH Consens Statement (No authors listed) (1994): Effect of corticosteroids for fetal maturation on perinatal outcomes. NIH Consens Statement $\underline{12}, 1-24$

NIH Consens Statement (No author listed) (2000): Antenatal corticosteroids revisited: repeat courses. NIH Consens Statement $\underline{17}, 1-18$ 
Nyirenda MJ, Lindsay RS, Kenyon CJ, Burchell A, Seckl JR (1998): Glucocorticoid exposure in late gestation permanently programs rat hepatic phosphoenolpyruvate carboxykinase and glucocorticoid receptor expression and causes glucose intolerance in adult offspring. J Clin Invest 101, 2174-81

Nyirenda MJ, Carter R, Tang JI, De Vries A, Schlumbohm C, Hillier SG, Streit F, Oellerich M, Armstrong VM, Fuchs E, et al.(2009): Prenatal programming of metabolic syndrome in the Common Marmoset is associated with increased expression of 11- $\beta$ Hydroxysteroid Dehydrogenase Type I. Diabetes $\underline{58}, 2873-9$

O`Regan D, Kenyon CJ, Seckl JR, Holmes MC (2004): Glucocorticoid exposure in late gestation in the rat permanently programs gender-specific differences in adult cardiovascular and metabolic physiology. Am J Physiol Endocrinol Metab 287, E863-70

Pedain C: Sexualentwicklung und Reproduktionsphysiologie: Hypothalamisch-hypophysärgonadale Steuerung der Sexualfunktion. In: Behrends JC, Bischofberger J, Deutzmann R, Ehmke H, Frings S, Grissmer S, Hoth M, Kurtz A, Leipziger J,Müller F et al. (Hrsg.): Duale Reihe Physiologie. 1. Auflage; Georg Thieme Verlag, Stuttgart 2010, 413-421

Rassow J (2008a): Biochemie der Leber. In: Rassow J, Hauser K, Netzker R, Deutzmann R (Hrsg.): Duale Reihe Biochemie. 2. aktualisierte Auflage; Georg Thieme Verlag, Stuttgart 2008, 669-675

Rassow J (2008b): Teil A- Biochemie des Energiestoffwechsels (A I - A VI). In: Rassow J, Hauser K, Netzker R, Deutzmann R (Hrsg.): Duale Reihe Biochemie. 2. Aktualisierte Auflage; Georg Thieme Verlag, Stuttgart 2008, 4-270

Ritter M: Koordination spezieller Organfunktionen: Hormone. In: Deetjen P, Speckmann EJ, Hescheler J (Hrsg.): Physiologie. 4. vollständig überarbeitete Auflage; Urban und Fischer Verlag, München 2005; 754-819

Seckl JR (1997): Glucocorticoids, feto-placental 11 beta-hydroxysteroid dehydrogenase type 2 , and the early life origins of adult disease. Steroids $\underline{62}, 89-94$

Speer CP: Neonatologie.In: Speer CP, Gahr M (Hrsg.): Pädiatrie. 4. Auflage; Springer Verlag, Berlin-Heidelberg 2012, 125-191

Stratec Medizintechnik GmbH: Handbuch XCT 2000; [Pforzheim 1998] 
Sugden MC, Langdown ML, Munns MJ, Holness MJ (2001): Maternal glucocorticoid treatment modulates placental leptin and leptin receptor expression and materno-fetal leptin physiology during late pregnancy, and elicits hypertension associated with hyperleptinaemia in the early-growth-retarded adult offspring. Eur J Endocrinol 145, 529-539

Tamashiro KLK, Moran TH (2010): Perinatal environment and its influences on metabolic programming of offspring. Physiol Behav $\underline{100}, 560-566$

Tamashiro KLK, Terrillion CE, Hyun J, Koenig JI, Moran TH (2009): Prenatal Stress or High-Fat Diet Increases Susceptibility to Diet-Induced Obesity in Rat Offspring. Diabetes $\underline{58}, 1116-1125$

Tardif SD, Power ML, Ross CN, Rutherford JN, Layne-Colon DG, Paulik MA (2009): Characterization of obese phenotypes in a small nonhuman primate, the common marmot set (Callithrix jacchus). Obesity (Silver Spring) 17, 1499-505

Viehbahn C, Wartenberg H: Harn- und Genitalsystem: Entwicklung des Harn- und Genitalsystems. In: Benninghoff A, Drenckhahn D (Hrsg.): Anatomie: Makroskopische Anatomie, Histologie, Embryologie, Zellbiologie. Band 1. 17. durchgesehene Auflage; Urban und Fischer Verlag, München 2008,732-749

Vidal AC, Neelon SE, Liu Y, Tuli AM, Fuemmeler BF, Hoyo C, Murtha AP, Huang Z, Schildkraut J, Overcash F, et al.(2014): Maternal Stress, Preterm Birth, and DNA Methylation at Imprint Regulatory Sequences in Humans. Genet Epigenet $\underline{6}$, 37-44

Vissers D, Hens W, Taeymans J, Baeyens J-P, Poortmans J, Van Gaal L, Breuer Votruba S (2013): The Effect of Exercise on Visceral Adipose Tissue in Overweight Adults: A Systematic Review and Meta-Analysis. PLoSOne $\underline{8}$, e56415

Walfisch A, Hallak M, Mazor M (2001): Multiple courses of antenatal steroids: risks and benefits. Obstet Gynecol 98, 491-7

Wang D, Vandermeulen J, Atkinson SA (2007): Early life factors predict abnormal growth and bone accretion at prepuberty in former premature infants with/without neonatal dexamethasone exposure. Pediatr Res $\underline{61}, 111-6$

Wapner RJ, Sorokin Y, Thom EA, Johnson F, Dudley DJ, Spong CY, Peaceman AM, Leveno KJ, Harper M, Caritis SN et al. (2006): Single versus weekly courses of antenatal corticosteroids: evaluation of safety and efficacy. Am J Obstet Gynecol 195, 633-42 
Woods LL, Weeks DA (2005): Prenatal programming of adult blood pressure: role of maternal corticosteroids. Am J Physiol Regul Integr Comp Physiol 289, R955-62 


\section{Anhang}

\subsection{Tabellen}

Tabelle 1: BMI und entsprechende geschlechtsspezifische Refenzwerte des Leptins

\begin{tabular}{|l|l|l|}
\hline BMI-Wert & Leptin Frauen & Leptin Männer \\
\hline $18-25$ & $\leq 24,0 \mathrm{ng} / \mathrm{ml}$ & $\leq 10,0 \mathrm{ng} / \mathrm{ml}$ \\
\hline $26-27$ & $6,00-32,0 \mathrm{ng} / \mathrm{ml}$ & $1,00-15,0 \mathrm{ng} / \mathrm{ml}$ \\
\hline $28-29$ & $8,00-50,0 \mathrm{ng} / \mathrm{ml}$ & $2,00-23,0 \mathrm{ng} / \mathrm{ml}$ \\
\hline $30-31$ & $11,0-68,0 \mathrm{ng} / \mathrm{ml}$ & $3,00-36,0 \mathrm{ng} / \mathrm{ml}$ \\
\hline $32-33$ & $14,0-90,0 \mathrm{ng} / \mathrm{ml}$ & $5,00-56,0 \mathrm{ng} / \mathrm{ml}$ \\
\hline $34-35$ & & $8,00-70,0 \mathrm{ng} / \mathrm{ml}$ \\
\hline $36-37$ & $19,0-121 \mathrm{ng} / \mathrm{ml}$ & $12,0-135 \mathrm{ng} / \mathrm{ml}$ \\
\hline
\end{tabular}

Diese Tabelle entstammt dem Endokrinologikum, Labore Hamburg, Lornsenstraße 4-6, 22767 Hamburg, online verfügbar unter http://www.endokrinologikum.com/labor/analytik/ hormone/hormone-parameter/ho-parameter/leptin.html (abgerufen am 24.08.2013) 
Tabelle 2: Zusammensetzung des Alleinfuttermittels für Marmosets von Ssniff Mar

\begin{tabular}{|c|c|c|c|}
\hline Rohnährstoffe & $(\%)$ & Mineralstoffe & $(\%)$ \\
\hline Trockensubstanz & 93,5 & Calcium & 1,00 \\
\hline Rohproteine $(\mathrm{N} \times$ 6,25) & 26,1 & Phosphor & 0,70 \\
\hline Rohfett & 7,0 & Natrium & 0,20 \\
\hline Rohfaser & 2,5 & Magnesium & 0,18 \\
\hline Rohasche & 6,8 & Kalium & 0,92 \\
\hline N-freie Extraktstoffe & 51,1 & Aminosäuren & $(\%)$ \\
\hline Stärke & 23,4 & Lysin & 1,70 \\
\hline Zucker & 20,4 & Methionin & 0,49 \\
\hline Fettsäuren & $(\%)$ & Met+Cys & 0,88 \\
\hline C 8:0 & 0,15 & Threonin & 1,16 \\
\hline C 10:0 & 0,12 & Tryptophan & 0,41 \\
\hline C 12:0 & 0,90 & Arginin & 1,63 \\
\hline C 14:0 & 0,36 & Histidin & 0,66 \\
\hline C 16:0 & 0,74 & Valin & 1,38 \\
\hline C 16:1 & 0,02 & Isoleucin & 1,27 \\
\hline C 18:0 & 0,19 & Leucin & 2,24 \\
\hline C 18:1 & 1,39 & Phenylalanin & 1,32 \\
\hline C $18: 2$ & 2,22 & Phe+Tyr & 2,37 \\
\hline C $18: 3$ & 0,17 & Glycin & 0,97 \\
\hline C 20:0 & 0,01 & Glutaminsäure & 4,78 \\
\hline
\end{tabular}




\begin{tabular}{|c|c|c|c|}
\hline Vitamine & per kg & Aminosäuren & $(\%)$ \\
\hline Vitamin A & $18.000 \mathrm{IE}$ & Asparginsäure & 2,78 \\
\hline Vitamin D3 & $3.000 \mathrm{IE}$ & Prolin & 1,71 \\
\hline Vitamin E & $120 \mathrm{mg}$ & Alanin & 1,18 \\
\hline Vitamin C & $3.500 \mathrm{mg}$ & Serin & 1,30 \\
\hline Vitamin $\mathrm{K}$ & $5 \mathrm{mg}$ & Spurenelemente & per kg \\
\hline Thiamin $\left(\mathrm{B}_{1}\right)$ & $14 \mathrm{mg}$ & Eisen & $154 \mathrm{mg}$ \\
\hline Riboflavin $\left(\mathrm{B}_{2}\right)$ & $22 \mathrm{mg}$ & Mangan & $44 \mathrm{mg}$ \\
\hline Pyridoxin $\left(\mathrm{B}_{6}\right)$ & $17 \mathrm{mg}$ & Zink & $70 \mathrm{mg}$ \\
\hline Cobalamin $\left(\mathrm{B}_{12}\right)$ & $100 \mu \mathrm{g}$ & Kupfer & $11 \mathrm{mg}$ \\
\hline Nicotinsäure & $70 \mathrm{mg}$ & Jod & $2,1 \mathrm{mg}$ \\
\hline Pantothensäure & $34 \mathrm{mg}$ & Selen & $0,2 \mathrm{mg}$ \\
\hline Folsäure & $7 \mathrm{mg}$ & Cobalt & $2,0 \mathrm{mg}$ \\
\hline Biotin & $440 \mu \mathrm{g}$ & & \\
\hline Cholin-Cl & $2.400 \mathrm{mg}$ & & \\
\hline Inositol & $100 \mathrm{mg}$ & & \\
\hline Energie & & $\mathrm{MJ} / \mathrm{kg}$ & \\
\hline Bruttoenergie (GE) & & 18,5 & \\
\hline \multicolumn{2}{|l|}{ Umsetzbare Energie (ME) } & 15,6 & \\
\hline Jomtoilno don, 5507 & $T$ & $280 h$ ouc Protei & $\mathrm{E}$ \\
\hline
\end{tabular}

Die Zusammensetzung des Alleinfuttermittels für Marmosets wurde den Angaben des Herstellers Ssniff Spezialitäten $\mathrm{GmbH}$ entnommen und ist online verfügbar unter http://www.ssniff.de/documents/07_katalog_dt_primaten.pdf (abgerufen am14.04.2013) 
Tabelle 3: Name und Nummer der Versuchstiere sortiert nach ihrer Gruppenzugehörigkeit.

\begin{tabular}{|l|l|l|}
\hline Kontrollgruppe & 5-early-Gruppe & 5-late-Gruppe \\
\hline Hadar (1) & Laser (29) & Pooki (27) \\
\hline Anorak (7) & Eldar (35) & Enwer (37) \\
\hline Pfefferkuchen (65) & Aron (39) & Kord (45) \\
\hline Max (73) & Hero (56) & Ergo (61) \\
\hline Aurelius (75) & Zonko (57) & Olgy (69) \\
\hline Errant (87) & Loreo (83) & Aragon (79) \\
\hline Knecht (89) & Krishna (85) & Adidas* \\
\hline Goofy (91) & Orin (99) & Karribo* \\
\hline Zazu (95) & Ovid (100) & \\
\hline Allegro (97) & Wolfgang (103) & \\
\hline
\end{tabular}

Die mit * gekennzeichneten Tiere waren nur bei den Messungen im fpVCT im Alter von 24 Monaten dabei. 
Tabelle 4: Liste der EUPEAH-Versuchstiere, sortiert nach ihrem Geburtsdatum und ihrer laufenden Nummer sowie ihrer Gruppenzugehörigkeit.

\begin{tabular}{|c|c|c|c|c|}
\hline $\begin{array}{l}\text { Geburtsdatum } \\
\text { des Tieres }\end{array}$ & $\begin{array}{l}\text { LaufendeNr. } \\
\text { des Tieres }\end{array}$ & $\begin{array}{l}\text { DPZ-Nr. des } \\
\text { Tieres }\end{array}$ & $\begin{array}{l}\text { Name des } \\
\text { Tieres }\end{array}$ & Versuchsgruppe \\
\hline 20.4 .03 & $1 \mathrm{MI}$ & 12026 & Hadar & Kontrollgruppe \\
\hline 7.6 .03 & 7MIV & 12093 & Anorak & Kontrollgruppe \\
\hline 30.12 .03 & 27MXIV & 12376 & Pooki & 5-late-Gruppe \\
\hline 8.1 .04 & 29MXV & 12379 & Laser & 5-early-Gruppe \\
\hline 12.1 .04 & 31MXVI & 12398 & Harro $^{+}$ & 5-late-Gruppe \\
\hline 16.1 .04 & $35 \mathrm{MXVIII}$ & 12409 & Eldar & 5-early-Gruppe \\
\hline 19.1.04 & 37MXIX & 12412 & Enwer & 5-late-Gruppe \\
\hline 23.1 .04 & $39 \mathrm{MXX}$ & 12422 & Aron & 5-early-Gruppe \\
\hline 28.1 .04 & 45MXXIII & 12427 & Kord & 5-late-Gruppe \\
\hline 28.1 .04 & 47MXXIV & 12428 & Hassan & 5-late-Gruppe \\
\hline 28.1 .04 & 49MXXV & 12430 & Lorien $^{+}$ & 5-late-Gruppe \\
\hline 3.5 .04 & 56MXXVIII & 12583 & Hero & 5-early-Gruppe \\
\hline 3.5 .04 & 57MXXIX & 12581 & Zonko & 5-early-Gruppe \\
\hline 4.5 .04 & 61MXXXI & 12589 & Ergo & 5-late-Gruppe \\
\hline 8.5 .04 & 65MXXXIII & 12595 & Pfefferkuchen & Kontrollgruppe \\
\hline 10.5.04 & 69MXXXV & 12606 & Olgy & 5-late-Gruppe \\
\hline 18.7 .04 & 73MXXXVII & 12759 & Max & Kontrollgruppe \\
\hline 25.7 .04 & 75MXXXVIII & 12761 & Aurelius & Kontrollgruppe \\
\hline 31.7 .04 & 77MXXXIX & 12762 & Joseph $^{+}$ & 5-late-Gruppe \\
\hline
\end{tabular}




\begin{tabular}{|l|l|l|l|l|}
\hline $\begin{array}{l}\text { Geburtsdatum } \\
\text { des Tieres }\end{array}$ & $\begin{array}{l}\text { LaufendeNr. } \\
\text { des Tieres }\end{array}$ & $\begin{array}{l}\text { DPZ-Nr. des } \\
\text { Tieres }\end{array}$ & $\begin{array}{l}\text { Name des } \\
\text { Tieres }\end{array}$ & Versuchsgruppe \\
\hline 31.7 .04 & $79 \mathrm{MXL}$ & 12766 & Aragon & 5-late-Gruppe \\
\hline 4.8 .04 & $83 \mathrm{MXLII}$ & 12771 & Loreo & 5-early-Gruppe \\
\hline 8.8 .04 & $85 \mathrm{MXLIII}$ & 12775 & Krishna & 5-early-Gruppe \\
\hline 11.8 .04 & $87 \mathrm{MXLIV}$ & 12789 & Errant & Kontrollgruppe \\
\hline 23.8 .04 & $89 \mathrm{MXLV}$ & 12793 & Knecht & Kontrollgruppe \\
\hline 7.10 .04 & $91 \mathrm{MXLVI}$ & 12878 & Goofy & Kontrollgruppe \\
\hline 11.10 .04 & $95 \mathrm{MXLVIII}$ & 12884 & Zazu & Kontrollgruppe \\
\hline 12.10 .04 & $97 \mathrm{MXLIX}$ & 12888 & Allegro & Kontrollgruppe \\
\hline 13.10 .04 & $99 \mathrm{ML}$ & 12889 & Orin & 5-early-Gruppe \\
\hline 13.10 .04 & $100 \mathrm{ML}$ & 12890 & Ovid & 5-early-Gruppe \\
\hline 8.12 .04 & $103 \mathrm{MLII}$ & 12969 & Wolfgang & 5-early-Gruppe \\
\hline
\end{tabular}

Die mit ${ }^{+}$gekennzeichneten Tiere wurden nicht im fpVCT untersucht, sondern standen nur für die anderen Untersuchungen der Studie zur Verfügung. 


\subsection{Abbildungsverzeichnis}

Abbildung 1.1: Callithrix jacchus auf dem Arm eines Mitarbeiters der Abteilung. 14

Abbildung 2.1: Oberkörperdarstellung eines CJ in der Weichgewebeeinstellung auf dem

Bildschirm der Advantage Workstation 4.2 von GEH

Abbildung 2.2: Darstellung des gleichen Oberkörpers wie in Abbildung 2.1 abzüglich des

Weichgewebes auf dem Bildschirm der Advantage Workstation 4.2 von

GEH

Abbildung 2.3: Darstellung der Messung des Brustwirbelbereichs eines CJ auf dem

Bildschirm der Advantage Workstation 4.2 von GEH ohne

Weichgewebe

Abbildung 2.4: Darstellung eines CJ in der Weichgewebseinstellung vom unteren

Rippenrand bis zur Tibia auf dem Bildschirm der Advantage

Workstation 4.2 von GEH.

Abbildung 2.5: Darstellung eines CJ ohne Weichgewebe vom unteren Rippenrand bis zur

Tibia auf dem Bildschirm der Advantage Workstation 4.2 von GEH. 24

Abbildung 2.6: Darstellung der Messung des Beinbereichs eines CJ ohne Weichgewebe auf dem Bildschirm der Advantage Workstation 4.2 von GEH

Abbildung 3.1: Gewichtsentwicklung der männlichen CJ der 5-early-Gruppe und der 5late-Gruppe verglichen mit der Kontrollgruppe innerhalb von 24

Monaten.

Abbildung 3.2: BMI der männlichen CJ der 5-early-Gruppe und der 5-late-Gruppe verglichen mit der Kontrollgruppe im Alter von 18 Monaten und 24 Monaten. 30

Abbildung 3.3: Scheitel-Fersenlänge der männlichen CJ der 5-early-Gruppe und der 5late-Gruppe verglichen mit der Kontrollgruppe im Alter von 18 und 24 Monaten.

Abbildung 3.4: Scheitel-Steißlänge der männlichen CJ der 5-early-Gruppe und der 5-late-

Gruppe verglichen mit der Kontrollgruppe im Alter von 18 und 24

Monaten.

Abbildung 3.5: Mittels qCT gemessener Fettanteil im Bereich L4-L5der männlichen CJ der 5-early-Gruppe und der 5-late-Gruppe verglichen mit der Kontrollgruppe im Zeitraum von 24 Monaten. 
Abbildung 3.6: Mittels fpVCT gemessener Fettanteil im Bereich L4-L5 der männlichen

CJ der 5-early-Gruppe und der 5-late-Gruppe verglichen mit der

Kontrollgruppe im Alter von 24 Monaten.

Abbildung 3.7: Mittels fpVCT gemessener Fettanteil im gesamten Lendenwirbelbereich der männlichen CJ der 5-early-Gruppe und der 5-late-Gruppe

verglichen mit der Kontrollgruppe im Alter von 24 Monaten. 36

Abbildung 3.8: Mittels fpVCT gemessener Fettanteil im Brustwirbelbereichder männlichen CJ der 5-early-Gruppe und der 5-late-Gruppe verglichen mit der Kontrollgruppe im Alter von 24 Monaten. 37

Abbildung 3.9: Mittels fpVCT gemessener Fettanteil im Oberschenkelbereich beider Beine der männlichen CJ der 5-early-Gruppe und der 5-late-Gruppe verglichen mit der Kontrollgruppe im Alter von 24 Monaten.

Abbildung 3.10: Mittels fpVCTgemessener Fettanteil im Unterschenkelbereich beider Beine der männlichen CJ der 5-early-Gruppe und der 5-late-Gruppe verglichen mit der Kontrollgruppe im Alter von 24 Monaten. 39

Abbildung 3.11: Prozentrelativiertes Gesamtfett der männlichen CJ der 5-early-Gruppe und der 5-late-Gruppe verglichen mit der Kontrollgruppe im Alter von 24 Monaten

Abbildung 3.12: Testosteron der männlichen CJ der 5-early-Gruppe und der 5-lateGruppe verglichen mit der Kontrollgruppe im Verlauf von 24 Monaten.... 42

Abbildung 3.13: Leptin der männlichen CJ der 5-early-Gruppe und der 5-late-Gruppe verglichen mit der Kontrollgruppe mit 6 und 24 Monaten .... 43

Abbildung 3.14: Cholesterol der männlichen CJ der 5-early-Gruppe und der 5-lateGruppe verglichen mit der Kontrollgruppe mit 4, 6 und 12 Monaten. 45

Abbildung 3.15: Triglycerideder männlichen CJ der 5-early-Gruppe und der 5-lateGruppe verglichen mit der Kontrollgruppe mit 4, 6 und 12 Monaten. 46 


\section{Danksagung}

Mein besonderer Dank gilt Frau PD Dr. med. Seidlová-Wuttke und Herrn Prof. Dr. med. Wuttke für die Möglichkeit der wissenschaftlichen Arbeit in der Abteilung Klinische und Experimentelle Endokrinologie der Medizinischen Fakultät der Universität Göttingen sowie für die persönliche und umfassende Betreuung. Außerdem möchte ich Frau PD Dr. med. Seidlová-Wuttke für die Bereitstellung der qCT Daten, die die Grundlage dieser Promotion bilden, danken. Ebenso danke ich Frau Dr. Christine Schlumbohm, Tierärztin am DPZ in Göttingen, für die medizinische Betreuung der Versuchstiere. Außerdem danke ich den Mitarbeitern, die die Versuchstiere betreut und die Untersuchungen durchgeführt haben und mir die Informationen dazu zur Verfügung gestellt haben. Überdies geht ein besonderer Dank an Herrn Christian Dullin, Diplom-Physiker aus der Abteilung Diagnostische und Interventionelle Radiologie der Universitätsmedizin Göttingen, der die computertomographischen Messungen am fpVCT und die Bildrekonstruktionen durchgeführt hat. Ein weiterer Dank gilt den medizinisch-technischen Assistentinnen der Abteilung Klinische und Experimentelle Endokrinologie der Universität Göttingen für die Bestimmung der Blutparameter. 